\title{
2017 REPORT TO CONGRESS
}

\section{Young Adults and Transitioning Youth with Autism Spectrum Disorder}

Prepared by the:

Department of Health and Human Services

Submitted by the:

National Autism Coordinator

U.S. Department of Health and Human Services
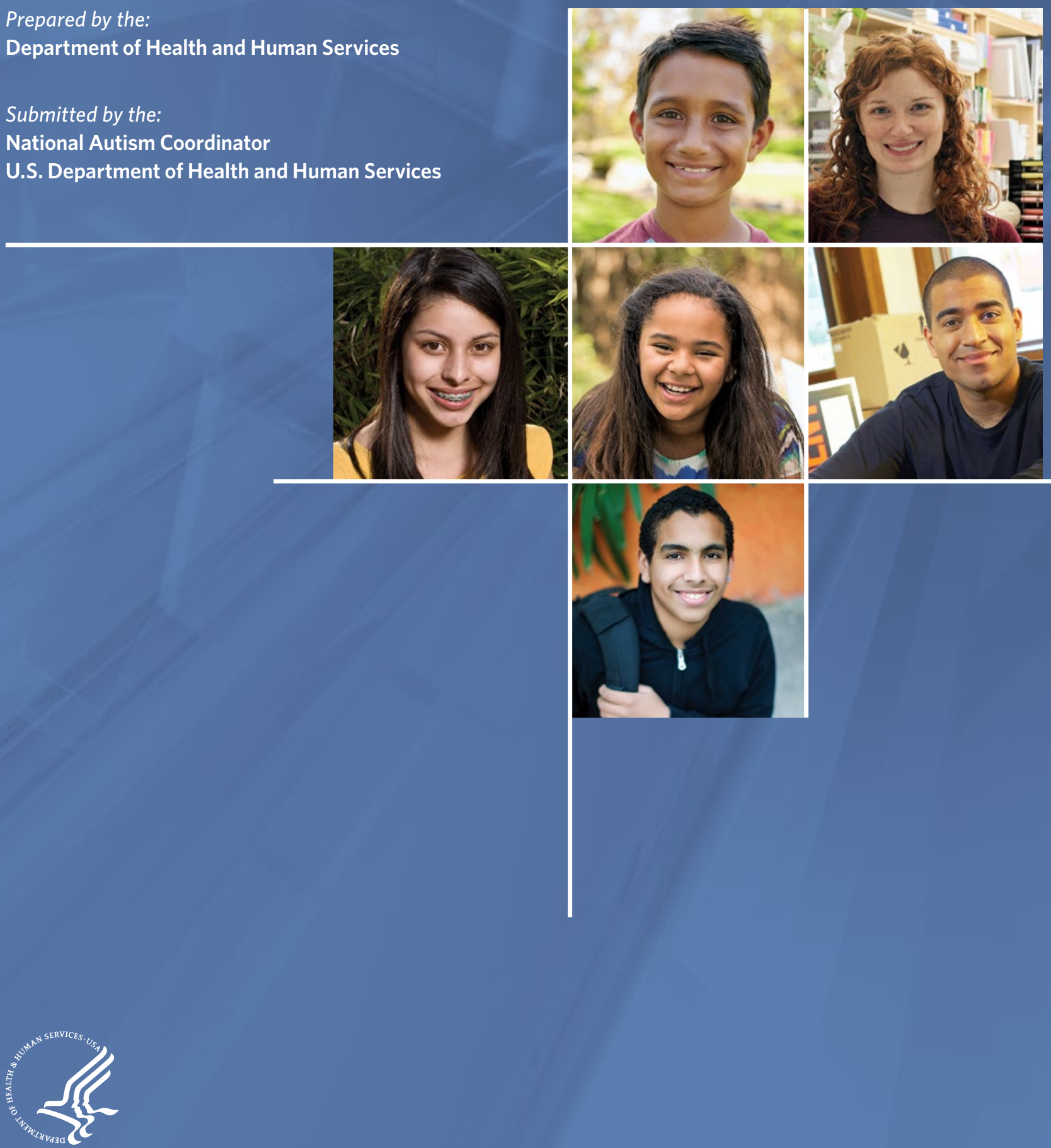


\section{Cover Design}

Medical Arts Branch, Office of Research Services, National Institutes of Health

\section{Copyright Information}

All material appearing in this report is in the public domain and may be reproduced or copied. A suggested citation follows.

\section{Suggested Citation}

U.S. Department of Health and Human Services. Report to Congress: Young Adults and Transitioning Youth with Autism Spectrum Disorder. October 2017. Retrieved from the U.S. Department of Health and Human Services website: https://www.hhs.gov/sites/default/files/2017AutismReport.pdf 


\section{Young Adults and Transitioning Youth with Autism Spectrum Disorder}

The Autism Collaboration, Accountability, Research, Education and Support Act (Autism CARES Act) of 2014

\section{REPORT TO CONGRESS}

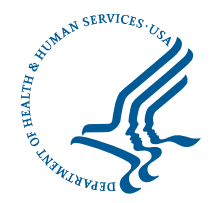




\section{Table of Contents}

\section{Interagency Workgroup on Young Adults and Youth with Autism Spectrum Disorder}

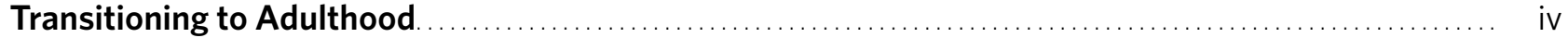

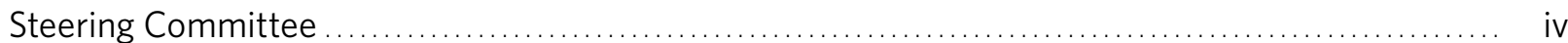

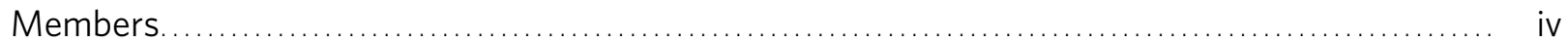

OASH Stakeholder Listening Panel Participants ............................................ vii

Part 1: Background on Autism Spectrum Disorder and the Transition to Adulthood .................. 1

Introduction to Autism Spectrum Disorder .................................................... 2

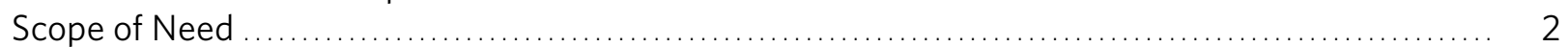

Population Characteristics ............................................................. 2

Trends in Health and Well-being ....................................................... 4

Transition Needs ........................................................................ 6

Figure 1. ASD Research Funding by IACC Strategic Plan Question $\ldots \ldots \ldots \ldots \ldots \ldots \ldots \ldots \ldots \ldots \ldots \ldots . \ldots$

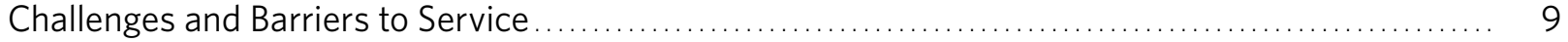

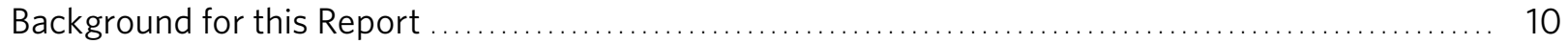

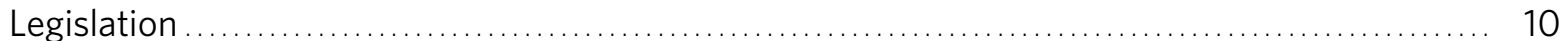

Coordination of Autism Activities............................................................. 11

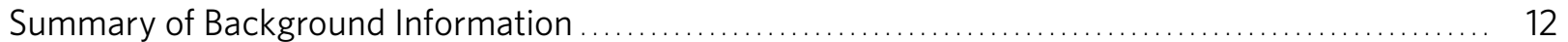

Table 1. Participating Federal Agencies in the Interagency Work Group ............................ 13

Part 2: Federal Agency Activities on Young Adults and Youth with Autism Spectrum

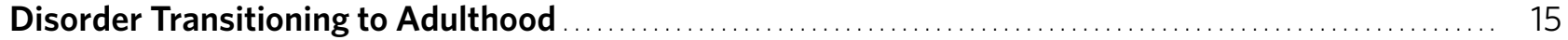

U.S. Department of Health and Human Services ................................................ 15

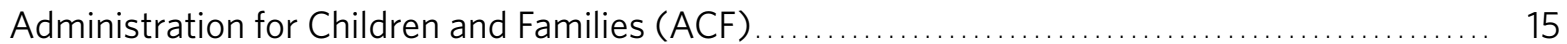

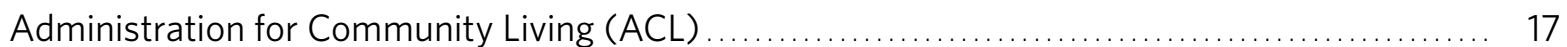

Agency for Healthcare Research \& Quality (AHRQ) .................................... 18

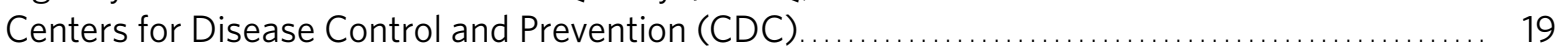

Centers for Medicare \& Medicaid Services (CMS) ......................................... 19

Health Resources and Services Administration (HRSA) ................................. 21

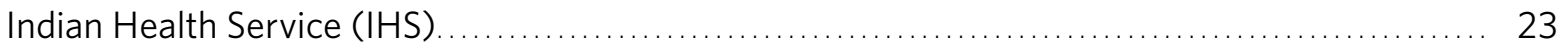

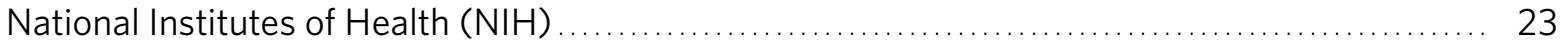

Substance Abuse and Mental Health Services Administration (SAMHSA) ................... 24

U.S. Department of Defense ................................................................. 25

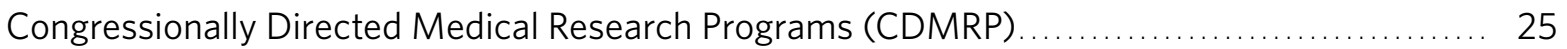

U.S. Department of Education ............................................................ 26

Office of Special Education and Rehabilitative Services (OSERS) ........................... 26

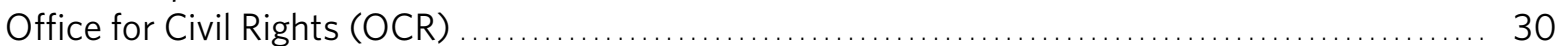

Promoting the Readiness of Minors in Supplemental Security Income (PROMISE) ............. 31

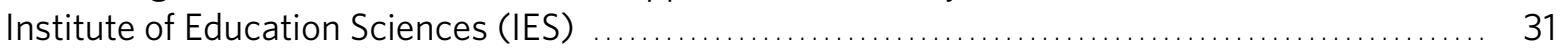

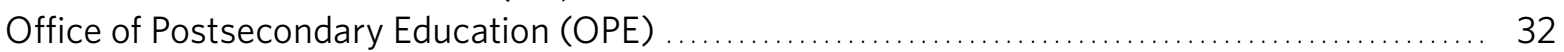

U.S. Department of Housing and Urban Development..................................... 32

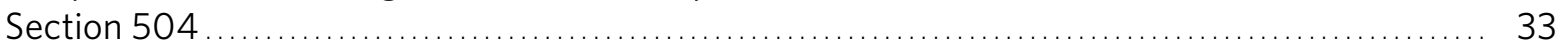

Section 811 Supportive Housing for Persons with Disabilities . ........................... 33

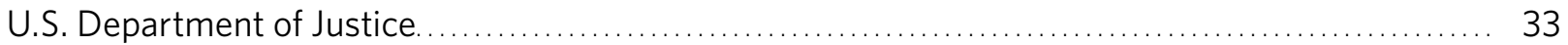

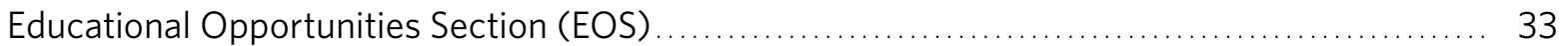

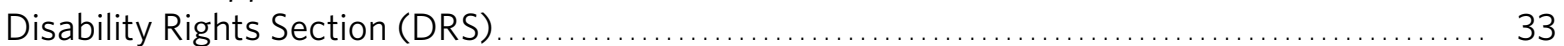




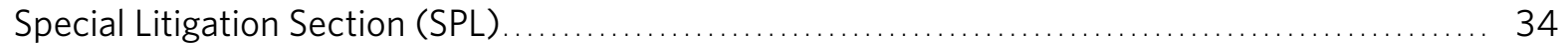

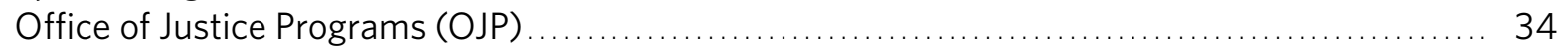

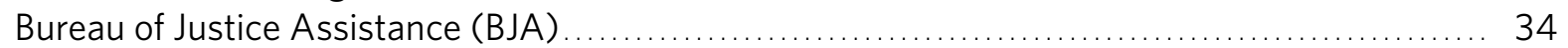

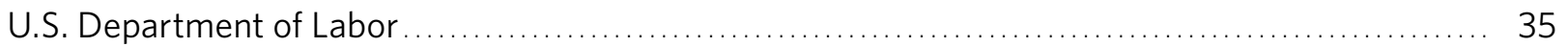

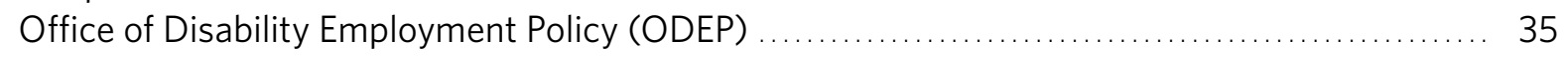

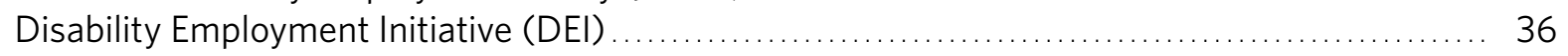

Advisory Committee on Increasing Competitive Integrated Employment for

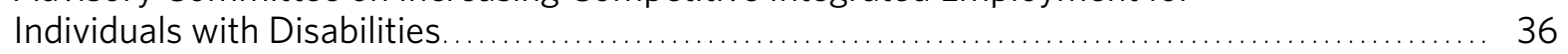

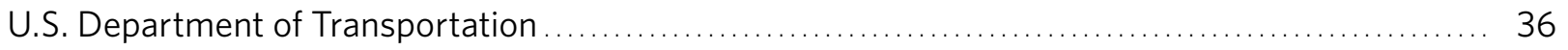

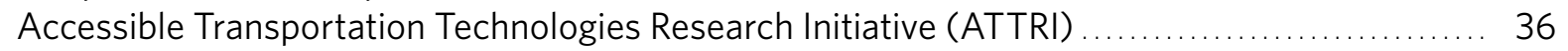

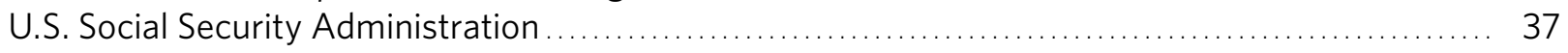

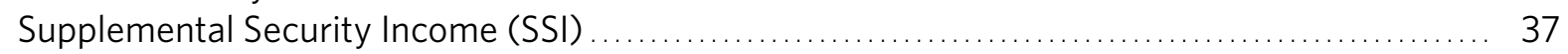

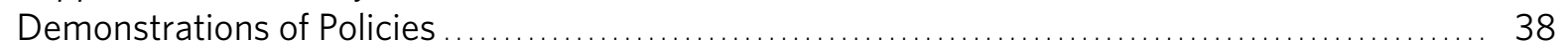

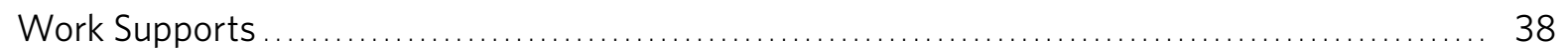

The 2020 Federal Youth Transition Plan ................................................. 38

Summary of Current Federal Investments for Transitioning Youth with ASD . ................... 40

Table 2. Federal Activities by Agency Relevant to Young Adults and Youth with Autism

Spectrum Disorder Transitioning to Adulthood ............................................... 42

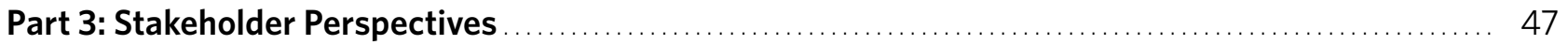

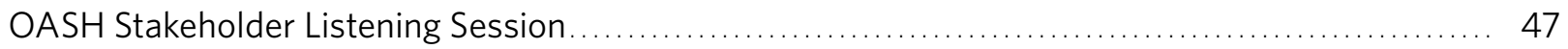

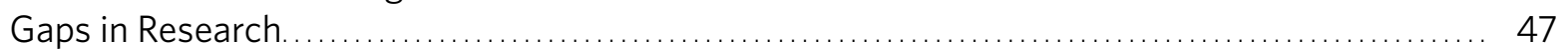

Gaps in Services and Programming .................................................... 50

Public Comments to IACC .......................................................... 52

GAO Roundtable Views of Services Needed ............................................ 53

Table 3. Key Services Identified by GAO . ................................................ 53

Summary of Input from External Stakeholders ........................................... 54

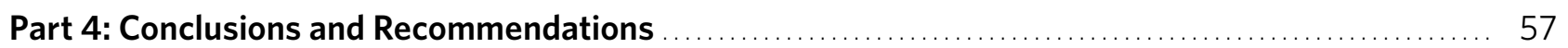

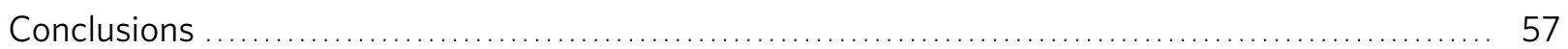

A Coordinated, Comprehensive Approach to Services and Support........................ 57

Support Coordinating Across Systems ............................................. 59

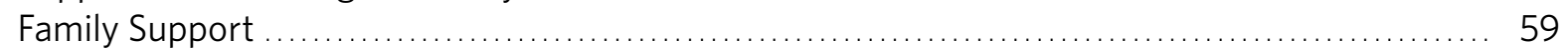

Data and Research on Transition-age Youth and Young Adults with ASD ................... 60

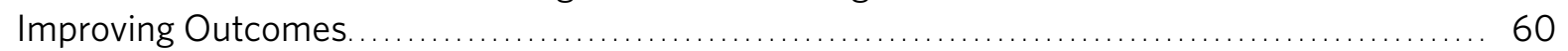

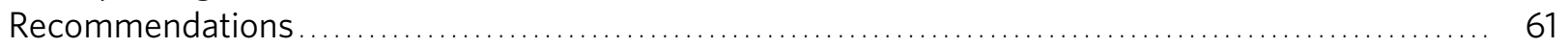

Epidemiological Data Collection and Monitoring ........................................ 61

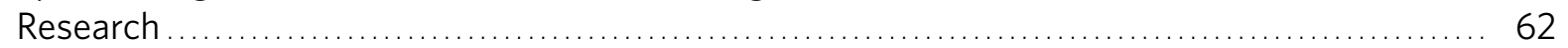

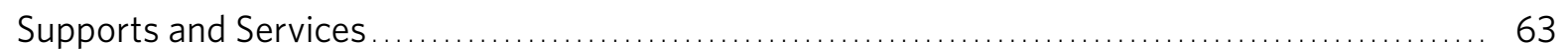

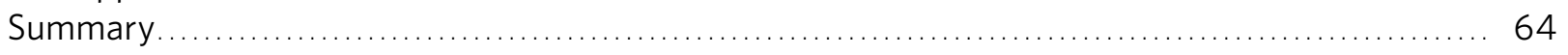

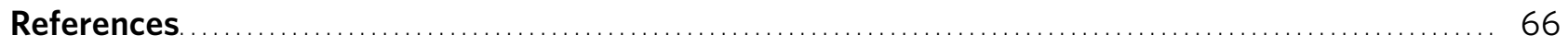

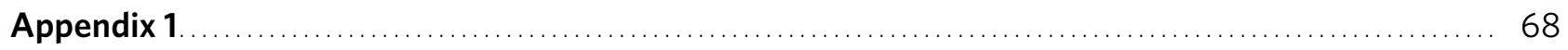

Autism CARES Act of 2014, amending Sec. 399DD(b) of the Public Health Service Act ............ 68

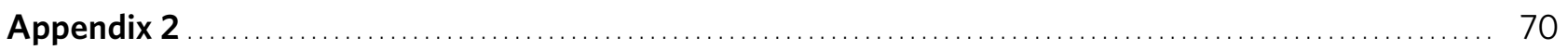

Authorizing Legislation by Agency and Program ............................................ 70

Other Federal Policies that May Apply To Young Adults with ASD .............................. 76 


\section{Interagency Workgroup on Young Adults and Youth with Autism Spectrum Disorder Transitioning to Adulthood}

\section{STEERING COMMITTEE}

Thomas E. Novotny, MD, MPH (National Autism

Coordinator)

Deputy Assistant Secretary for Health (Science \& Medicine)

Office of the Assistant Secretary for Health

Office of the Secretary

U.S. Department of Health and Human Services

Susan Daniels, $\mathrm{PhD}$

Director, Office of Autism Research Coordination

National Institutes of Health

U.S. Department of Health and Human Services

Alicia Richmond Scott, MSW

Senior Policy Analyst, Office of the Assistant Secretary

for Health

Office of the Secretary

U.S. Department of Health and Human Services

Robin Harwood, PhD

Health Scientist, Office of the Assistant Secretary for Health

Office of the Secretary and Health Resources and

Services Administration

U.S. Department of Health and Human Services

Julianna Rava, MPH

Science Policy Analyst, Office of Autism Research Coordination National Institutes of Health

U.S. Department of Health and Human Services

\section{MEMBERS}

Melinda Baldwin, PhD, LCSW

Child Welfare Development Specialist, Children's Bureau

Administration for Children and Families

U.S. Department of Health and Human Services

Gary Blau, PhD

Chief, Child, Adolescent and Family Branch

Center for Mental Health Services

Substance Abuse and Mental Health Administration

U.S. Department of Health and Human Services

\section{Susan Crawford}

Director, Compliance Disability Rights Division

Office of Enforcement

Fair Housing and Equal Opportunity

U.S. Department of Housing and Urban Development

Daniel Dodgen, PhD

Director, Office for at Risk Individuals

Office of the Assistant Secretary for Preparedness

and Response

Office of the Secretary

U.S. Department of Health and Human Services

Nicole Dowling, PhD

Chief, Developmental Disabilities Branch

Division of Congenital and Developmental Disabilities

National Center on Birth Defects and Developmental

Disabilities

Centers for Disease Control and Prevention

U.S. Department of Health and Human Services

Joel Dubenitz, PhD

Social Science Analyst, Office on Disability, Aging, and Long-Term Care Policy

Office of the Assistant Secretary for Planning and Evaluation

Office of the Secretary

U.S. Department of Health and Human Services 
Tiffany Farchione, MD

Acting Deputy Director, Division of Psychiatry Products

Food and Drug Administration

U.S. Department of Health and Human Services

\section{Richard Gonzales}

Director, Interagency and Tribal Affairs

Office of the Deputy Assistant Secretary for

Early Childhood Development

Administration for Children and Families

U.S. Department of Health and Human Services

\section{Melissa Harris}

Senior Policy Advisor, Disabled and Elderly Health

Programs Group

Center for Medicaid and CHIP Services

Centers for Medicare \& Medicaid Services

U.S. Department of Health and Human Services

\section{Stephen Holve, MD}

Chief Clinical Consultant for Pediatrics

National Council of Chief Clinical Consultants

Indian Health Service

U.S. Department of Health and Human Services

Jennifer Johnson, EdD

Acting Deputy Commissioner, Administration on Disabilities

Administration for Community Living

U.S. Department of Health and Human Services

\section{Denise Juliano-Bult, MSW}

Social Work Program Specialist, National Institute of Mental Health

National Institutes of Health

U.S. Department of Health and Human Services

\section{Alex Khalife Sands}

Legislative Analyst

Office of the Assistant Secretary for Legislation

Office of the Secretary

U.S. Department of Health and Human Services

\section{Ashley Knotts}

International Health Analyst

Office of Global Affairs

Office of the Secretary

U.S. Department of Health and Human Services

\section{Cheryl Levine, PhD}

Senior Program Analyst

Office of the Assistant Secretary for Preparedness

and Response

Office of the Secretary

U.S. Department of Health and Human Services

Jennifer Masoodi, JD, PhD

Program Analyst, Special Litigation/Disability Rights Section

Civil Rights Division

U.S. Department of Justice

Hae Young Park, MPH

Deputy Director, Division of Maternal and Child Health

Workforce Development

Maternal and Child Health Bureau

Health Resources and Services Administration

U.S. Department of Health and Human Services

Lauren Raskin Ramos, MPH

Director, Division of Maternal and Child Health Workforce

Development

Maternal and Child Health Bureau

Health Resources and Services Administration

U.S. Department of Health and Human Services

Scott Michael Robertson, PhD

Policy Advisor

Office of Disability Employment Policy

U.S. Department of Labor

\section{Marguerite Schervish, JD}

Technical Director, Division of Benefits and Coverage

Center for Medicaid and CHIP Services

Centers for Medicare \& Medicaid Services

U.S. Department of Health and Human Services 
Mathew Schutzer, JD

Trial Attorney, Special Litigation Section

Civil Rights Division

U.S. Department of Justice

\section{Harvey Schwartz, PhD}

Senior Advisor, Priority Populations

Office of Extramural Research, Education, and Priority

Populations

Agency for Healthcare Research and Quality

U.S. Department of Health and Human Services

\section{Christine Smith}

Senior Equal Employment Opportunity Specialist

Office of the Assistant Secretary for Administration

Office of the Secretary

U.S. Department of Health and Human Services

\section{Melissa Spencer}

Deputy Associate Commissioner, Office of Disability Policy

U.S. Social Security Administration

\section{Lawrence Wexler, EdD}

Director, Research to Practice Division

Office of Special Education and Rehabilitative Services

U.S. Department of Education

Lisa Wiggins, $\mathrm{PhD}$

Epidemiologist

National Center on Birth Defects and Developmental

Disabilities

Centers for Disease Control and Prevention

U.S. Department of Health and Human Services
Nicole Williams, PhD

Program Manager, Autism Research Program

Congressionally Directed Medical Research Programs

U.S. Department of Defense

\section{Marshalyn Yeargin-Allsopp, MD}

Associate Director for Children with Special Healthcare Needs National Center on Birth Defects and Developmental

Disabilities

Center for Disease Control and Prevention

U.S. Department of Health and Human Services

\section{Mohammed Yousuf}

Program Manager, Accessible Transportation Technologies

Research Initiative

Federal Highway Administration

U.S. Department of Transportation 


\section{OASH STAKEHOLDER LISTENING PANEL PARTICIPANTS}

\section{Kristy Anderson, MSW}

Research Associate

A.J. Drexel Autism Institute

Drexel University

\section{Scott Badesch}

President, Chief Executive Officer

Autism Society

\section{Julia Bascom}

Executive Director

Autistic Self Advocacy Network

\section{Shelby Crants}

Intern

Autism Speaks

Marc Ellison, EdD, LPC

Executive Director

West Virginia Autism Training Center

Marshall University

\section{Angela Lello}

Senior Director for Public Policy

Autism Speaks

\section{David Mandell, ScD}

Associate Professor of Psychiatry

Director, Center for Medical Health Policy and Services

Research,

University of Pennsy/vania
Margaret (Peggy) McManus, MHS

Co-Project Director

Got Transition

Anne Roux, MPH, MA

Research Scientist

A.J. Drexel Autism Institute

Drexel University

Paul Shattuck, PhD

Associate Professor

Director, Life Course Outcomes Research Program

A.J. Drexel Autism Institute

Drexel University

Stuart Spielman, Esq.

Senior Policy Advisor and Counsel

Autism Speaks

Julie Lounds Taylor, PhD

Assistant Professor

Pediatrics and Special Education

Vanderbilt University

Patience White, MD, MA

Co-Project Director

Got Transition 

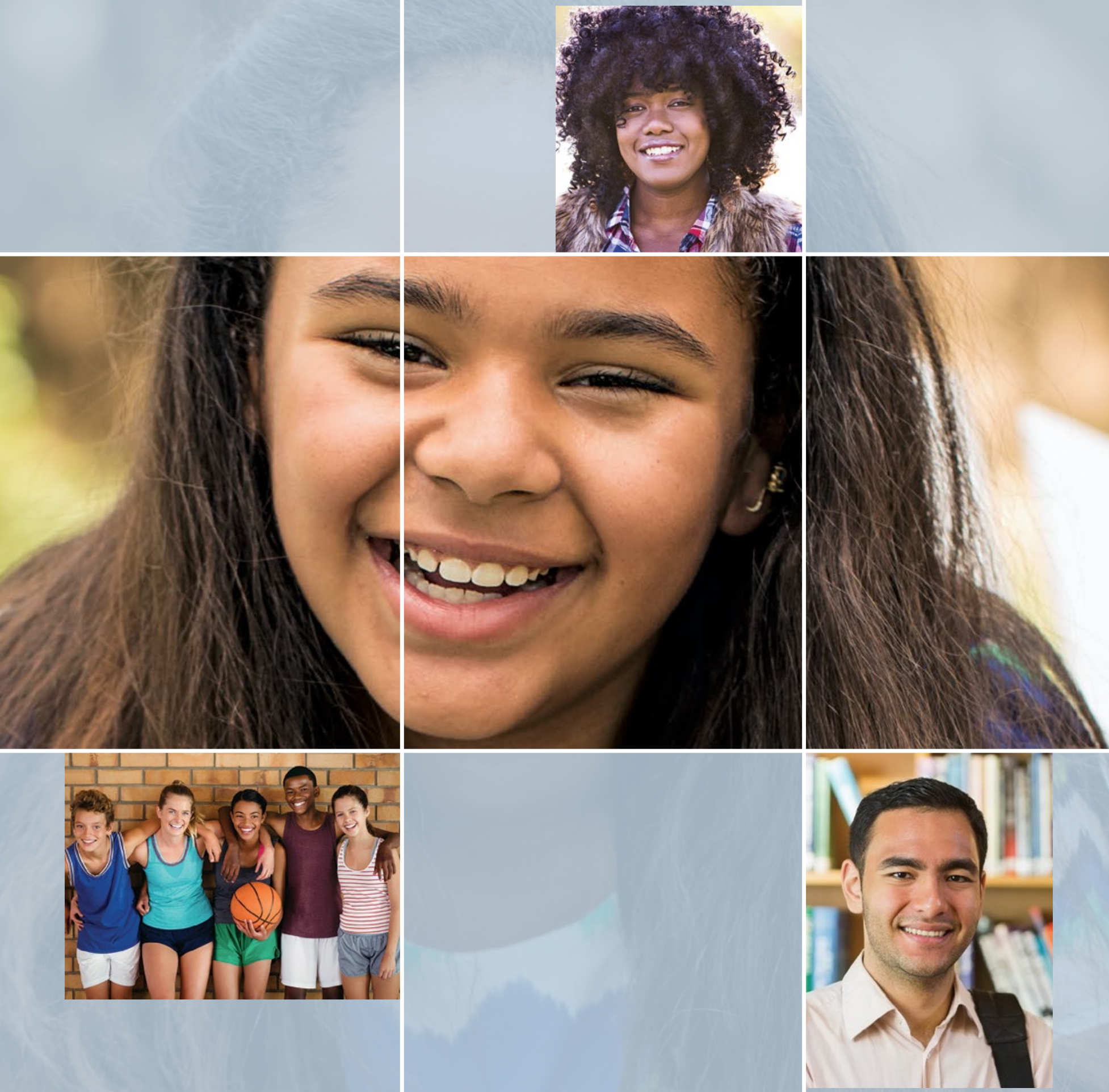


\section{Part 1:}

\section{Background on Autism Spectrum Disorder and the Transition to Adulthood}

This Report concerning young adults with autism spectrum disorder (ASD) and the challenges related to the transition from existing pediatric and school-based services to those services available during adulthood is mandated by the Autism CARES Act of 2014 (P.L. 113-157, see Appendix 1 for the complete text of the relevant section of the legislation).

The purposes of this Report are to summarize existing federal investments focused on the transition period from childhood to adulthood for individuals with ASD, and to identify gaps in federal research, programs, and services that support youth with ASD during this critical time period.

Part 1 of the Report provides background information on ASD and the need for support and services during the transition to adulthood. Part 2 presents an overview of federal programs that provide research, services, and supports applicable to youth and young adults with ASD. Part 3 summarizes information obtained from key stakeholders on this topic. Part 4 of the Report offers a synthesis of findings and recommendations for further consideration of systematic improvements in research, services, and supports focused on ASD and transition.

In this Report, 'services and supports' is used to convey the range of needs that youth and young adults with ASD may have, including health and behavioral health care, community-based supports and services, as well as support for tasks that all youth entering adulthood must navigate, such as obtaining employment, pursuing postsecondary education and training, managing independent living, and developing relationships and social networks that are meaningful to the individual.

The definition regarding what constitutes "transition age" varies. However, as a period of life that marks the transition from adolescence to adulthood, it is typically viewed as beginning in mid to late adolescence (e.g., ages 14 to 16) and ending in young adulthood (e.g., ages 24 to 26 ), roughly representing a period of time that typically encompasses not only most of high school, but also postsecondary education and training, and the establishment of employment and independent living.

Source references are included as endnotes following the Report and indicated in the text with Roman numerals; additional information that may be of interest to readers is included as footnotes at the bottom of the page and indicated in the text with symbols.

\footnotetext{
* These gaps were identified pursuant to statutory directions from Congress and as such do not constitute recommendations from the Administration for federal legislation.
} 


\section{Introduction to Autism Spectrum Disorder}

Autism is a neurodevelopmental condition. The American Psychiatric Association's Diagnostic and Statistical Manual (5th edition) ${ }^{2}$ identifies the diagnostic criteria for ASD as including:

- Persistent impairments in social interaction, including difficulties in social skills and nonverbal communications, as well as difficulty in developing, maintaining, and understanding implicit social norms regarding relationships with others; and

- Restricted, repetitive patterns of behavior, such as repetitive motor movements, inflexibility with regard to routines, restricted interests, and unusual reactions to sensory input.

The U.S. Centers for Disease Control and Prevention (CDC), an agency of the U.S. Department of Health and Human Services (HHS), maintains an active epidemiological surveillance system that provides estimates of the prevalence and characteristics of $\mathrm{ASD}^{\dagger}$ among children aged eight years whose parents or guardians reside in 11 surveillance network sites in the United States. According to this Autism and Developmental Disabilities Monitoring (ADDM) Network, an estimated 1 in 68 eight-year-olds in the United States met the criteria for ASD in the most recently published report. ${ }^{3}$ The ADDM Network bases its estimate on standardized evaluation of educational and health care records that were submitted by qualified service professionals in network sites.
Although often diagnosed in childhood (most commonly after age four; widely accepted diagnostic tools do not exist for children younger than 18 months ), ASD is a condition that typically continues throughout life and may be diagnosed in later childhood or even in adulthood. Because ASD is very heterogeneous in nature, its associated challenges and support needs can range widely from minor to very extensive. ${ }^{4}$ Regardless of the impact of associated challenges, youth with ASD should be able to access opportunities available to all youth entering adulthood in the United States, including pursuing life goals, participating in community life, and living independently (including living independently with assistance). Like any young adult, individual life goals may include opportunities to pursue postsecondary education and training, and to attain competitive and integrated employment.

\section{Scope of Need}

This section provides a description of the U.S. population with ASD and its needs, and serves as a foundation for understanding existing resources and potential gaps in those resources for those in the transition period.

\section{Population Characteristics}

National surveys that provide population-level data such as the National Survey of Children's Health (NSCH), the National Survey of Children with Special Health Care Needs (NS-CSHCN), and the National Health Interview Survey (NHIS) ${ }^{\text {s }}$ contain information

\footnotetext{
$\dagger$ In this Report, the terms autism, autism spectrum disorder, and ASD will be used interchangeably.

$\mp$ Researchers continue to explore indicators of autism in the first 18 months of life with some promising results, although no widely accepted screening tool exists for children younger than 18 months. See Giserman Kiss I, Feldman MS, Sheldrick RC, Carter AS. J Autism Dev Disord. 2017;47:1269. doi:10.1007/s10803-017. Providers need to continue to be alert to signs of ASD throughout the first three years of life and to signs of undiagnosed ASD in all children, youth, and adults.

$\S$ The NSCH and NS-CSHCN are led by the National Center for Health Statistics (NCHS) at CDC, under the direction and sponsorship of the Maternal and Child Health Bureau (MCHB) at the Health Resources and Services Administration (HRSA). The NHIS is a data collection program of the NCHS, within CDC.
} 
on children through age 17 years, including the percentage of these with ASD. Data available from both the NSCH $\left(2007^{5}\right.$ and $\left.2011-2012^{6}\right)$ and the $\mathrm{NHIS}^{7}$ indicate that in addition to gender differences, socioeconomic and racial/ethnic variation exist in the reported prevalence of ASD in the U.S. child population. In particular, based on 2014 data from the NHIS, higher prevalence of ASD is found among the following groups:

- Males (75.0 percent of persons reported as having been diagnosed with ASD);

- Non-Hispanic white children (59.9 percent of persons with ASD);

- Children living:

- With families in large metropolitan areas (54.7 percent of persons with ASD);

- With two parents (68.0 percent of persons with ASD); and

- With at least one parent who had more than high school education (67.6 percent of persons with ASD).

These data, however, cover only the pediatric population (ages 0 through 17 years); thus, information that tracks prevalence of ASD into adulthood is not available from existing populationbased national datasets.

The variation in reported prevalence across different racial/ethnic populations is likely not a true variation but instead may be due to uneven access to health care resources and services that enable early identification and diagnosis of ASD across different racial/ethnic and socioeconomic groups; this hypothesis is consistent with the fact that the socioeconomic and racial/ethnic gap in ASD diagnosis has decreased over the past decade as awareness of ASD has increased across a broader range of medical and other service providers. ${ }^{8}$ There is also evidence that girls with less extensive support needs are underdiagnosed with ASD as compared to boys with similar support needs. ${ }^{9,10}$

In addition to population-based surveys of children's health, the National Longitudinal Transition Study 2012 (NLTS 2012) recently released data comparing middle school and high school youth with ASD to youth with other disabilities as defined under the Individuals with Disabilities Education Act (IDEA). ${ }^{8}$ Data for the NLTS 2012 were collected in 2012-2013 from approximately 12,000 in-school youth and their parents, of which about 10,000 are students receiving special education and related services" under the IDEA. These students represent each of the 13 federal disability categories, including autism. Demographic findings from the NLTS 2012 report are consistent with other national survey data presented above. In particular, statistical analyses indicated that youth with ASD, when compared to students receiving special education and related services under IDEA overall, are significantly:

- More likely to be male (84 percent versus 67 percent);

- Less likely to be from socioeconomically disadvantaged families ( 37 percent versus 58 percent);

- Less likely to be Black not Hispanic (12 percent to 19 percent) or Hispanic (16 percent versus 24 percent); and

- More likely to have at least one parent with a four-year college degree (43 percent versus 26 percent) and parents who are married (72 percent versus 63 percent).

It is important to note that under the IDEA, autism is defined in part as "a developmental disability significantly affecting verbal and nonverbal communication and social interaction, generally evident before age three that adversely affects a child's educational performance" (34 CFR $\$ 300.8(\mathrm{c})(1)(\mathrm{i}))$. The focus on adverse impact

I The NLTS 2012 includes students with ASD with an IEP as well as those receiving services under section 504 of the Rehabilitation Act. 
on educational performance is appropriate given the purpose of the IDEA. Yet, due to the heterogeneous nature of ASD, ${ }^{4}$ not all youth and young adults with autism have concurrent intellectual disability* or behavioral issues that interfere with their performance or conduct in the classroom; instead, their condition may be primarily evident in social interactions with peers at recess or outside of school. Thus, although the NLTS 2012 generalizes to students in special education, it is not representative of the entire population of youth with ASD, but only to those who experience adverse impact on educational performance because of ASD and qualify for and receive special education and related services under the IDEA. ${ }^{11}$

However, peer challenges in childhood and adolescence, including experiences of bullying, have been linked to social and emotional challenges (such as depression, anxiety, and suicidal ideation) both concurrently and in adulthood. ${ }^{12}$ One study found prevalence estimates regarding bullying ${ }^{t h}$ among adolescents with ASD to be 46.3 percent for victimization, 14.8 percent for perpetration, and 8.9 percent for behavior that combines victimization and perpetration. ${ }^{13}$ This compares to overall prevalence of being bullied on school property for students in grades 9 to 12 of 20.2 percent. Because social interaction challenges are a defining characteristic of ASD, it is important to understand and address the potential needs of all youth and young adults with ASD.

In conclusion, there is no currently available single national dataset that provides information on the full population of transition-aged youth with ASD. Instead, existing national surveys that provide data on the health of the U.S. child population, such as the $\mathrm{NSCH}$ and NHIS, report on autism only through age 17 years; the NLTS2 and NLTS 2012 include data for persons across the full transition age range but include only youth with ASD who qualify for special education and related services under the IDEA.

\section{Trends in Health and Well-being}

The 2017 National Autism Indicators Report ${ }^{14}$ states that approximately 50,000 youth with ASD turn 18 each year, and that there are currently about 450,000 youth with ASD aged $16-24$ years old in the United States. This estimate is derived from two separate sources:"11 prevalence estimates from CDC's ADDM Network, combined with U.S. Census estimates regarding the number of 18-year olds in the United States in a given year.

As with all youth, these 450,000 adolescents and young adults with ASD, and those who come after them, should have the opportunity to find meaningful roles in adult society through competitive integrated employment, independent life skills, good health and well-being, satisfying relationships, continued education and training, and career development and exploration according to their individualized life goals.

The National Longitudinal Transition Study-2 (NLTS2), ${ }^{\text {sS }}$ commissioned by the U.S. Department of Education and conducted between 2000 and 2009, draws from a population of youth with disabilities who, at the beginning of the study, were enrolled in special education with an IEP in school; in 2009, they

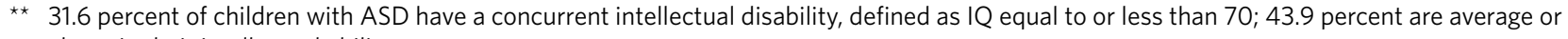
above in their intellectual ability.

it Children and youth with disabilities have been found to be two to three times more likely to have experienced bullying than youth who do not have a disability. The CDC's 2015 Youth Risk Behavior Survey reported 20.2 percent overall prevalence of being bullied on school property for students in grades 9-12. Little is known regarding the relative prevalence of bullying among different subpopulations of youth with disabilities.

The NLTS2 is discussed in more detail in the next section.

§§ For information and reports based on the now-completed NLTS2 study sponsored by the U.S. Department of Education, visit its website at https://nlts2.sri.com/index.html
} 
had exited secondary school and were 20-25 years old. Findings from both the NLTS2 and the NLTS 2012 (described in the preceding section) generalize nationally to special education students as a group, as well as to each of 13 disability categories including ASD that receive special education. Together, the NLTS $2012^{8}$ and NLTS2 ${ }^{15}$ provide information regarding the health and wellbeing of youth and young adults with ASD who either qualify or qualified for special education and related services while in secondary school.

\section{Trends in Secondary School}

As described above, the NLTS 2012 compared middle school and high school youth with ASD to youth with other disabilities; all of these youth received special education and related services under the IDEA. ${ }^{8}$ This study found that youth with ASD who receive special education and related services under IDEA, compared to all students receiving special education and related services under IDEA are:

- More likely to have a co-occurring chronic health or mental health condition (43 percent versus 28 percent);

- Less likely to be able to manage independently and develop friendships:

- More likely to experience challenges communicating (50 percent versus 29 percent);

- Less likely to independently manage activities of daily living (17 percent versus 46 percent);

- Less likely to know how to make friends (76 percent versus 92 percent); and

- Less likely to report getting together with friends weekly (29 percent versus 52 percent).

- Less likely to take steps to prepare for college and employment:

- Less likely to be given at least some input into IEP and transition planning (41 percent to 59 percent);
- Less likely to have taken a college entrance or placement test (29 percent to 42 percent); and

- Less likely to have paid work experiences in the past year (23 percent to 40 percent).

In summary, compared to other youth receiving special education and related services, youth with ASD are more likely to have co-occurring health and mental health conditions, less likely to be able to manage independently and develop friendships, and less likely to take steps in secondary school that will prepare them for college and employment.

\section{Trends in Adulthood}

Data from the NLTS2, which examined young adults aged 20-25 with ASD who had been in special education in secondary school, indicate that: ${ }^{15,16}$

- Less than 1 in 5 (19 percent) had ever lived independently (away from their parents without supervision) following high school (compared to more than 66 percent for those with serious mental illness or 34 percent with intellectual disabilities not concurrent with ASD);

- Nearly two-thirds (63.9 percent) received Supplemental Security Income (SSI) benefits;

- Only 58 percent had ever worked during their early 20s compared with those with other types of special health care and service needs, including emotional disturbances, speech and language impairments, and learning disabilities (all greater than 90 percent) as well as intellectual disabilities (74 percent); and

- Only 36 percent of youth with ASD had ever participated in postsecondary education or training of any kind between high school and their early 20 s.

In addition, recent research has revealed disturbing trends in the early mortality of adults with ASD. Although further research is needed to confirm these findings, several studies have found that adults with ASD, compared to the general population: 17, 18, 19, 20 
- Die an average of 16 years earlier than people not on the spectrum;

- Are 40 times more likely to die prematurely of a neurological condition (such as epilepsy) if they also have a learning disability;

- Are nine times more likely to die from suicide;

- Are at heightened risk for co-occurring conditions such as depression and anxiety; and

- Are at higher risk for other non-communicable diseases including diabetes and heart disease.

Identifying what factors drive these differences, and improving services and supports to ameliorate or prevent co-occurring health and mental health conditions through the transition to adulthood and beyond, is thus a critical need for youth with ASD; this is an important component of what would be considered a tertiary public health prevention effort." Such efforts may be shown to have significant returns on investment (ROI), and require monitoring and evaluation to support the evidence for such returns. Adults with ASD who receive supportive services have a high likelihood of subsequently gaining employment, thus improving the ROI for timely services. ${ }^{21}$

\section{Transition Needs}

The goals of transition planning and services-that is, preparing for the transition from adolescence to adulthood-include promoting career exploration and development, extending education or training opportunities, supporting independent life skills, and enhancing health and well-being.

Federal law requires schools to provide special educational and related services, including transition services, for students with ASD who meet the eligibility criteria under IDEA. However, the legal mandate for this provision ends following graduation from high school with a regular high school diploma, leaving many young adults with ASD who have either finished high school with a regular high school diploma, or aged out of IDEA requirements, without the continuing services and supports they may need. The 2015 National Autism Indicators Report: Transition into Young Adulthood ${ }^{16}$ examined 12 services that adolescents and young adults with ASD commonly use, including speech-language therapy, occupational therapy, social work, case management, transportation, and/or personal assistant services. During high school, nearly all (97 percent) received at least one of these 12 services. However, service usage dropped sharply following high school. In their early 20s, 37 percent were defined as "disconnected" - that is, they neither worked outside the home nor continued education after high school; 28 percent of these young adults that were neither employed nor attending postsecondary school or training were receiving no services or supports.

ๆๆ Primary prevention involves interventions prior to the onset of a condition (such as risk factor reduction); secondary prevention involves interventions during early signs or pre-clinical states in order to prevent full expression of the condition; and tertiary prevention involves interventions after onset of the condition that prevent further disability or progression of disease.

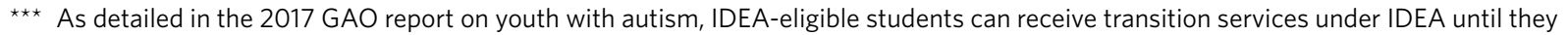
graduate from high school with a regular high school diploma or exceed the age range for which a given state makes a free and appropriate public education (FAPE) available to children with disabilities. Although federal law permits States to use IDEA funds to make FAPE available to students with disabilities who have not graduated high school with a regular high school diploma through age 21, whether States make FAPE available to students in this age range depends on state law or practice. Some States choose to terminate the obligation to make FAPE available when a student turns 21, and other States choose to continue to make FAPE available through a student's 22nd birthday. 
In 2016, the Interagency Autism Coordinating Committee (IACC) collected public comments regarding the most pressing needs that stakeholders believe should be addressed in the 2016-2017 update of the IACC Strategic Plan. In the area of transition to adulthood, themes that emerged from public comment were:

- An acute need exists for a range of services and supports, including:

- Postsecondary education and vocational training;

- Employment opportunities;

- Treatment for concurrent conditions, and access to occupational, speech, and language therapies;

- Housing;

- Transportation supports;

- Community integration services and supports; and

- Coordinated, 'wraparound' services-that is, services in which a team of individuals relevant to a young person's health and wellbeing (e.g., family members, other supports, service providers, agency representatives) collaboratively develop an individualized plan of services and supports that they implement, evaluate, and revise as necessary over time.
- Relief is needed for the adverse challenges faced by families and individuals who face barriers to access, coordinate, and finance what are experienced as 'piecemeal' services on their own, or services that, in many cases, they may not even be aware of; and

- Transition supports and information should be provided beginning in early adolescence.

The IACC tracks U.S. federal and private research funding in its annual ASD Research Portfolio Analysis Report. Data reported for $2015^{22}$ indicated that combined federal and private funding related to lifespan issues, which includes transition, received only 2 percent ( $\$ 6.1$ million) of overall federal and private ASD research funding (Source: Office of Autism Research Coordination, National Institutes of Health); this percentage does not change when including only federal funding sources. ${ }^{i t \dagger}$ When considering only projects related to transition issues, the proportion is less than 2 percent of total funding. In terms of number of projects rather than percentage of funding, lifespan issues made up only 3 percent of ASD projects, with 37 projects across both federal and private sources; of these, 24 addressed transition to adulthood research.

it广 Federal agencies included in the 2015 IACC ASD Research Portfolio Analysis: Administration for Community Living (ACL). Agency for Healthcare Research \& Quality (AHRQ), Centers for Disease Control and Prevention (CDC), Department of Defense, Department of Education, Environmental Protection Agency (EPA), Health Resources \& Services Administration (HRSA), National Institutes of Health $(\mathrm{NIH})$, National Science Foundation (NSF). Private organizations included: Autism Science Foundation, Autism Research Institute, Autism Speaks, Brain \& Behavior Research Foundation, Center for Autism \& Related Disorders, New England Center for Children, Organization for Autism Research, Patient-Centered Outcomes Research Institute, Simons Foundation. 
ASD Research Funding by IACC Strategic Plan

Question - Combined Federal and Private Funding, 2015

Total Funding: $\$ 342,636,029$

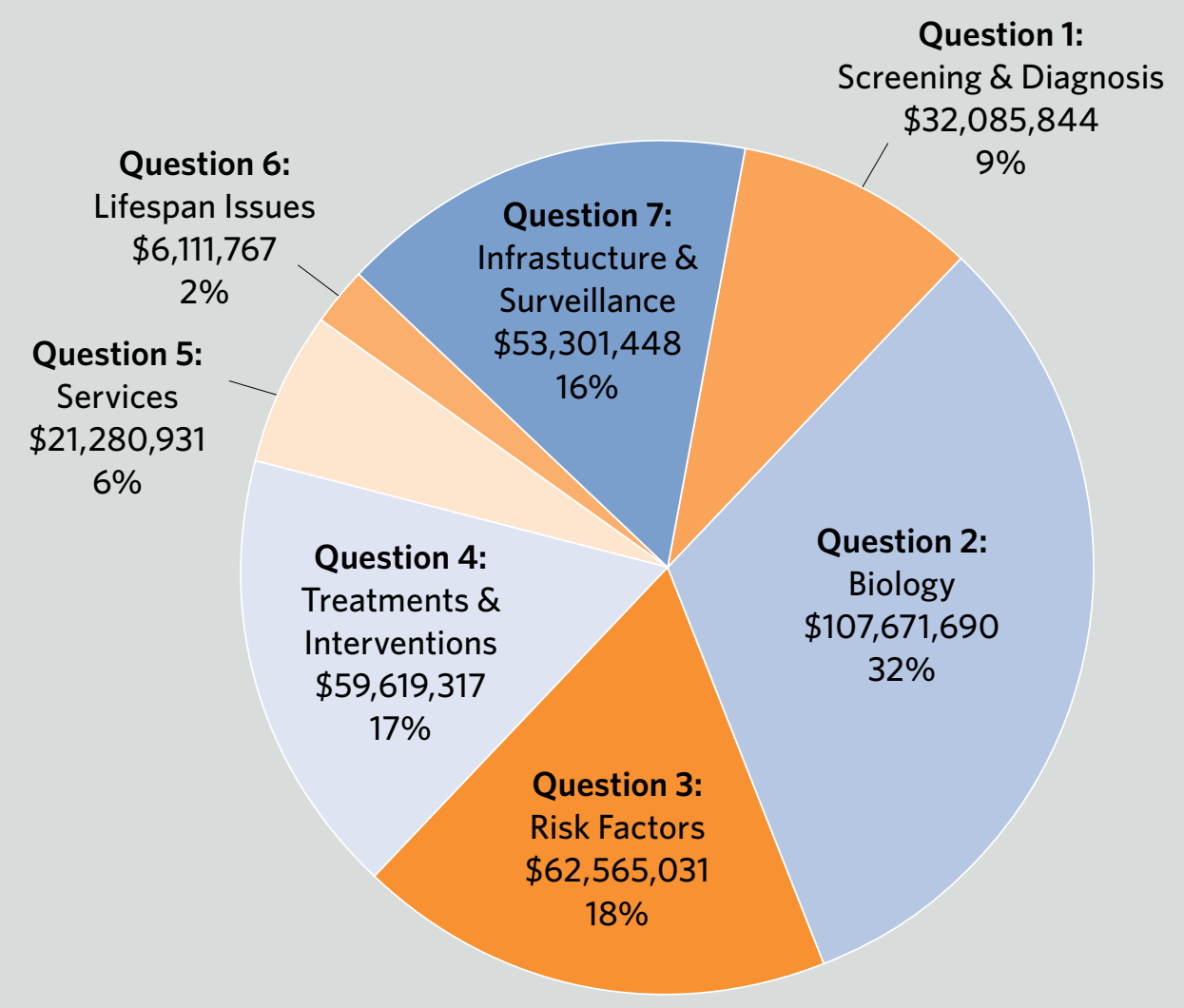

NOTE: Topic areas are defined by each question in the IACC Strategic Plan. Question 6, which focuses on issues across the lifespan, represents only 2 percent of the overall ASD research funding across both federal and private funding sources. SOURCE: Office of Autism Research Coordination, National Institute of Mental Health. 


\section{Challenges and Barriers to Service}

ASD is a complex and heterogeneous condition, affecting different individuals in different ways and with differing experiences of barriers and challenges. Many of the barriers to services associated with ASD are common across children and youth with special health care, educational, and service needs, barriers are more specific (although not unique) to ASD itself.

Like many individuals with disabilities and/or special health care and service needs, transition-age youth and young adults with ASD may experience barriers ${ }^{23}$ around issues such as:

- The coordination of complex clinical care and service and support needs across multiple systems;

- Access to needed resources, which may be limited by availability of specialists and related services, as well as by adequacy of health insurance (with respect to health care services) and/or location of services;

- Access to services and supports that facilitate individual and family management of the financial, personal, and social challenges and barriers related to managing a complex, neurodevelopmental condition, and co-occurring health conditions;

- Achievement and management of independent living, including housing and transportation, as well as education and training appropriate to the individual's goals, career interests, and necessary employment supports, and other resources that any young person would need to enter adulthood and independently navigate its demands; and
- The development of meaningful relationships and broader social networks as the individual desires.

Challenges that are more specific but not necessarily exclusive to ASD include:

- Lack of availability of and consistency in ASDspecific training across a range of providers and provider types, which complicates identification, diagnosis, service provision, and access to needed supports and services; inconsistency in provider training and screening procedures is problematic for the quality of services that are available;

- The communication challenges faced by adults with ASD in accessing and interacting with health service providers about their physical and mental health; in addition, the lack of provider understanding of these barriers faced by their patients or clients with ASD may hinder delivery of quality healthcare services for this population; and

- A need to build greater community awareness and acceptance regarding the potential strengths and weaknesses that transition-age youth and young adults with ASD may bring to both workplace and community settings. This includes finding and maintaining competitive integrated employment; obtaining community-based housing; utilizing transportation services that enable independence and employment; and handling stigmatization, bullying, and victimization. ${ }^{24}$ These data suggest the need among employers, schools, care and service providers, and the public for greater awareness and acceptance of the neurodevelopmental differences associated with ASD.

The HRSA Maternal and Child Health Bureau defines children and youth with special health care needs as those who have or are at increased risk for chronic physical, developmental, behavioral or emotional conditions and who also require health and support services of a type or amount beyond that required by children generally. https://mchb.hrsa.gov/maternal-child-health-topics/ children-and-youth-special-health-needs. 


\section{Background for this Report}

This Report is mandated by the Autism Collaboration, Accountability, Research, Education and Support Act (Autism CARES Act) of 2014 (P.L. 113-157). ${ }^{25}$ It was led by an Interagency Work Group comprised of a Steering Committee (led by the National Autism Coordinator in the Office of the Assistant Secretary for Health and the Office of Autism Research Coordination in the National Institute of Mental Health), and representatives from each of the federal agencies that support research and program efforts relevant to youth with ASD who are transitioning to adulthood.

\section{Legislation}

\section{The Autism CARES Act}

The Autism CARES Act was signed into law on August 8, 2014 (see Appendix 1 for the section of the Autism CARES Act that mandates this Report). An amendment to the Public Health Service Act, the Autism CARES Act reauthorized funding that began in fiscal year 2006 as the Combating Autism Act (CAA), and continued in fiscal year 2011 as the Combating Autism Reauthorization Act (CARA). The Autism CARES Act reauthorized activities related to ASD research, services, and support, including but not limited to:

- Epidemiological studies and research on ASD and other developmental disabilities;

- Autism-related educational services, early detection, and intervention;

- Support for regional centers of excellence in ASD for research and training;

- Use of research centers or networks for the provision of training in respite care and for research to determine practices for interventions to improve the health and well-being of individuals with ASD;
- The addition of language that includes adults as well as children as the focus of funded activities; and

- A report to Congress on federal activities related to youth and young adults with ASD and the challenges they face regarding the transition from school-based to adult service systems.

\section{Legislative Requirements of the Report to Congress}

The 2014 Autism CARES Act specifies the elements of this report in an amendment to Section 399DD of the Public Health Service Act (42 USC 280i-3). The exact wording is provided below and in Appendix 1 :

A. Demographic characteristics of youth transitioning from school-based to community-based supports;

B. An overview of policies and programs relevant to young adults with autism spectrum disorder relating to post-secondary school transitional services, including an identification of existing Federal laws, regulations, policies, research, and programs;

C. Proposals on establishing best practices guidelines to ensure:

1. Interdisciplinary coordination between all relevant service providers receiving Federal funding;

2. Coordination with transitioning youth and the family of such transitioning youth; and

3. Inclusion of the individualized education program for the transitioning youth as prescribed in section 614 of the Individuals with Disabilities Education Act (20 U.S.C. 1414);

D. Comprehensive approaches to transitioning from existing school-based services to those services available during adulthood, including:

1. Services that increase access to, and improve integration and completion of, post-secondary education, peer support, vocational training (as defined in section 103 of the Rehabilitation 
Act of 1973 (29 U.S.C. 723)), rehabilitation, self-advocacy skills, and competitive, integrated employment;

2. Community-based behavioral supports and interventions;

3. Community-based integrated residential services, housing, and transportation;

4. Nutrition, health and wellness, recreational, and social activities;

5. Personal safety services for individuals with autism spectrum disorder related to public safety agencies or the criminal justice system; and

6. Evidence-based approaches for coordination of resources and services once individuals have aged out of post-secondary education;

E. Proposals that seek to improve outcomes for adults with autism spectrum disorder making the transition from a school-based support system to adulthood by:

1. Increasing the effectiveness of programs that provide transition services;

2. Increasing the ability of the relevant service providers described in (C) above to provide supports and services to underserved populations and regions;

3. Increasing the efficiency of service delivery to maximize resources and outcomes, including with respect to the integration of and collaboration among services for transitioning youth;

4. Ensuring access to all services necessary to transitioning youth of all capabilities; and

5. Encouraging transitioning youth to utilize all available transition services to maximize independence, equal opportunity, full participation, and self-sufficiency.

\section{Coordination of Autism Activities}

The Autism CARES Act makes provision for the coordination of autism activities across federal agencies. In particular, the 2014 Autism CARES Act:

- Reauthorizes the IACC to continue through 2019;

- Requires the U.S. Department of Health and Human Services (HHS) to designate an official (the National Autism Coordinator) to ensure implementation and accountability of Autism CARES activities, and to take the lead for writing this mandated Report to Congress on young adults and transitioning youth; and

- Requires the submission of two Reports to Congress-one that covers all federal autismrelated activities, and this current report, which focuses on the service needs of individuals with ASD who are transitioning into adulthood.

\section{The Interagency Autism Coordinating Committee (IACC)}

The IACC is a federal advisory committee comprised of public and private members that coordinates autism efforts and provides advice to the Secretary of Health and Human Services on ASD. The membership of the IACC includes officials from agencies supporting programs that serve individuals with autism, public stakeholders representing the viewpoints of individuals on the autism spectrum, family members, community advocates, communitybased providers, and researchers. The IACC serves as a forum for public input on issues related to ASD, and the committee uses this input to inform its activities, including the annual update of the IACC Strategic Plan for ASD. In addition, the committee monitors federal and community activities related to ASD through its annual Portfolio Analysis Reports, and it compiles an annual IACC Summary of Advances in ASD Research to inform Congress and the public of major advances in ASD research. ${ }^{x x v i}$ New provisions within the Autism CARES Act include a call for the 
IACC to increase focus on services and supports for people with ASD. The IACC is supported by the National Institute of Mental Health's (NIMH) Office of Autism Research Coordination (OARC).

\section{National Autism Coordinator and Federal Interagency Work Group}

As described in the 2014 legislation, the role of the National Autism Coordinator is to ensure implementation and accountability of Autism CARES activities. The Coordinator was appointed in April 2016, and convened, in October 2016, a federal interagency work group (IWG) to provide input into the mandated Report to Congress on young adults and transitioning youth with ASD; the IWG consists of representatives from multiple agencies across the federal government (Table 1). The National Autism Coordinator and IWG align and coordinate their efforts with OARC, which manages the IACC; the IACC includes members from several federal departments and agencies as well as public stakeholders. The IWG members have reviewed and commented on this Report. No appropriations were provided for required coordinating activities under the 2014 Autism CARES Act, but this Report has been completed by HHS using existing personnel and resources.

\section{Government Accountability Office Report on Youth with Autism}

In compiling this report, the IWG Steering Committee also drew information from the 2017 Government Accountability Office (GAO) report, Youth with Autism: Roundtable Views of Services Needed During the Transition into Adulthood, GAO-17-109. ${ }^{4}$ GAO's report describes the highly heterogeneous nature of ASD, with varying levels of impairment (from none to severe) across five domains of functioning: social impediments; communication difficulties; intense focus/interests; sensitivities; and routine and repetition. This variation means that life goals, as well as specific life challenges that each of these goals may entail, are highly individualized. (Further detail on this 2017 GAO report is found in Part 4.)

In addition, in its 2012 review, Students with Disabilities: Better Federal Coordination Could Lessen Challenges in the Transition from High School, GAO-12-594, ${ }^{27}$ GAO found that students with disabilities face several longstanding challenges in accessing services that may assist them as they transition from high school into postsecondary education and the workforce-services such as tutoring, vocational training, and assistive technology. That report recommended that the U.S. Departments of Education (ED), Health and Human Services (HHS), Labor (DOL), and the Social Security Administration (SSA) develop an interagency transition strategy that addresses (1) operating toward common outcome goals for transitioning youth; (2) increasing awareness of available transition services; and (3) assessing the effectiveness of their coordination efforts. All four agencies agreed with the recommendation.

\section{Summary of Backgroud Information}

The transition period from adolescence to adulthood for persons living with ASD involves increased challenges for those persons, their caregivers, and for government agencies and non-governmental organizations serving them. These complexities begin with the heterogeneity of the condition itself and any co-occurring health and mental health conditions, and become magnified by the complexities in transitioning from a largely educational systembased set of supports for those 21 years or younger, to a set of health and social service systems geared to adults. Many of these adult systems encompass general disability program services, but the eligibility requirements for them are in themselves challenging and perhaps not sufficiently coordinated for the individual client or even widely accessible to the ASD transitioning population. 


\section{Table 1}

\section{Participating Federal Agencies in the Interagency Work Group on Young Adults and Transitioning Youth with Autism Spectrum Disorder}

\section{Steering Committee, U.S. Department of Health and Human Services}

Office of the Secretary

- Office of the Assistant Secretary for Health, National Autism Coordinator

National Institutes of Health

- Office of Autism Research Coordination

\section{Federal Agencies Represented by Interagency Work Group Members}

\section{U.S. DEPARTMENT OF HEALTH AND HUMAN SERVICES}

Office of the Secretary

- Office of the Assistant Secretary for Legislation

- Office of the Assistant Secretary for Planning and Evaluation

- Office of the Assistant Secretary for Preparedness and Response

- Office of Global Affairs

- Office of the Assistant Secretary for Administration

Administration for Children and Families

" Children's Bureau

- Office of the Deputy Assistant Secretary for Early Childhood Development

Administration for Community Living

- Administration on Disabilities

Agency for Healthcare Research and Quality

- Office of Extramural Research, Education, and Priority Populations

Centers for Disease Control and Prevention

- National Center on Birth Defects and Developmental Disabilities

Centers for Medicare \& Medicaid Services

- Center for Medicaid and CHIP Services

Food and Drug Administration

- Division of Psychiatry Products
Health Resources and Services Administration

- Maternal and Child Health Bureau, Division of Maternal and Child Health Workforce Development

Indian Health Service

- National Council of Chief Clinical Consultants

National Institutes of Health

- National Institute of Mental Health

Substance Abuse and Mental Health Administration

- Center for Mental Health Services

\section{U.S. DEPARTMENT OF EDUCATION}

Office of Special Education and Rehabilitative Services

- Office of Special Education Programs

- Rehabilitation Services Administration

Office of Civil Rights

Institute of Education Sciences

- National Center for Education Statistics

- National Center for Education Evaluation

- National Center for Special Education Research

Office of Postsecondary Education

\section{U.S. DEPARTMENT OF DEFENSE}

Congressionally Directed Medical Research Programs

- Autism Research Program

\section{U.S. DEPARTMENT OF HOUSING AND URBAN DEVELOPMENT}

Fair Housing and Equal Opportunity

- Office of Enforcement, Compliance and Disability Rights Division

\section{U.S. DEPARTMENT OF JUSTICE}

Civil Rights Division

U.S. DEPARTMENT OF LABOR

Office of Disability Employment Policy

\section{U.S. DEPARTMENT OF TRANSPORTATION}

Federal Highway Administration

U.S. SOCIAL SECURITY ADMINISTRATION

Office of Disability Policy 

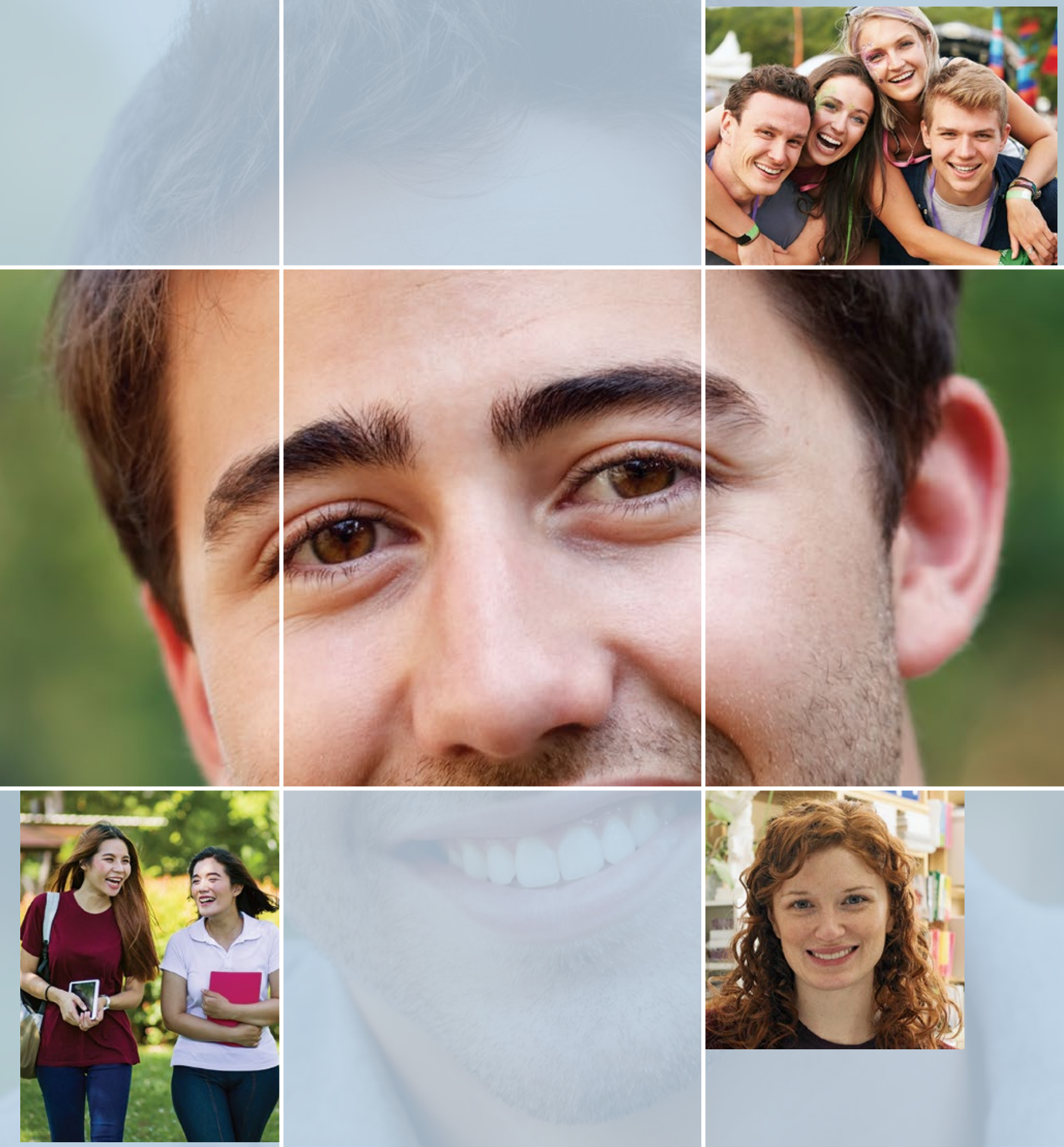


\section{Part 2:}

\section{Federal Agency Activities on Young Adults and Youth with Autism Spectrum Disorder Transitioning to Adulthood}

This part of the Report describes the current federal research, policies, and programs related to the transition period from adolescence to adulthood for persons with ASD. Table 2 provides a summary of these identified federal research, training, and service programs relevant to transition-age youth with ASD, by agency.

It is important to note that many of these programs are not designed specifically to serve or fund research focused on individuals with ASD; however, as general population programs, or as efforts targeted broadly to people with disabilities, these programs do inevitably serve or include transitionage youth and young adults with ASD. Depending on the fundamental goals of the program, they may or may not track ASD status among those they serve or study. It is, thus, not currently possible to know how many youth and young adults with ASD are receiving services and supports from each specific agency.

Information regarding each of these programs follows. An overview of this information is presented in Table 2 at the end of Part 2. Federal policies and legislation that authorize these programs are found in Appendix 2.

\section{U.S. Department of Health and Human Services}

The majority of health-related federal research, programs, and services targeted to individuals with ASD are administered through the U.S.
Departmentof Health and Human Services (HHS), which has as its mission enhancing and protecting the health and well-being of all Americans. Youth and young adults with ASD may, depending on eligibility requirements, benefit from, and/or participate in, supports and services provided by these programs, either with their families or as individuals. HHS includes 11 operating divisions, nine of which administer programs relevant to this report:

\section{Administration for Children and Families (ACF)}

This operating division promotes the social and economic health and well-being of the nation's children and families. ACF collects data through three mechanisms about children/youth in the foster care system where child welfare agencies are required through Title IV-E of the Social Security Act to submit data. However, there are no ACF-sourced metrics that track the number of children/youth in the U.S. foster care and/or the larger child protection and welfare systems who have been diagnosed with Autism/ASD. Nevertheless, valuable information about those involved in ACF programs is provided through ACF reports. 
a. The Adoption and Foster Care Analysis and Reporting System (AFCARS) collects case-level information from state and tribal IV-E (i.e., child protection and welfare) agencies on all children in foster care and those who have been adopted with Title IV-E agency involvement. Examples of data reported in AFCARS include demographic information on the child in care as well as the foster/adoptive parents, the number of removals the child may have experienced, and the current placement setting. ASD is included in a data element called "Other Medically Diagnosed Condition," and is not specifically identified in the collection of AFCARS data.

b. The National Child Abuse and Neglect Data System (NCANDS) is a voluntary data collection system that gathers information from all 50 states, the District of Columbia and Puerto Rico about reports of child abuse and neglect. Key findings are published in the Child Welfare Outcomes Reports to Congress and in the annual Child Maltreatment reports. There are no data elements that specifically track whether clients have been diagnosed with Autism/ASD.

C. The National Youth in Transition Database (NYTD) collects information on youth in foster care including demographic characteristics and the outcomes of youth that have aged out of the child welfare system. This tracking system began in 2010, and the first data were reported in May 2011. States are to collect information in a manner consistent with federal law on each youth who receives independent living services paid for or provided by the state agency that administers the John $\mathrm{H}$. Chafee Foster Care Independence Program (CFCIP) of section 477 of the Social Security Act. States also collect demographic and outcome information on youth in foster care whom the state will follow over time. This information allows ACF to track which independent living services States provide and to assess the outcomes of those participating youth. There is one data element that addresses whether or not a youth received a special education service $^{\text {sss; }}$, however, there is no particular information about a youth's specific diagnosis.

d. Three Major Data Collection Projects have been funded in whole or in part by ACF. The data can be accessed through the National Data Archive on Child Abuse and Neglect.

i. The Longitudinal Studies of Child Abuse and Neglect (LONGSCAN) involved a consortium of research groups initiated in 1990 with grants from the ACF Children's Bureau and coordinated through the University of North Carolina Injury Prevention Research Center. LONGSCAN is a multi-site longitudinal study of 1354 children identified in infancy or early childhood as being maltreated or at risk of maltreatment. The children who were included in the study were culturally and ethnically diverse and from five distinct geographical areas. Maltreatment data were collected from multiple sources and yearly telephone interviews were conducted. This data set did not specify whether a child had been diagnosed with Autism/ASD.

ii. The National Incidence Study of Child Abuse and Neglect (NIS) has been conducted approximately once each decade beginning in 1974 in response to requirements of the Child Abuse Prevention and Treatment Act. There are four years of data available: 1980 (NIS-1), 1987 (NIS-2), 1996 (NIS-3), and 2006 (NIS4). NIS studies are designed to estimate more broadly the incidence of child maltreatment nationally. A unique contribution of the NIS has been the use of a common definitional framework for classifying children according to types and severity of maltreatment. Information specifically about Autism/ASD is not collected.

§§§ As defined in the Final Rule (45 CFR Section 1356.81(g)(19)), "special education" refers to specifically designed instruction, at no cost to parents, to meet the unique needs of a child with a disability. 


\section{iii. The National Survey of Child and Adolescent} Well-Being (NSCAW) contains information about Autism/ASD. NSCAW is a nationally representative, longitudinal survey of children and families who have been the subjects of investigation by Child Protective Services. There have been two cohorts of children enrolled in the survey, which includes data from reports by children, parents, and caregivers; reports from caseworkers and teachers collected in a manner consistent with federal law; and reviews of administrative records. NSCAW also examines child and family well-being outcomes in detail and seeks to relate those outcomes to experience with the child welfare system and to family characteristics. This dataset represents the child welfare population in states that do not require first contact with agencies in order to participate in research studies. The prevalence rate of ASD was 3 percent, or approximately double what it is (1.47 percent) in the general child population according to CDC's surveillance system (See Part 1). It should be noted that the NSCAW is a survey rather than a surveillance system, and as such uses parent self-report rather than diagnostic evaluation to determine the presence of ASD. However, using a similar self-report methodology, the 2011-2012 National Survey of Children's Health (NSCH, 2011-2012vii) reported a national prevalence rate of currently diagnosed children with ASD of 1.8 percent, much closer to the official estimate of 1.47 percent derived from CDC's epidemiological surveillance system. Thus, compared to a data source that also employs parent selfreport of diagnosed ASD, the rate of ASD found among children tracked through the nation's child protective service system is still two-thirds higher than the rate reported in the general population.

\section{Administration for Community Living ( $A C L$ )}

The ACL works to increase access to community support systems for older Americans and for people with disabilities across the lifespan. Its main activities and statutory authorities include administration of disability programs that support community living from which young adults with ASD may benefit.

\section{a. The Administration on Intellectual and} Developmental Disabilities (AIDD) administers programs under the Developmental Disabilities Assistance and Bill of Rights Act of 2000 (the DD Act). This Act was authorized to ensure that individuals with developmental disabilities and their families participate in the design of, and have access to, needed community services, individualized supports, and other forms of assistance that promote self-determination, independence, productivity, and integration and inclusion in all facets of community life through culturally competent programs authorized under the law. These programs include:

i. State Councils on Developmental Disabilities

ii. Protection and Advocacy Systems

iii. University Centers for Excellence in Developmental Disabilities Education (UCEDD) Research and Service

iv. Projects of National Significance

b. The Rehabilitation Act of 1973, as amended in 2014 by WIOA, authorizes the following programs:

i. The Independent Living Services (ILS) Program provides 63 formula grants, based on population, to states and territories to fund independent living services programs and activities for individuals with significant disabilities. 
ii. The Centers for Independent Living (CILs) Program provides 356 discretionary grants to centers that are consumer-controlled, community-based, cross-disability, nonresidential, private nonprofit agencies to provide independent living services to individual with significant disabilities. One of the Core Services for these centers added under WIOA is the transition to adulthood among youth with significant disabilities aged 14 to 24, who were eligible for an Individualized Education Program (IEP), and who have completed their secondary education or otherwise left school.

iii. The National Institute on Disability, Independent Living, and Rehabilitation Research (NIDILRR) funds research on disability and rehabilitation. NIDILRR's mission includes: (a) generating and promoting the use of new knowledge in order to enable people with disabilities to perform activities of their choice in the community, and (b) expanding society's capacity to provide full opportunities and accommodations for its citizens with disabilities.

c. The Assistive Technology Act of 1998, amended in 2004, helps make assistive technology available to people with disabilities so they can more fully participate in education, employment, and other daily activities as full members of their communities. The law covers people of all ages and types of disabilities, and in all environments, including in school and at work.

i. The State Grant for Assistive Technology Program supports state efforts to improve the provision of assistive technology to individuals with disabilities of all ages through comprehensive, statewide programs that are consumer responsive. The State Grant for Assistive Technology Program makes assistive technology devices and services more available and accessible to individuals with disabilities and their families. The program provides one grant to each of the states, the District of Columbia, Puerto Rico, and territories (American Samoa, the Commonwealth of the Northern Mariana Islands, Guam, and the U.S. Virgin Islands). The State Grant for Assistive Technology Program is a formula-based grant program, and thus there are no grant competitions. The amount of each state's annual award is based largely on state population.

\section{ii. The State Protection and Advocacy for} Assistive Technology (PAAT) Program provides protection and advocacy services to assist individuals of all ages with disabilities in the acquisition, utilization or maintenance of assistive technology services or devices. $\mathrm{ACL}$ provides formula grants to Protection and Advocacy agencies established under the Developmental Disabilities Assistance and Bill of Rights Act.

\section{Agency for Healthcare Research \& Quality (AHRQ)}

AHRQ produces evidence for the nation focused on health care safety and quality. This HHS operating division supports the following project with direct relevance to young adults and transitioning youth with ASD:

a. "A Deliberative Approach to Develop Autism Data Collection in Massachusetts" is a health services research grant funded in 2016 that involves a deliberative citizen jury, the majority of which are individuals on the autism spectrum, to provide guidance to the Massachusetts Executive Office of Health and Human Services regarding the creation of a statewide registry for ASD. A patient registry is a collection of standardized information about a group of patients who share a particular condition or experience. When complete, the registry will provide an integrated data system to track diagnosis, treatment, services, and 
outcomes for individuals with ASD, with the long-term goal of improving coordination of care and disseminating information on best practices. Although not specifically targeted to transitionage youth and young adults, it will, when completed, provide a way to track services and outcomes for this population in Massachusetts.

\section{Centers for Disease Control and Prevention (CDC)}

The CDC protects the health of the U.S. population through surveillance activities and large-scale responses to significant disease threats. The Children's Health Act of 2000 mandated that CDC establish autism surveillance and research programs to address the number, incidence, correlates, and causes of ASD and related developmental disabilities.

a. The Autism and Developmental Disabilities Monitoring Network (ADDM) is overseen by CDC's National Center on Birth Defects and Developmental Disabilities (NCBDDD). The purpose of ADDM is to estimate the prevalence of autism among children living in select communities. ADDM has conducted autism surveillance on 8-year-old children who were born in 1992, 1994, 1996, 1998, 2000, 2002, and 2004; children who were born in 1994, 1996, 1998, and 2000 are now between 16 and 24 years of age, and thus may provide a useful source of information for additional research efforts on transition age youth and young adults with ASD. ADDM continues to monitor and report, biannually, the estimated prevalence of autism in network sites throughout the United States.

b. The Study to Explore Early Development (SEED) is a multi-site, case-control study designed to assess risk factors for children with ASD aged 2-5 years, and characterize behavioral, developmental, and medical features of ASD with the goal of defining potentially etiologically distinct ASD subtypes. In
2007, NCBDDD funded six sites to conduct the first phase of SEED. In 2017, the oldest children enrolled in the first phase of SEED will reach adolescence. The SEED Teen study, which is currently under development, seeks to investigate the health and functioning, healthcare utilization, and educational attainment, of children 12-15 years old with ASD, as compared to those without ASD, as well as family impacts of having a child with ASD.

\section{c. The National Health Interview Survey (NHIS)} provides information on the health of the civilian noninstitutionalized population of the U.S., and is one of the major data collection programs of CDC's National Center for Health Statistics (NCHS). The NHIS was authorized through the National Health Survey Act of 1956, and its data are used to monitor trends in illness and disability; track progress toward achieving national health objectives; identify barriers to accessing and using appropriate health care services; and evaluate federal health programs.

\section{Centers for Medicare \& Medicaid Services (CMS)}

CMS is committed to strengthening and modernizing the nation's health care system to enhance quality, accessibility and improved outcomes in the most costeffective manner possible.

a. The Federal Medicaid program is a state-federal partnership in which Medicaid provides health coverage to millions of Americans, including eligible low-income adults, children, pregnant women, elderly adults and people with disabilities. Medicaid is administered by states, according to federal requirements. The program is funded jointly by states and the federal government. Each state has a Medicaid State Plan where the state sets forth its coverage of certain mandatory and optional eligibility groups and mandatory and optional services. 
b. Medicaid's Early and Periodic Screening, Diagnostic and Treatment (EPSDT) requires the states to provide medically necessary services authorized in section 1905(a) of the Social Security Act to Medicaid beneficiaries under the age of 21 . This benefit requires screening services as well as physical, mental, vision, hearing, and dental services for persons under age 21 that are needed in order to correct or ameliorate a physical or mental condition.

c. Medicare is the federal health insurance program for people who are 65 or older, certain younger people with disabilities, and people with EndStage Renal Disease (permanent kidney failure requiring dialysis or a transplant).

d. The Children's Health Insurance Program (CHIP) provides health coverage to eligible children, through both Medicaid and separate CHIP programs. CHIP is administered by states, pursuant to federal requirements.

e. The Medicaid Health Home State Plan Option, authorized under the Affordable Care Act (Section 2703), allows states to design Health Homes to provide comprehensive care coordination for Medicaid beneficiaries with chronic conditions. States will receive enhanced federal funding during the first eight quarters of implementation to support the roll out of this new integrated model of care; thereafter they will receive their regular service match rate. ${ }^{1 \eta \emptyset}$ Health Home services include 1) Comprehensive Care Management; 2) Care Coordination and Health Promotion; 3) Comprehensive Transitional Care, including appropriate follow-up, from inpatient to other settings; 4) Patient and Family Support (including authorized representatives); 5) Referral to Community and Social Support Services, if relevant; and 6) use of health information technology to link services, as feasible and appropriate. CMS guidance indicates services must be person and family-centered, include self-management support to individuals and their families, and provide access to individual and family support services. Individual and family supports could include providing caregiver counseling or skills to help the individual improve function, obtaining information about the individual's disability or conditions, and navigating the service system. In addition, individual and family supports help families identify resources to assist individuals and caregivers in acquiring, retaining, and improving self-help, socialization, and adaptive skills and provide information and assistance in accessing services such as self-help services, peer support services, and respite services. These supports and services are available to those who meet the eligibility requirements, including youth and young adults with ASD.

f. Additional Autism-related Policies have been published on the CMS website.

i. The Center for Medicaid and CHIP Services has published information on Medicaid home and community based services including guidance. States may provide HCBS optionally to certain populations, and they manage their own waiting lists. CM S is available to provide technical assistance to states on the various coverage authorities for treatment of ASD, including state plan and HCBS waiver authorities.

ii. Recent CMS guidance on the implementation of the Community First Choice State Plan Option a home and community-based benefit package available to states to promote community integration, can be found online.

iii. CMS offers information about personcentered planning on its website.

ๆๆ The eight quarters of enhanced match begin on the effective date of the state's program, so the timeframe is specific to each state plan approval, with no national-level start or stop date. 
iv. States may also offer Medicaid Health Homes as an optional benefit, to provide care coordination for beneficiaries with certain chronic conditions.

v. Some mental health services are available through Medicare.

\section{Health Resources and Services Administration (HRSA)}

HRSA focuses on improving health equity among all Americans through access to care and a skilled health workforce, with special consideration for underserved populations. Through its Maternal and Child Health Bureau, HRSA supports the following programs and initiatives to address ASD through education, early detection, and intervention:

a. Training

i. The Leadership Education in Neurodevelopmental and Other Related Disabilities (LEND) grant program provides medical, allied health professionals, family members, and self-advocates with interdisciplinary, graduate-level training that emphasizes family-centered care, the medical home, and lifespan issues. The primary goal of LEND is to train health professionals to improve the health of children who have, or are at risk of developing, neurodevelopmental disabilities including ASD. LEND programs may include activities focused on transition activities for youth with ASD and other developmental disabilities.

ii. The Leadership Education in DevelopmentalBehavioral Pediatrics (DBP) program trains developmental-behavioral pediatricians (i.e., fellows), pediatricians and primary care providers, and other health and allied health professionals through its training and continuing education programs. DBP training programs provide didactic and clinical- based training and continuing education events on all aspects of care for children and adolescents with ASD, including transition from pediatric to adult care and services. DBP grantees support activities related to transition for youth with ASD and other developmental and behavioral issues in a variety of ways, including providing training and technical assistance on transition to families, community service providers, adolescent and adult medical providers, educational institutions; developing resources on transition, and conducting research on transition.

\section{iii. The Interdisciplinary Technical Assistance} Center (ITAC) supports LEND and DBP programs by providing technical assistance, disseminating information and resources, and promoting collaboration among Autism CARES grantees.

b. Research

i. The Autism Research Networks Program funds five interdisciplinary research networks that serve to connect leaders in ASD research with health care providers, policy makers, and children and their families. The Networks form a common research platform for identifying autism research priorities, conducting ASD research, building capacity by mentoring junior researchers in the field, developing toolkits for parents and providers and guidelines for standards of care, increasing public awareness, and improving ASD service delivery. Of the five research networks receiving funds from 2014 through 2016, two have covered transition topics through their research studies and researchrelated activities.

ii. The R40 Autism Research Program supports field-initiated empirical research through two funding mechanisms that together 
advance the evidence base on the health and well-being of children and adolescents with ASD with a special focus on underserved populations. The R40 Autism Field-Initiated Innovative Research Studies (Autism FIRST) Program supports research on interventions designed to improve health and healthcare service delivery systems. The R40 Autism Secondary Data Analysis Research (AutismSDAR) Program funds secondary analysis studies using existing national databases. Among the 22 R40 Autism Research grantees first funded in 2013 to 2015, three projects focused on transition for youth with ASD.

iii. Both the 2009-2010 National Survey of Children with Special Health Care Needs (NS-CSHCN) and the 2011-2012 National Survey of Children's Health (NSCH) include measures of the health and well-being, including transition planning, for adolescents with ASD. The national surveys identify households with one or more children under 18 years old. The NS-CSHCN and the NSCH are being redesigned and will become a single survey that will be conducted annually. Both the content and methodology of this combined survey have been refined in 2016 to ensure that it meets future needs of data users. The first public release of data is scheduled for summer 2017.

c. State Services

i. The State Systems Grants support efforts to build more comprehensive, coordinated State-based systems of care for individuals with ASD, with a special emphasis on medically underserved populations. Although the state grants focus primarily on early identification of ASD and placement in early intervention services, at least 5 of the 14 state grantees active between 2014 and 2016 reported activities related to transition for youth with ASD. ii. The State Public Health Autism Resource Center (SPHARC) provides ongoing technical assistance to the state grantees funded under the 2014 Autism CARES Act and facilitates collaboration and coordination among the state grantees and other Autism CARES program areas.

iii. The Title V Maternal and Child Health (MCH) Services Block Grant Program (Section 501(a) of Title $V$ of the Social Security Act) intends "to improve the health of all mothers and children consistent with the applicable health status goals and national health objectives...." Administered through well-established Federal/State partnerships, States have broad discretion in implementing programs that meet their specific priority needs. The $\mathrm{MCH}$ Block Grantees are public health programs that are responsible for assessing needs in their state for the entire $\mathrm{MCH}$ population and prioritizing programs to meet those needs. States and jurisdictions use their Title $V$ funds to design and implement a wide range of $\mathrm{MCH}$ and Children with Special Health Care Needs (CSHCN) activities.

d. The Got Transition/Center for Health Care Transition Improvement is a cooperative agreement between HRSA and the National Alliance to Advance Adolescent Health. Focused on special health care needs broadly, Got Transition has developed clinical resources on transition from pediatric to adult health care, including the Six Core Elements of Transition ( 6 core elements) that define the basic components of transition support. These core elements, available in English and Spanish, are consistent with 2011's "Clinical Report on Health Care Transition," which was jointly developed by the American Academy of Pediatrics, the American Academy of Family Physicians, and the American College of Physicians. The 6 core elements have been shown to be an effective quality improvement intervention model. 


\section{Indian Health Service (IHS)}

IHS administers health programs and services for American Indians and Alaskan Natives.

a. The IHS Telebehavioral Health Center of Excellence (TBHCE) provides technical assistance, implementation, training, and evaluation support for remote health care, and serves isolated American Indian/Alaska Native (Al/ AN) communities and areas with limited or no access to behavioral health services. The TBHCE is consolidating the Indian Children's Program and revitalizing its national scope. The role of the TBHCE is to support providers via education, consultation, and other learning resources. This includes national training on Autism, Fetal Alcohol Spectrum Disorders, Pervasive Developmental Disorders, Intellectual Deficits, Childhood Traumatic Brain Injury, Learning Disorders, and others. These trainings are available to any providers and have free continuing medical education units (CME)/continuing education units (CEU) attached. The TBHCE also provides free, biweekly, pediatric neuropsychological consultation for any IHS, Tribal, or Urban provider encountering these issues.

b. The IHS Indian Children's Program conducts ASDfocused provider education through the TBHCE, including bi-weekly provider consultation for ASD and other neurobiological issues as well as ongoing care across the lifespan for those with ASD.

\section{National Institutes of Health (NIH)}

$\mathrm{NIH}$ is the nation's medical research agency.

a. The National Institute of Mental Health (NIMH) funds a small portfolio of research grants related to individuals on the autism spectrum in the period from youth transitioning to adulthood. Several grants within this portfolio are part of a special program targeting this area. The 2013 update of the IACC Strategic Plan for Autism Spectrum Disorder Research identified access to and effectiveness of ASD services as a research priority, with a particular emphasis on the needs of transition-age youth and adults. In response, NIMH issued the Services Research for Autism Spectrum Disorder across the Lifespan (ServASD) Request for Applications (RFA), which solicited pilot studies to develop and preliminarily test such services, with an emphasis on creating strategies that are deliverable and effective in diverse communities and care systems. In 2014, the institute funded seven pilot studies of service delivery models for these age groups. It is anticipated that, after completion of this pilot work, the principal investigators will apply for support to conduct full scale tests of effectiveness of the new service strategies, with studies structured to enable rapid dissemination and implementation of the services that show positive outcomes. Among these seven projects, four are focused on developing service strategies that will plan and support the transition from secondary school to adult service systems, and three on developing and testing strategies to establish and maintain engagement in community support, achieve vocational and employment success, improve social functioning, and other services aimed at supporting independent living. To address the ongoing need for empirically based service models, NIMH re-issued the RFA in 2016 and is now in the process of funding five additional pilot studies.

b. In addition to the projects supported under the NIMH ServASD initiative, NIH also supports four other projects that focus on young adults with autism transitioning to adulthood. In 2015, the Eunice Kennedy Shriver National Institute of Child Health and Human Development (NICHD) began funding a prospective longitudinal study focused on accurately describing ASD in adulthood as well as the transition to adulthood, and to identify mechanisms that contribute to 
positive and negative outcomes in individuals with ASD and their families. NIMH supports three other projects that address transitioning to adulthood for young adults with ASD. Topics addressed in these grants include: examining how biological stress response combines with behavioral functioning and environmental resources to influence the transition to adulthood and positive outcomes for young adults with ASD; testing the effectiveness of a school-based intervention targeting executive function in college-bound youth with ASD; and development and evaluation of a skill-building resource to support teens with autism on relationship skills and dating.

c. In addition to the above projects focused on transitioning youth and adults with ASD, NIH funds cross-disability programs for transitionage youth, including ASD. In 2010, NIH became a site for the international Project SEARCH (PS) program, a public-private partnership program that includes support by private organizations as well as government partners. This is a oneyear Transition Program for young adults with intellectual and developmental disabilities who are either in their last year of high school or are recent high school graduates. The program helps individuals develop the tools necessary for employment, as well as skills needed for self-determination, management and self-advocacy. Project SEARCH is a unique, business-led program and takes place entirely at the workplace. Total workplace immersion facilitates a seamless combination of classroom instruction, career exploration, and hands-on training through worksite rotations. The primary objective is for these young people to be "employment ready" upon graduation from the program. This means they have demonstrated the skills and abilities to secure paid employment. Since NIH began participating in this program in 2010, $17 \mathrm{NIH}$ institutes have been involved as training worksites and 8 have hired graduates upon completion of the program. Project SEARCH does not subdivide data by diagnosis of ASD, but nationally, 50-70 percent of transition age youth who graduate from Project SEARCH have been diagnosed with ASD.

\section{Substance Abuse and Mental Health Services Administration (SAMHSA)}

SAMHSA works to advance the behavioral health of the nation through reducing the impact of substance abuse and mental illness on America's communities.

a. The Child Mental Health Initiative (CMHI), commonly referred to as the "System of Care" grant program, intends to improve behavioral health outcomes for children and youth ( 0 -21 years of age) with serious emotional disturbances (SED) and their families. Since 2011, cooperative agreements have focused on the wide-scale operation, expansion, and integration of the system of care approach by creating sustainable infrastructure and services. Grantees are required to support the provision of mental health and related recovery support services to children and youth with SED and those with early signs and symptoms of serious mental illness, and their families. Activities include development of sustainable financing and cross-agency collaboration; creation of policy and infrastructure; development and implementation of evidence-based and evidence-informed services and supports; and capacity for training and workforce development. Since its inception in 1993, 331 cooperative agreements have been awarded to states, tribes, territories, and local jurisdictions. Currently, SAMHSA funds 91 grantees with four-year awards (awarded in 2013, 2014, 2015, and 2016). 
b. The "Now Is The Time" Healthy Transitions Program (NITT-HT) intends to improve access to treatment and supportive services for youth and young adults aged 16-25 that either have, or are at risk of developing, a serious mental health condition. SAMHSA has awarded NITT-HT grants to 16 states to provide outreach and engagement processes, as well as access to effective clinical and supportive interventions, for youth and young adults with, or at risk of developing, serious mental health conditions, or co-occurring mental health and substance use disorders. The Now Is the Time Technical Assistance (NITT-TA) Center provides training and technical assistance (T-TA) for NITT-HT grantees.

c. Additional Information about $\mathrm{CMHI}$ and NITT-HT

i. Both the CMHI and NITT-HT programs serve youth with a co-occurring diagnosis of at least one SED and ASD. For CMHI, 2.7 percent of all youth served fall into this category. Of these 958 youth, all were enrolled in communitybased service programs, with roughly 21 percent being referred from school and early education programs.

ii. All NITT-HT sites are required to have a transition team that coordinates a seamless transition of services for youth and young adults. These teams maximize coordination between provider agencies, youth and family organizations, and educational and vocational institutions, and support the sharing of resources between systems. Similarly, the $\mathrm{CMHI}$ sites are required to develop governance structures that are comprised of service providers, family organizations and youth groups.

iii. The NITT-HT serves youth and young adults ages 16-25 and CMHI program serves youth ages $0-21$. Within the $\mathrm{CMHI}$ program some Grantee communities have chosen to focus on youth and young adults of transition age. As such, these programs require linkages to comprehensive services such as postsecondary education programs, peer support services, vocational training and other services needed by the participating youth. However, because the funding for these programs is tied specifically to SEDs, youth and young adults must have co-occurring diagnoses in order to receive services. When youth do not have co-occurring diagnoses and only have an ASD diagnosis, they are referred to appropriate services within the community.

\section{U.S. Department of Defense}

\section{Congressionally Directed Medical Research Programs (CDMRP)}

The CDMRP is within the Department of Defense (DoD) and originated in 1992 via a Congressional appropriation to foster novel approaches to biomedical research.

a. The Autism Research Program (ARP) within the CDMRP funds innovative research designed to advance the understanding of ASD, leading to improved outcomes. One of the nine areas of interest (psychosocial research) of the ARP funds studies investigating factors that promote success in key transitions to independence for individuals living with ASD. Other areas of research include behavioral interventions, pharmaceutical interventions, biological and infectious risk factors, biomarkers, family well-being, complementary and alternative medicine, heterogeneity/subgrouping, and co-occurring conditions. 


\section{U.S. Department of Education}

The U.S. Department of Education (ED) promotes the achievement and preparation of U.S. students by fostering educational excellence and ensuring equal access to education. To meet these goals, two offices within ED (OSERS and OPE) support programs that help educate children and youth with disabilities and provide for the rehabilitation of youth and adults with disabilities, respectively. Another office within ED (IES) supports independent research to improve the lives of individuals with disabilities, and a fourth office (OCR) has enforcement responsibility to protect individuals with disabilities against discrimination.

\section{Office of Special Education and Rehabilitative Services (OSERS)}

OSERS supports programs that assist States and school districts in educating children and youth with disabilities, provides for the rehabilitation of youth and adults with disabilities, and supports discretionary grant programs to improve the lives of individuals with disabilities. Through its two main components, the Office of Special Education Programs (OSEP) and the Rehabilitation Services Administration (RSA), OSERS guides and supports a comprehensive array of programs and projects that support individuals with disabilities, including individuals with ASD. OSEP administers the Individuals with Disabilities Education Act (IDEA), and RSA administers the Rehabilitation Act of 1973, as amended by the Workforce Innovation and Opportunity Act of 2014 (WIOA).

\section{a. OSEP}

\section{i. The Individuals with Disabilities Education} Act (IDEA) Part B, consists of the Grants to States and Preschool Grants Programs. Under IDEA Part B, States and school districts must identify, locate, and evaluate children with disabilities, as defined in 34 CFR $\$ 300.8$ of the Part $B$ regulations, who need special education and related services, regardless of the severity of their disability, and must make a free appropriate public education (FAPE) available to all eligible children. FAPE includes special education and related services, provided at no cost to the parents, in conformity with an individualized education program (IEP). Autism is one of the 13 disability categories under IDEA. The IEP is a written document developed, reviewed, and revised at a meeting of the IEP Team, which includes the student's parents along with school officials, and the student, whenever appropriate. The IEP includes, among other information, the special education, related services, and other supports that the child requires in order to receive FAPE. Under IDEA, beginning with the first IEP to be in effect when the child turns 16, and updated annually thereafter, a student's IEP must include appropriate measurable postsecondary goals based upon age appropriate transition assessments related to training, education, employment, and, where appropriate, independent living skills; and the transition services (including courses of study) needed to assist the student in reaching those goals. 20 U.S.C. 1414(d)(1) (A)(i)(VIII). Under 34 CFR 300.320(b) of the IDEA Part $B$ regulations, postsecondary goals and the transition services needed to assist the child in reaching those goals could be included in the IEP of IDEA-eligible students younger than age 16, if determined appropriate by the IEP Team.

\section{ii. Part D (National Activities to Improve} Education of Children with Disabilities) of the IDEA authorizes discretionary grants for evaluation activities to support better implementation and assessment outcomes, demonstrations, technical assistance and 
dissemination, technology and personnel development, and parent-training and information centers. These grants are designed to improve early intervention, educational, and transitional results for children with disabilities, as well as to help state and local educational agencies strengthen their educational systems for children with disabilities.

\section{iii. Personnel Preparation in Special Education} provides grants that prepare master'slevel personnel (special educators, related services providers) to serve children with disabilities. Applicants may choose to focus their preparation on autism. From FY2014 through FY2016, OSEP funded four grants that specifically focused on preparing personnel to support youth with autism to transition from school-based services to postsecondary goals.

iv. The Autism Focused Intervention and Resource Modules (AFIRM) project has recently released 15 new learning modules. The AFIRM modules are designed to help practitioners learn the step-by-step process of planning for, using, and monitoring evidence-based practices of children with ASD from birth to 22 years of age. The AFIRM modules, available for free, include case examples that demonstrate the evidence-based practice in use and interactive assessments, so learners can assess their understanding of the content.

v. The Center for Parent Information and Resources, and the Parent Technical Assistance Centers (PTACs) provide families with information regarding a range of topics related to the educational, developmental, and transitional needs of their children with disabilities, including the range, type, and quality of options, programs, services, technologies, practices and interventions. $\mathrm{PT}$ Is provide information as requested by families to help them support the transition of all youth with disabilities, including those with ASD, from school-based services to postsecondary options. Additionally, PTIs support youth, including youth with ASD, in building their self-advocacy skills. The Center for Parent Information and Resources developed an inter-related series of parent guides, "Getting Ready for When Your Teen Reaches the Age of Majority," regarding the transition to adult life. Although not specific to youth with autism, the series addresses the development of independent decisionmaking in youth with disabilities as they and their parents navigate the age of majority and legal adulthood. The series covers decision-making generally and in more detail regarding finances, independent living, and health. ED's document, "A Transition Guide to Postsecondary Education and Employment for Students and Youth with Disabilities," revised May 2017, is also available for use as a resource.

b. RSA

i. The Rehabilitation Act, as amended by WIOA in 2014, seeks to empower individuals with disabilities to maximize employment, economic self-sufficiency, independence, and inclusion in and integration into society. Through several different programs discussed below, the Rehabilitation Act supports comprehensive and coordinated vocational rehabilitation for individuals with disabilities through direct services, training and technical assistance to VR personnel, model demonstration projects, and parent training centers.

ii. The State Vocational Rehabilitation Services Program provides formula grants to States to support a wide range of vocational rehabilitation services designed to help individuals with disabilities, including 
students and youth with disabilities, prepare for and engage in gainful employment consistent with their strengths, resources, priorities, concerns, abilities, capabilities, interests, and informed choice. The program authorizes a continuum of services, such as pre-employment transition services, transition services, job placement services, other vocational rehabilitation (VR) services, and supported employment services for students and youth with disabilities, including those with autism, as appropriate, to obtain competitive integrated employment. Eligible individuals are those who have a physical or mental condition that results in a substantial impediment to employment, who can benefit from VR services for employment, and who require $V R$ services to achieve an employment outcome. Priority is given to serving individuals with the most significant disabilities. Youth with ASD may meet eligibility criteria for VR services. In FY 2015, 10,317 individuals with ASD between ages 16 and 24 received VR services.

\section{- Pre-employment transition services are} offered through VR as an early start in preparing students with disabilities, who are eligible or potentially eligible for VR services, for the transition from school to work, including obtaining knowledge and experiences that will help inform their postsecondary education, training, and employment choices. Eligible students are those who are not younger than the earliest age for the provision of transition services under the IDEA (16 years old) or if the State elects a lower minimum age for the provision of pre-employment transition services, not younger than that minimum age and not older than 21 years old or if the State provides for a higher maximum age for the receipt of services under IDEA, not older than that maximum age, and is eligible for and receiving special education and related services under Part B of IDEA or is a student who is an individual with a disability for purposes of section 504 . Pre-employment transition services include: job exploration counseling; work-based learning experiences, which may include in-school or after school opportunities, or experience outside the traditional school setting (including internships) provided in an integrated environment to the maximum extent possible; counseling on opportunities for enrollment in comprehensive transition or postsecondary educational programs at institutions of higher education; workplace readiness training to develop social skills and independent living; and instruction in self-advocacy, (including instruction in person-centered planning), which may include peer mentoring. Students may also receive group services prior to or after submitting an application for VR services that increase the student's opportunities to participate in activities, such as group tours of universities and vocational training programs; employer site visits to learn about career opportunities; and career fairs coordinated with workforce development and employers.

- Individualized transition services or other individualized $V R$ are available to youth or young adults with ASD after they have been determined eligible for VR services, under an approved individualized plan for employment (IPE). Transition services are outcome-oriented services designed to facilitate the movement from the receipt of services from schools to the receipt of services from VR agencies, and/ or as appropriate, other state agencies. Transition services are also designed to facilitate movement towards post- 
school activities, including postsecondary education and vocational training that lead to employment outcomes in competitive integrated employment or supported employment. Examples of transition services provided in accordance with an approved IPE include travel expenses, vocational and other training services, employment development activities, job search and placement services, and job coaching. When developing the IPE, the student or youth with the disability may choose from any employment goal that meets the definition of an "employment outcome" for purposes of the VR program. This means the employment goal must be one in competitive integrated employment (including customized employment and self-employment) or supported employment.

\section{iii. The Supported Employment for Individuals} With the Most Significant Disabilities, Title VI-B State Grants provides grants to assist states in developing and implementing collaborative programs with appropriate entities to provide programs of supported employment services for individuals, including youth, with the most significant disabilities who require supported employment services to achieve employment outcomes. Supported employment is competitive integrated employment, including customized employment, or employment in an integrated work setting in which an individual with a most significant disability is working on a shortterm basis toward competitive integrated employment that is individualized and customized, consistent with the strengths, abilities, interests, and informed choice of the individual. Supported employment is for individuals with most significant disabilities for whom competitive integrated employment has not historically occurred, or for whom competitive integrated employment has been interrupted or intermittent as a result of a significant disability and who, because of the nature and severity of their disability, need intensive supported employment services and extended services after transitioning from supported employment. Supported employment services are based on a determination of the needs of an eligible individual as specified in an Individualized Plan for Employment (IPE) and are provided by the state VR agency for a period of not more than 24 months, except that period may be extended, if necessary, in order to achieve the employment outcome identified in the IPE. A key supported employment service is job coaching. A job coach provides intensive training and other support to an individual to learn and remember job tasks, expected work behaviors and to develop positive working relationships with their co-workers. Other supported employment services may include transportation, or services outside of the job relating to attendance or arriving to work on time.

\section{iv. The American Indian Vocational Rehabilitation} Services (AIVRS) program (Title I, Section 121) is a discretionary grant program in which the Department of Education makes grants to the governing bodies of Indian Tribes located on federal and state reservations (and consortia of such governing bodies) to pay 90 percent of the costs of vocational rehabilitation services for American Indians who are individuals with disabilities living on or near such reservations. The grants are made for a period of 5 years, and applications of grantees that have been previously funded under the program receive priority consideration. These grants allow tribal governments to serve American Indian youth and young adults with 
disabilities, including those with ASD, in a way that is culturally sensitive to their own tribal practices as long as they also meet the assurance that they provide rehabilitation services that are, to the maximum extent feasible, comparable to rehabilitation services provided by the state VR agency to other individuals with disabilities.

v. Under the Rehabilitation Training program (Title III, Section 302), the Department provides discretionary grants to States and public or non-profit agencies and organizations (including institutions of higher education) to pay part of the costs of projects to provide training, traineeships and related activities, including the provision of technical assistance, that are designed to assist in increasing the numbers of, and upgrading the skills of, qualified personnel (especially rehabilitation counselors) who are trained in providing vocational, medical, social and psychological rehabilitation services.

vi. Under the Demonstration and Training Programs (Title III, Section 303), the Department provides discretionary grants to States and public non-profit agencies and organizations to pay all or part of the costs of projects to demonstrate ways to facilitate the provision of vocational rehabilitation services leading to an employment outcome in an integrated setting.

\section{vii. Under Parent Information and Training} Programs (Title III, Section 303(c)), the Department makes discretionary grants to private non-profit organizations for the purpose of establishing programs to provide training and information to enable individuals with disabilities, and the parents, family members, guardians, advocates or other authorized representatives of the individuals to participate more effectively with professionals in meeting the vocational, independent living, and rehabilitation needs of individuals with disabilities.

c. OSEP and RSA fund the National Technical Assistance Center on Transition (NTACT). OSEP's Technical Assistance funds and RSA's Rehabilitation Long Term Training Program funds support NTACT's efforts to assist state education agencies, local education agencies, state VR agencies and other VR service providers to implement evidence-based and promising practices to ensure students with disabilities (including those with autism) stay in school, progress in school, and graduate with knowledge, skills, and supports needed to succeed in postsecondary education and employment.

\section{Office for Civil Rights (OCR)}

The OCR has enforcement responsibilities to resolve complaints and conduct compliance reviews involving disability discrimination under two federal anti-discrimination laws: (a) Section 504 of the Rehabilitation Act of 1973 (Section 504); and (b) Title II of the Americans with Disabilities Act of 1990 (Title II). Section 504 prohibits discrimination on the basis of disability in programs or activities receiving federal financial assistance. Title II prohibits discrimination on the basis of disability by public entities, regardless of receipt of federal financial assistance. In the education context, OCR shares enforcement responsibility for Title II with the U.S. Department of Justice. 28 C.F.R. $\$ 35.190$ (b)(2). OCR is responsible for resolving complaints, conducting compliance reviews, and providing guidance, technical assistance and other forms of public education involving disability discrimination under Section 504 of the Rehabilitation Act of 1973 and Title II of the Americans with Disabilities Act of 1990, as amended. OCR is responsible for resolving complaints, conducting compliance reviews, and providing guidance, technical assistance and other forms of public education involving disability discrimination 
under Section 504 of the Rehabilitation Act of 1973 and Title II of the Americans with Disabilities Act of 1990, as amended.

a. Section 504 provides a broad spectrum of protections against discrimination on the basis of disability, including the right to a free, appropriate public education (FAPE). All elementary and secondary school students who are individuals with disabilities as defined by Section 504 and need FAPE are entitled to FAPE. Under Section 504, FAPE is the provision of regular or special education and related aids and services that are designed to meet the individual educational needs of students with disabilities as adequately as the needs of students without disabilities are met and that satisfy certain procedural requirements related to educational setting, evaluation and placement, and procedural safeguards. An individualized education program (IEP) developed and implemented in accordance with the IDEA is one means of meeting the Section 504 FAPE standard.

\section{Promoting the Readiness of Minors in Supplemental Security Income (PROMISE)}

The PROMISE program is an interagency collaboration of the U.S. Departments of Education, Health and Human Services, Labor, and the Social Security Administration. Under this fiveyear initiative administered by the Department of Education, six state agencies have partnered to develop and implement model demonstration projects (MDPs) that provide coordinated services and supports designed to improve the education and career outcomes of youth with disabilities receiving supplemental security income (SSI), including services and supports to their families. It is anticipated that the evaluation examining outcomes of the PROMISE program will lead to improvements in short- and long-term outcomes encompassing both service-delivery outcomes (assessment of youth and family needs and greater coordination and use of services), and youth and parent outcomes (expectations, self-determination, education, employment, public assistance, and income).

\section{Institute of Education Sciences (IES)}

IES supports statistics, research, and evaluation programs to inform education practice and policy, and disseminates this information to educators, parents, policymakers, researchers, and the public. Within IES, the National Center for Special Education Research (NCSER) supports a comprehensive program of education research designed to expand knowledge and understanding of infants, toddlers, and children with disabilities and those at risk for disabilities. The National Center for Education Evaluation and Regional Assistance (NCEE) conducts evaluations of education programs supported by federal funds, including special education services authorized under the IDEA. The National Center for Education Statistics (NCES) collects and analyzes data related to education. The National Center for Education Research (NCER) supports research that addresses the nation's most pressing education needs, from early childhood to adult education. This includes supporting research in postsecondary and adult education for individuals with disabilities. The work of IES that contributes to understanding the transition of students with autism is described below.

\section{a. NCSER}

i. In 2012, NCSER funded the Center on Secondary Education for Students with Autism Spectrum Disorders (CSESA) to develop and test a comprehensive, school-based intervention to improve the cognitive, communicative, academic, social, behavioral, functional, and transition outcomes of secondary students with ASD. CSESA also disseminates information regarding evidencebased practices and reviews of research. 
ii. Through the Special Education Research Grants Program competition, NCSER has awarded 28 field-initiated research projects to date on the topic of Transition Outcomes for Secondary Students with Disabilities since 2016. All of these research grants include students with or at risk for disabilities in the samples; however, only one of these studies to date focuses exclusively on students with ASD.

b. NCEE

i. Through the Special Education Studies and Evaluation program, NCEE supports several large-scale research studies focused on students or youth with disabilities, including those with autism. In early 2017, NCEE released baseline reports from the National Longitudinal Transition Study 2012, based on a nationwide sample of 12,000 transition-aged youth, including students with autism.

c. NCES

i. NCES conducts several national longitudinal studies. Beginning in 2017-18, the Middle Grades Longitudinal Study will follow a cohort of students through the middle grades, collecting information on various education topics, including special education services and transition supports. The study includes a focal sample of students with autism within this nationally representative sample.

\section{Office of Postsecondary Education (OPE)}

OPE works to strengthen the capacity of colleges and universities to promote reform, innovation and improvement in postsecondary education, promote and expand access to postsecondary education, increase college completion rates for America's students, and broaden global competencies that drive the economic success and competitiveness of the United States. a. The Model Transition Programs for Students with Intellectual Disabilities Into Higher Education (TPSID) provides grants to institutions of higher education or consortia of institutions of higher education to enable them to create or expand high quality, inclusive model comprehensive transition and postsecondary programs for students with intellectual disabilities, which may include certain forms of autism. Funds from this program also support a national Coordinating Center, which develops evaluation standards for TPSID grantees and provides technical assistance, information, and opportunities for communication among institutions with postsecondary programs for students with intellectual disabilities. The current TPSID Coordinating Center is Think College, a project of the Institute for Community Inclusion at the University of Massachusetts Boston. According to the 2016 annual report from Think College, autism is the second most common disability among students in TPSID programs after intellectual disability; approximately 26 percent of TPSID students identify as having autism.

The National Coordinating Center for Transition and Postsecondary Programs for Students with Intellectual Disabilities provides TPSID grantees with resources on a variety of topics, including transition and postsecondary education, some of which include information on students with autism.

\section{U.S. Department of Housing and Urban Development}

The U.S. Department of Housing and Urban Development (HUD) works to strengthen the housing market in order to bolster the economy and protect consumers; meet the need for quality affordable rental homes; utilize housing as a platform for improving quality of life; and build inclusive and sustainable communities free from discrimination. 
The U.S. Department of Housing and Urban Development (HUD) administratively enforces several civil rights laws prohibiting housing discrimination, including the Fair Housing Act, Section 504 of the Rehabilitation Act, and the Americans with Disabilities Act (ADA). With few exceptions, the Fair Housing Act covers housing throughout the country.

\section{Section 504}

Section 504 provisions apply to recipients of HUD financial assistance, including the Community Development Block Grant, Public Housing, Multifamily, Housing Choice Voucher, and other programs. HUD's Section 504 regulations (at 24 CFR $\$$ 8.4c) permit exclusion of non-disabled persons from the benefits of a program if the program is limited by federal statute or executive order to individuals with disabilities, and also permits exclusion of a specific class of individuals with disabilities from a program if the program is limited by federal statute or executive order to a different class of individuals. However, HUD does not have disabilityspecific programs, such as housing specifically for persons with autism-spectrum disabilities.

\section{Section 811 Supportive Housing for Persons with Disabilities}

Section 811 program, HUD provides funding to develop and subsidize rental housing with the availability of supportive services for very low- and extremely low-income adults with disabilities.

\section{U.S. Department of Justice}

The U.S. Department of Justice (DOJ) ensures fair and impartial administration of justice for all Americans. Within DOJ, the Civil Rights Division works to uphold the civil and constitutional rights of people with disabilities, including people with autism spectrum disorder and other developmental disabilities. The Division coordinates the activities of the various federal agencies that have obligations under Section 504 and Title Il of the Americans with Disabilities Act. The Civil Rights Division collaborates with other federal agencies to promulgate guidance for schools, localities and state agencies to guarantee equal opportunity for all people, including people with disabilities.

\section{Educational Opportunities Section (EOS)}

EOS enforces anti-discrimination statutes and court decisions in elementary and secondary schools and institutions of higher education, including the ADA, Section 504 of the Rehabilitation Act, the Equal Educational Opportunities Act (EEOA), Title $\mathrm{VI}$ of the Civil Rights Act, and upholds rights under the 14th Amendment to the U.S. Constitution in educational settings.

\section{a. The Supportive School Discipline Initiative (SSDI) was created by DOJ and ED to address the use of disciplinary policies and practices that push students out of school and into the justice system, which tend to disproportionately impact students with disabilities. The initiative supports school discipline practices that foster safe, inclusive and positive learning environments while keeping students in school.}

b. In 2014, DOJ and ED released a School Discipline Guidance Package to assist states, districts and schools in developing practices and strategies to enhance school climate, and ensure those policies and practices comply with federal law.

\section{Disability Rights Section (DRS)}

DRS enforces Titles I, II and III of the ADA and administers the ADA. The Section uses the broad tools of the ADA to achieve equal opportunity for 
people with disabilities in the United States. The Section also coordinates the activities of the federal agencies under Section 504 of the Rehabilitation Act and Title II of the ADA. Key concepts that are common to the Department's section 504 and ADA regulations include: reasonable accommodations/ modifications; program accessibility; and effective communication.

a. Guidance on the Application of the Integration Mandate of Title II of the Americans with Disabilities Act and Olmstead v. L.C. to State and Local Governments' Employment Service Systems for Individuals with Disabilities was released in 2016 and explains the requirements of the ADA integration mandate and Olmstead as applied to employment service systems for individuals with disabilities, which includes youth with autism spectrum disorders in transition from secondary school.

b. Guidance on Testing Accommodations was released in 2015 to ensure that people with disabilities who are taking standardized gateway examinations for the purpose of gaining entry to high school, college, or graduate programs, or for those attempting to obtain professional licensure or certification for a trade, have the opportunity to fairly compete for and pursue such opportunities by requiring testing entities to offer exams in a manner that is accessible to people with disabilities and does not measures a person's disability, but instead measures the individual's aptitude or achievement level.

c. Guidance on Effective Communication was released in 2014 to ensure that state and local governments and businesses and nonprofit organizations that serve the public communicate with people with vision, hearing, or speech disabilities in a manner that is equally as effective as their communication with people without disabilities.

d. In collaboration with ED's Office for Civil Rights and Office of Special Education and Rehabilitative Services, DOJ's Civil Rights
Division released Frequently Asked Questions on Effective Communication for Students with Hearing, Vision, or Speech Disabilities in Public Elementary and Secondary Schools in 2014 to address the obligation of public schools to meet the communication needs of students with disabilities.

\section{Speciall Litigation Section (SPL)}

SPL enforces Title II of the ADA, the Civil Rights of Institutionalized Persons Act, and Section 14141 of the Violent Crime Control and Law Enforcement Act of 1994. The Section's work has addressed conditions at health care facilities for individuals with disabilities, the rights of individuals with disabilities to live in their communities and not facilities, and the appropriate diversion of individuals with disabilities from the criminal justice system.

\section{DOJ Office of Justice Programs (OJP)}

OJP provides leadership to federal, state, local, and tribal justice systems through national dissemination of state-of-the art knowledge and practices, and the provision of grants for the implementation of crime fighting strategies.

\section{Bureau of Justice Assistance (BJA)}

BJA provides leadership and assistance to local criminal justice programs that improve and reinforce the nation's criminal justice system. BJA works to reduce and prevent crime, violence, and drug abuse and to improve the way in which the criminal justice system functions. In 2013 BJA funded The Arc of the United States, Inc.'s project for the National Center on Justice and Disability, to build a national resource center to address challenges the justice system faces when it encounters people with disabilities in the areas of law enforcement, courts, and corrections. The Center's "Pathways to Justice" initiative works to increase capacity of criminal justice professionals to 
respond to individuals with disabilities by providing training, technical assistance, and education. The Center brings together professionals from the disability and criminal justice fields to share expertise and provides training using a team approach, with the goal of becoming the go-to resource in their community or state on issues related to criminal justice and disability.

\section{U.S. Department of Labor}

The U.S. Department of Labor (DOL) works to improve full access to gainful employment opportunities for all Americans, including Americans with disabilities. DOL also supports career pathways for youth and adults through its support for workforce development and job training programs.

\section{Office of Disability Employment Policy (ODEP)}

a. ODEP in DOL developed the Guideposts for Success in conjunction with its grantee, the National Collaborative on Workforce and Disability for Youth. The Guideposts for Success is an evidence-based policy and practice framework for serving all youth, including youth with disabilities. The Guideposts indicate that all youth, including those with significant disabilities, should receive high quality supports and services in the areas of: career exploration and development, school-based preparation, family involvement, youth leadership and development, and connecting activities.

b. The Pathways to Careers Demonstration Grants support researching, developing, testing and evaluating innovative approaches to providing comprehensive, coordinated, and integrated inclusive education and career development services to youth and young adults with disabilities ages 14-24, including youth and young adults with significant disabilities. The grants are also intended to increase institutional capacity within the community college system by building an evidence base of policies and practices that are most effective in helping youth and young adults with disabilities to thrive in community college settings.

c. Employment First is a policy framework for systems change that is centered on the premise that all citizens, including those with significant disabilities, are capable of fully participating in competitive integrated employment (CIE) and community life. ODEP manages the Employment First State Leadership Mentoring Program (EFSLMP) with 14 participating states. Through EFSLMP, ODEP provides training and technical assistance to these states to assist with their development and implementation of holistic systems change. EFSLMP also assists states in sharing information, resources, and recommendations for implementing Employment First policies and practices. The objectives of the EFSLMP are to provide mentoring, intensive technical assistance and training from a national pool of subject matter experts and peer mentors to core states as they transform existing policies, service delivery systems, and reimbursement structures to reflect an Employment First approach. EFSLMP also facilitates virtual training and knowledge translation on effective practices, facilitates dialogue on shared experiences related to effectuating Employment First policies and practice, links participating states with current federal initiatives that are focused on promoting state-level systems-change conducive to Employment First objectives, and evaluates the impacts of the investments in state Employment First systems change efforts over time to identify common challenges faced by state governments and validate innovative strategies and effective practices that lead to the successful implementation of Employment First objectives. 


\section{Disability Employment Initiative (DEI)}

DEl is a collaborative of ODEP and DOL's

Employment and Training Administration to increase the capacity of the national American Job Center network to provide services to job seekers with disabilities. Since 2010, DOL has awarded grants totaling $\$ 126$ million to $49 \mathrm{DEl}$ projects in 28 states in order to improve workforce development services for job seekers with disabilities, including those with significant disabilities. The most recent DEI projects have incorporated a focus on career pathways and alignment with the Workforce Innovation and Opportunity Act of 2014.

\section{Advisory Committee on Increasing Competitive Integrated Employment for Individuals with Disabilities}

The Advisory Committee on Increasing Competitive Integrated Employment for Individuals with Disabilities was established under the Rehabilitation Act of 1973, as amended by the Workforce Innovation and Opportunity Act (WIOA) of 2014, to advise in three areas:

a. Ways to increase competitive integrated employment (CIE) opportunities for individuals with intellectual or developmental disabilities (I/DD) or other individuals with significant disabilities;

b. The use of a certificate program carried out under Section 14(c) of the Fair Labor Standards Act (FLSA) for the employment of individuals with I/DD or other individuals with significant disabilities; and

c. Ways to improve oversight of the use of such certificates.

The Committee was established in September 2014 according to the provisions of the Federal Advisory Committee Act (FACA), which helps ensure the independent nature of the Committee in providing advice and recommendations to the Administration. The primary purpose of the work of the Committee was to address issues and make recommendations to improve the employment participation of people with I/DD and others with significant disabilities by ensuring opportunities for CIE. The Final Report of the committee can be accessed online.

\section{U.S. Department of Transportation}

The U.S. Department of Transportation (USDOT) works to ensure transportation that is fast, safe, efficient, accessible and convenient to improve the quality of life of people in the United States.

\section{Accessible Transportation Technologies Research Initiative (ATTRI)}

ATTRI is a joint USDOT initiative, co-led by the Federal Highway Administration (FHWA) and the Federal Transit Administration (FTA), with support from the Intelligent Transportation Systems Joint Program Office (ITS JPO) and the National Institute on Disability, Independent Living, and Rehabilitation Research (NIDILRR), and other public and private organizations. Working with these organizations, ATTRI leverages technologies and innovations from disability research and development activities to improve accessible transportation for travelers with disabilities, and to extend these benefits to all travelers.

a. ATTRI research focuses on the needs of three stakeholder groups (people with disabilities, veterans with disabilities, and older adults) and four functional disabilities (visual, hearing, cognitive, and mobility) within these groups. ATTRI is in the process of developing 
technological solutions to lower or remove the transportation barriers that affect these stakeholder groups with the specified functional disabilities.

b. ATTRI leverages recent advances in vehicle, infrastructure, and pedestrian-based technologies, as well as accessible data, mobile computing, robotics, artificial intelligence, object detection, and navigation. The technology is enabled by wireless communications that connect travelers and their mobile devices with other travelers, vehicles, and infrastructure. The technologies used by ATTRI provide access to real-time situational data sources, including data specific to transportation, municipalities, and points of interest, as well as crowd-sourced information and accessibility data.

c. ATTRI is being implemented in three phases: 1) exploratory and user needs research; 2) innovation, prototype development, and testing; and 3 ) demonstration. The first phase is now complete, and ATTRI is focusing on activities for the second phase and is currently working on developing four transformative applications:
i. Smart way finding and navigation systems;
ii. Pre-trip concierge and virtualization;
iii. Shared use, automation and robotics; and
iv. Safe intersection crossings.

d. Connected and automated vehicles, as well as robotics and automation technologies are playing a larger role in transportation and logistical applications, such as moving people to desired destinations. Robotics applications are being developed that provide concierge services within transportation networks, including transportation terminals and home, work, healthcare, and other destinations. Similarly, the use of robotics technologies in smart city/ community infrastructure provides people with disabilities with a wide variety of potential uses. These technologies provide universally integrated and virtually connected environments, allowing individuals to plan and execute their travel logistics before they leave home.

e. The solutions explored by ATTRI and other related research programs at the USDOT are expected to bring new systems and tools to make independent travel possible for travelers with eligible disabilities, including those on the autism spectrum.

\section{U.S. Social Security Administration}

\section{Supplemental Security Income (SSI)}

SSI through the Social Security Administration (SSA) provides supplemental income for those with ASD who file disability claims and meet certain severity criteria. The required level of severity for ASD may be met when the following requirements are determined by a licensed physician:

a. Qualitative deficits in verbal communication, nonverbal communication, and social interaction; and

b. Significantly restricted, repetitive patterns of behavior, interests, or activities.

These medical criteria must cause serious limitation in at least two, or very serious limitation in at least one, of the following areas of mental functioning:

a. Understanding, remembering, or applying information;

b. Interacting with others;

c. Concentrating, persisting, or maintaining pace; and

d. Adapting or managing oneself. 
Children with ASD may be eligible for SSI disability benefits if their family's income and assets are not above the SSI limits. An adult with ASD can apply for SSI or Social Security Disability Insurance (SSDI). However, SSDI is available only to those with a work history from jobs that paid Social Security taxes. An adult child of a parent receiving Social Security retirement or disability benefits (a child more than 18 years old who has had autism before turning age 22) can receive SSDI benefits on the earning record of the parent.

\section{Demonstrations of Policies}

Under the SSA include the Youth Transition Demonstration, as well as the interagency PROMISE program described in the Department of Education section. These include a distribution of individuals mirroring the underlying distribution of disabilities observed in SSI and SSDI. The Social Security Administration also supports analyses of SSI and SSDI beneficiaries that may focus on specific impairments or the broader population.

\section{Work Supports}

Available to children and youth, including children with ASD, through the Social Security Administration include:

a. The Student Earned Income Exclusion allows youth under age 22 who are regularly attending school to exclude up to $\$ 1,790$ (in 2017) of earned income per month from countable income when determining SSI benefit amount, up to an annual maximum of $\$ 7,200$.

b. The Red Book contains a comprehensive list of resources that can help youth as they transition to adulthood. In 2016, SSA began mailing a brochure to all youth receiving SSI ages 14-17 informing them that SSA will review their eligibility for continued SSI benefits at age 18 using the disability rules for adults. The brochure also identifies the SSA and non-SSA services and supports that may help prepare for a successful transition to adult life.

\section{The 2020 Federal Youth Transition Plan: A Federal Interagency Strategy}

Federal Partners in Transition (FPT) is an interagency policy workgroup led by $\mathrm{DOL}$, bringing together several partner agencies including but not limited to DOL, ED, HHS, and SSA. Formed in 2005, the group has identified several policy priorities to achieve the goals described in The 2020 Youth Transition Plan: A Federal Interagency Strategy, and to improve transition outcomes for youth and young adults with disabilities, including:

1. Facilitating access to quality health care and health care insurance;

2. Promoting collaboration, coordination, and cooperation among youth and adult service systems and agencies;

3. Bridging the service gap between youth and adult programs;

4. Promoting work-based learning;

5. Supporting professional development for service providers;

6. Demonstrating the value of hiring youth and young adults with disabilities; and

7. Improving education and outreach to the public regarding policy and practices governing youth transition programs. 
The goals of FPT, which address some of the concerns of the $2017 \mathrm{GAO}$ report, are presented in The 2020 Federal Youth Transition Plan: A Federal Interagency Strategy. ${ }^{28}$ In 2016, the FPT also produced a fact sheet on youth transition.

This interagency strategic plan for youth in transition, published in February 2015, addressed transition from secondary education to postsecondary education, employment, and community living for youth with disabilities. Set forth by a Strategic Planning Committee of the FPT that included career and senior staff from several federal agencies, including but not limited to DOL, ED, HHS, and SSA, this strategy outlined how FPT will enhance interagency activities and improve outcomes for youth with disabilities by 2020 . The strategy's vision called for the development of self-directed pathways to support the interests, aspirations, and goals of youth with disabilities to ensure their full inclusion and community integration. FPT asserted that all youth, including those with disabilities, should be able to:

1. Access health care services and integrated work-based experiences in high school to better understand how to manage their physical, mental, and emotional well-being, to enhance their job-readiness skills and career planning, and to make a successful transition from school to work and greater independence;

2. Develop self-determination and engage in selfdirected individualized planning to prepare them for postsecondary education, health care management, vocational training, and/or employment;

3. Be connected to programs, services, activities, information, and supports for which they are eligible that prepare them to self-manage their health and wellness, pursue meaningful careers, become financially literate and capable, and make informed choices about their lives;
4. Develop leadership and advocacy skills needed to exercise informed decision-making and personal and community leadership; and

\section{Have involvement from families and other caring} adults with high expectations to support them in achieving their goals.

This vision clearly applies to youth with ASD and emphasizes the need for cross-agency coordination and collaboration. GAO, in its 2012 report on the transition from high school for students with disabilities, ${ }^{27}$ has stated that coordination for youth programming is enhanced by having clear and compelling rationales to work across agency boundaries in support of common federal program goals. The Autism CARES Act specifies that HHS should provide an overview of existing federal investments that address transitioning youth and young adults with ASD, highlighting areas where coordination can be improved across service systems and federal agencies as well as with the family, and state and local agencies. Such coordination can provide a more comprehensive approach by supporting a variety of complementary, non-duplicative programs, with the shared goal of improving outcomes among transitioning youth and young adults with ASD. Although not legislatively mandated and not specifically targeted to youth and young adults with ASD, this workgroup offers a model for interagency policy and service coordination. 


\section{Summary of Current Federal Investments for Transitioning Youth with ASD}

Current federal investments that benefit youth and young adults with ASD transitioning to adulthood fall primarily into the following four categories:

\section{Research}

According to IACC's analysis of the ASD research portfolio (including both federal and private funders), ${ }^{22}$ funding allocated to projects on lifespan issues, including the transition to adulthood, represented the smallest segment of ASD research funding. In 2015, projects on lifespan issues received 2 percent (\$6.1 million) of overall combined federal and private ASD funding, similar to the investments made in previous years; this percentage does not change when including only federal sources. ${ }^{* * * x}$ When considering only the topic of transition, the proportion is less than 2 percent of total funding. In terms of number of projects rather than percentage of funding, lifespan issues again were 2 percent of the entire ASD research portfolio, with 37 projects across both federal and private sources; of these, 24 were devoted to transition issues.

As can be seen in Table 2, programs currently supporting research related specifically to the transition to adulthood among youth and young adults with ASD were found in only four agencies: $\mathrm{NIH}, \mathrm{HRSA}$, ED, and DOD. In 2013-2016, only $18^{\mathrm{tith}}$ federally-funded research projects focused on transitioning youth and young adults with ASD were newly awarded across these four agencies; seven of these were in response to NIH's Services Research for Autism Spectrum Disorder across the Lifespan (ServASD) Initiative, and four were in response to autism-specific research programs within HRSA. Across all federal agencies surveyed, only six investigator-initiated research projects focusing on transitioning youth and young adults with ASD were funded through broadly targeted programs: four projects through investigator-initiated extramural research programs in NIMH and NICHD, one study in response to ED's (NCSER) cross-disability call for research on transition, and one investigator-initiated research project funded through DOD.

\section{General or Mainstream Programs}

Mainstream programs are publicly funded programs that are available to all U.S. citizens who meet certain eligibility requirements, including youth and young adults with ASD. Examples include but are not limited to HRSA's Maternal and Child Health Title $\checkmark$ Block Grant program, CMS's Medicaid program, ACF's Adoption and Foster Care program, SAMHSA's Child Mental Health Initiative, and others.

These programs aim to promote health and well-being among the U.S. population by providing services for those individuals and/or families who meet certain eligibility criteria. A few of these programs collect data that document services to youth with ASD. Knowing how many youth and young adults with ASD are served by a program allows providers, policy makers, researchers, and the public to verify apparent trends, proactively address emerging issues, measure progress towards stated goals, and capitalize on opportunities to improve service delivery. For example, ACF collects data on autism for its National Survey

$\star \star \star \star$ Federal agencies included in the 2015 IACC ASD Research Portfolio Analysis: Administration for Community Living (ACL). Agency for Healthcare Research \& Quality (AHRQ), Centers for Disease Control and Prevention (CDC), Department of Defense, Department of Education, Environmental Protection Agency (EPA), Health Resources \& Services Administration (HRSA), National Institutes of Health $(\mathrm{NIH})$, National Science Foundation (NSF). Private organizations included: Autism Science Foundation, Autism Research Institute, Autism Speaks, Brain \& Behavior Research Foundation, Center for Autism \& Related Disorders, New England Center for Children, Organization for Autism Research, Patient-Centered Outcomes Research Institute, Simons Foundation.

Tit Th This Report to Congress on Youth with ASD Transitioning to Adulthood, listed at the top of Table 2, is mandated by the Autism CARES Act of 2014 to identify existing federal resources for youth and young adults with ASD, and is not itself counted here as one of those already existing resources. 
on Child and Adolescent Well-being (NSCAW) using a representative sample drawn from Child Protective Services (CPS) across the country. Based on these data, it has been determined that the rate of ASD among CPS-participating families is 67 percent to 100 percent higher than that of the general child and youth population (3 percent compared to 1.8 percent for national parent self-report data regarding ASD diagnosis, and compared to 1.47 percent for the CDC surveillance data based on diagnostic evaluation). Findings such as these can provide direction to future research as well as inform and improve systems, programs, and service delivery planning and implementation for youth with ASD as they transition to adulthood.

However, most mainstream programs do not collect information on ASD (or many other population characteristics) among their participants, in large part because every additional required reporting item adds to the cost of program provision. Measures of impact are thus limited to program-specific goals, which typically do not include tracking participants with ASD throughout their lifespan.

\section{Cross-Disability Services and Supports}

Most federally funded disability services and supports are designed to be cross-disability. For example, several agencies (e.g., ACL, ED, DOL, DOT, SSA) offer programs for individuals with disabilities that youth and young adults with ASD may use. Similar to mainstream programs, some disability programs track utilized services and goals according to specific diagnoses, including ASD; other programs do not track specific diagnoses or only track broad categories (e.g., physical disability, cognitive disability).

In addition, eligibility requirements for most crossdisability programs typically reflect a combination of state budget constraints, income-based program requirements, and level of individual need. As a result, youth and young adults with ASD who have less extensive service needs may not always be eligible for specific federally funded programs that provide services and supports that they may otherwise need.

\section{Autism CARES Act Programs}

In addition to mainstream programs and crossdisability benefits and services, programs funded through the Autism CARES Act have an explicit focus on ASD. The vast majority of Autism CARES-funded programs are administered by CDC and HRSA. CDC programs focus on population surveillance of eightyear-old children and risk factor research among 2 to 5 year-old children. HRSA concentrates on capacity-building in the field through training, autism intervention research and research networks, and state demonstration programs.

\section{Conclusions Regarding Existing Federal Resources}

ASD-related research and programming regarding the transition period is conducted under and administered through multiple agencies, including $\mathrm{ED}, \mathrm{DOD}, \mathrm{SSA}$, and HHS, and, within HHS, multiple operating divisions, includes NIH, HRSA, SAMHSA, $A C L, C D C$, and others. Most agencies do not receive appropriations targeted specifically to individuals with ASD (such as through the Autism CARES Act), but instead provide broadly targeted programs through legislative authorizations that typically predate the Combating Autism Act of 2006 and its reauthorizations; these broadly targeted programs are available to individuals with ASD who meet the eligibility criteria. In most cases, the ASD population is not specifically tracked within these broader programs. The complexity of program eligibility requirements, the lack of outcomes research geared specifically to ASD and transition, and the variability of access to federal programs have been cited by ASD stakeholders and researchers as significant barriers for transitioning youth and adults with ASD. Part 4 provides additional analysis of these barriers and recommendations for further consideration. 


\section{Table 2}

\section{Federal Activities by Agency Relevant to Young Adults and Youth with Autism Spectrum Disorder Transitioning to Adulthood}

\begin{tabular}{|c|c|c|}
\hline Agency & $\begin{array}{l}\text { Main Activities that Include or are Available to } \\
\text { Youth and Young Adults with ASD }\end{array}$ & $\begin{array}{l}\text { Number of } \\
\text { Activities Focused } \\
\text { Specifically on the } \\
\text { Transition of Youth } \\
\text { with ASD to Adulthood }\end{array}$ \\
\hline $\begin{array}{l}\text { U.S. Department of Health } \\
\text { and Human Services } \\
\text { (HHS)/ Office of the } \\
\text { Assistant Secretary for } \\
\text { Health (Science and } \\
\text { Medicine) }\end{array}$ & - Autism Coordinator & $\begin{array}{l}\text { Report to Congress } \\
\text { on Youth with ASD } \\
\text { Transitioning to } \\
\text { Adulthood }\end{array}$ \\
\hline $\begin{array}{l}\text { HHS/NIH/Office of Autism } \\
\text { Research Coordination }\end{array}$ & " Interagency Autism Coordinating Committee & $=0$ \\
\hline $\begin{array}{l}\text { HHS/Administration for } \\
\text { Children and Families } \\
\text { (ACF) }\end{array}$ & $\begin{array}{l}\text { - Adoption and Foster Care Analysis and Reporting System (AFCARS) } \\
\text { - National Child Abuse and Neglect Data System (NCANDS) } \\
\text { - National Youth in Transition Database (NYTD) } \\
\text { - } \text { - National Incidence Study of Child Abuse and Neglect (NIS) } \\
\text { - National Survey of Child and Adolescent Well-Being (NSCAW) }\end{array}$ & $=0$ \\
\hline $\begin{array}{l}\text { HHS/Administration for } \\
\text { Community Living ( } \mathrm{ACL} \text { ) }\end{array}$ & $\begin{array}{l}\text { - Administration on Intellectual and Developmental Disabilities } \\
\text { (AIDD) } \\
\text { " Independent Living Services (ILS) Program } \\
\text { " Centers for Independent Living (CILs) Program } \\
\text { " National Institute on Disability, Independent Living, and } \\
\text { Rehabilitation Research (NIDILRR) } \\
\text { " State Grants for Assistive Technology Program } \\
\text { - State Protection and Advocacy Systems for Assistive Technology } \\
\text { (PAAT) program }\end{array}$ & $=0$ \\
\hline $\begin{array}{l}\text { HHS/Agency for Health } \\
\text { Care Research and Quality } \\
\text { (AHRQ) }\end{array}$ & $\begin{array}{l}\text { "A Deliberative Approach to Develop Autism Data Collection in } \\
\text { Massachusetts" }\end{array}$ & $=0$ \\
\hline
\end{tabular}




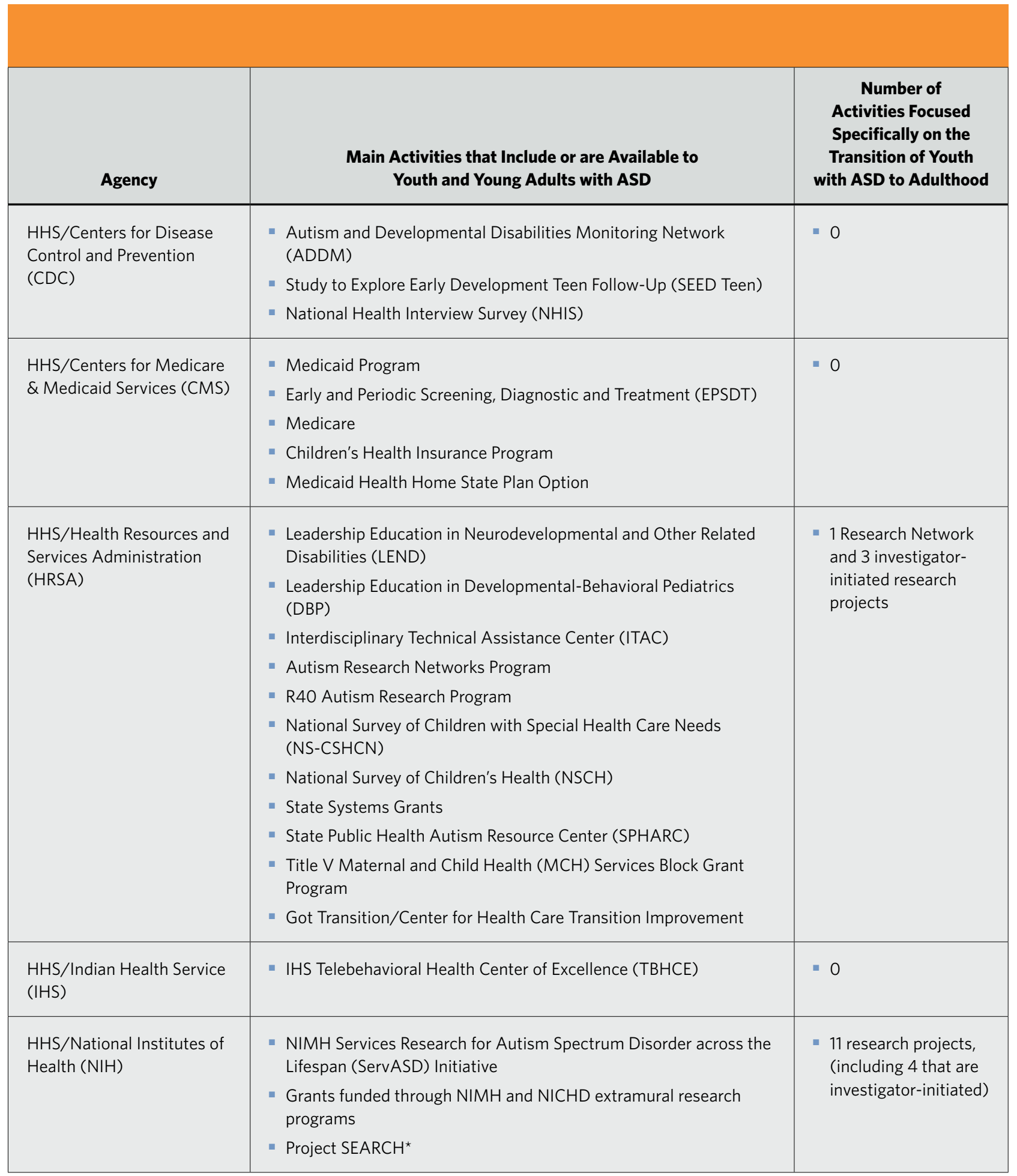




\section{YOUNG ADULTS AND TRANSITIONING YOUTH}

WITH AUTISM SPECTRUM DISORDER

\begin{tabular}{|c|c|c|}
\hline Agency & $\begin{array}{l}\text { Main Activities that Include or are Available to } \\
\text { Youth and Young Adults with ASD }\end{array}$ & $\begin{array}{l}\text { Number of } \\
\text { Activities Focused } \\
\text { Specifically on the } \\
\text { Transition of Youth } \\
\text { with ASD to Adulthood }\end{array}$ \\
\hline $\begin{array}{l}\text { HHS/Substance Abuse and } \\
\text { Mental Health Services } \\
\text { Administration (SAMHSA) }\end{array}$ & $\begin{array}{l}\text { " Child Mental Health Initiative (CMHI) } \\
\text { - "Now is the Time" Healthy Transitions Program (NITT-HT) } \\
\text { " Now Is the Time Technical Assistance (NITT-TA) Center }\end{array}$ & $=0$ \\
\hline $\begin{array}{l}\text { U.S. Department of } \\
\text { Education (ED)/Office } \\
\text { of Special Education and } \\
\text { Rehabilitative Services } \\
\text { (OSERS) }\end{array}$ & $\begin{array}{l}\text { - Part B of the Individuals with Disabilities Education Act (IDEA) } \\
\text { - Part D of the Individuals with Disabilities Education Act (IDEA) } \\
\text { Discretionary Grant Program } \\
\text { " Promoting the Readiness of Minors in Supplemental Security } \\
\text { Income (PROMISE) } \\
\text { - Vocational Rehabilitation State Grants } \\
\text { - Supported Employment Services State Grants } \\
\text { - } \text { American Indian Vocational Rehabilitation Services Program } \\
\text { - Rehabilitation Training Program } \\
\text { - Demonstration and Training Programs } \\
\text { - Parent Information and Training Program }\end{array}$ & $=0$ \\
\hline $\begin{array}{l}\text { ED/Office for Civil Rights } \\
(O C R)\end{array}$ & $\begin{array}{l}\text { - Section } 504 \text { of the Rehabilitation Act of 1973, as amended } \\
\text { - Title II of the Americans with Disabilities } \\
\text { Act of 1990, as amended }\end{array}$ & $=0$ \\
\hline $\begin{array}{l}\text { ED/Institute of Education } \\
\text { Sciences (IES) }\end{array}$ & $\begin{array}{l}\text { - Special Education Research Grants/ Transition Outcomes for } \\
\text { - Secondary Students with Disabilities } \\
\text { - Special Education Studies and Evaluations } \\
\text { - } \text { - Middle Grades Longitudinal Study }\end{array}$ & $\begin{array}{l}1 \text { Research and } \\
\text { Development Center; } \\
1 \text { investigator- } \\
\text { initiated research } \\
\text { project }\end{array}$ \\
\hline $\begin{array}{l}\text { ED/Office of Postsecondary } \\
\text { Education (OPE) }\end{array}$ & $\begin{array}{l}\text { Model Comprehensive Transition and Postsecondary Programs for } \\
\text { Students with Intellectual Disabilities (TPSID) }\end{array}$ & $=0$ \\
\hline $\begin{array}{l}\text { U.S. Department of } \\
\text { Defense (DOD) }\end{array}$ & $\begin{array}{l}\text { - Autism Research Program (ARP) within the Congressionally } \\
\text { Directed Medical Research Programs (CDMRP) }\end{array}$ & $\begin{array}{l}1 \text { investigator- } \\
\text { initiated research } \\
\text { project }\end{array}$ \\
\hline
\end{tabular}




\begin{tabular}{|c|c|c|}
\hline Agency & $\begin{array}{l}\text { Main Activities that Include or are Available to } \\
\text { Youth and Young Adults with ASD }\end{array}$ & $\begin{array}{l}\text { Number of } \\
\text { Activities Focused } \\
\text { Specifically on the } \\
\text { Transition of Youth } \\
\text { with ASD to Adulthood }\end{array}$ \\
\hline $\begin{array}{l}\text { U.S. Department of } \\
\text { Housing and Urban } \\
\text { Development (HUD) }\end{array}$ & $\begin{array}{l}\text { - Fair Housing Act } \\
\text { - Section } 504 \text { of the Rehabilitation Act } \\
\text { - Americans with Disabilities Act } \\
\text { - Section } 811 \text { Supportive Housing for Persons with Disabilities } \\
\text { program }\end{array}$ & $=0$ \\
\hline $\begin{array}{l}\text { U.S. Department of Justice } \\
\text { (DOJ) }\end{array}$ & $\begin{array}{l}\text { " Guidance issued on school discipline, testing accommodations, } \\
\text { and effective communication } \\
\text { " National Center on Justice and Disability "Pathways to Justice } \\
\text { Initiative" }\end{array}$ & $=0$ \\
\hline $\begin{array}{l}\text { U.S. Department of Labor } \\
\text { (DOL) }\end{array}$ & $\begin{array}{l}\text { " Guideposts for Success } \\
\text { - Pathways to Careers Demonstration Grants } \\
\text { " Employment First State Leadership Mentoring Program } \\
\text { " Disability Employment Initiative (DEI) } \\
\text { " } 2016 \text { Final Report from the Advisory Committee on Increasing } \\
\text { Competitive Integrated Employment for Individuals with Disabilities }\end{array}$ & $=0$ \\
\hline $\begin{array}{l}\text { U.S. Department of } \\
\text { Transportation (DOT) }\end{array}$ & - Accessible Transportation Technologies Research Initiative (ATTRI) & $=0$ \\
\hline $\begin{array}{l}\text { U.S. Social Security } \\
\text { Administration (SSA) }\end{array}$ & $\begin{array}{l}\text { " Supplemental Security Income (SSI) } \\
\text { " Social Security Disability Insurance (SSDI) }\end{array}$ & $=0$ \\
\hline $\mathrm{DOL}, \mathrm{ED}, \mathrm{HHS}$, and SSA & - Federal Partners in Transition & $=0$ \\
\hline \multicolumn{3}{|c|}{$\begin{array}{l}\text { *Project SEARCH is a public-private partnership-supported program in which NIH participates. } \\
\text { Information regarding each of these programs follows; federal policies and legislation that authorizes these programs are found in } \\
\text { Appendix } 2 .\end{array}$} \\
\hline
\end{tabular}




\section{Part 3:}

\section{Stakeholder Perspectives}

Part 3 of this Report summarizes input from public stakeholders on ASD and transition from three sources: a stakeholder listening session by the Office of the Assistant Secretary for Health (HHS/OASH), public commentary provided to the IACC in 2016, and a 2017 GAO Report of a stakeholder panel study.

\section{OASH Stakeholder Listening Session}

In preparing this Report, the Office of the Assistant Secretary for Health (OASH) conducted a Listening Session on February 6, 2017 (with follow up phone consultations thereafter), with stakeholders who included leading researchers in the field, advocacy groups, and individuals on the autism spectrum as well as parents of such individuals. This listening session reviewed general findings regarding federal investments on transitioning youth with ASD, and gained insights from these stakeholder groups regarding research and service gaps for this population. Their shared insights mirror those provided to the IACC in its Request for Public Comments, as well as those provided by a panel of stakeholders interviewed by the GAO.

\section{Gaps in Research}

\section{Descriptive Data}

The stakeholders expressed concern that little national level data exists to help understand the needs of transition-age youth with ASD relative to the types and degrees of strengths and challenges they have. The nationally representative data for this population exists across multiple datasets and ends at age 25 , and existing national surveys do nottypically contain enough information to characterize adequately individual variation in strengths and needs. Similarly, little to no publicly available data exists to help understand what students are receiving in terms of transition planning.

In addition, the extent to which individuals with ASD are receiving the specific supports and services they need is not known. There are services available to this population through existing resources, but an accurate estimate of how many people are found ineligible for them is lacking. The extent to which existing supports and services received are actually effective for this population, or alternatively, what happens to people when they drop out of existing services, is also not sufficiently understood.

Finally, a landscape assessment of privately funded resources is suggested in order to complement this Report on publicly funded programs and research. An established interagency coordination activity could incorporate and use data from such a landscape assessment (which would need to be constantly maintained and updated) to design better systems and conduct evaluations of outcomes. 


\section{Existing Programs Available to Study}

Stakeholders view research regarding which programs and their components are most effective with which ASD subgroups as critical. However, research in this field is hampered by the fact that there is limited availability of transition programming specific to youth and young adults with ASD. There are 'islands' of comprehensive programming, but these are scattered across the United States, and insofar as they are mostly located in densely populated areas, represent a disparity in access for those who live in rural areas. Many of these programs are local and rely on private rather than public funding; some benefit from non-profit, leader-driven resourcing that may be difficult to replicate in other communities without that specific leader. In order to begin to identify effective program components, several research areas are suggested, including:

- Identification, operationalization, and measurement of what constitutes positive outcomes and the aspects of transition planning most likely to lead to such outcomes for this heterogeneous population;

- Development of new programs designed to facilitate transition planning and optimize outcomes;

- Research studies designed to test whether programs are effective in producing their intended outcomes (efficacy testing);

- Adaptation and efficacy testing of promising programs in different settings and with different subpopulations of ASD youth and young adults;

- Implementation and dissemination of research findings of promising programs, based on efficacy testing;

- Scale-up of program models found to be effective in different settings and with different population(s);
- Analyses of outcomes obtained by effective models to identify which program components are most effective for which subpopulation(s); and

- Translation of research into practice through outreach and dissemination of information across a variety of cultural contexts.

Thus, there remain many questions about youth with ASD who are in transition, such as: What programs are producing positive effects for which subgroups of youth and young adults with ASD? Which components of innovative programs are key for success? What service models already exist for other disability groups that could be modified to meet the needs of transition-aged youth and young adults with ASD?

\section{Research on Outcomes}

Outcomes research is critically needed to help develop and optimize services and supports for adults with ASD, in the view of stakeholders. Outcomes for those with ASD are extraordinarily disparate, reflecting the heterogeneity of the population. Research is essential to understanding which functional outcomes (e.g., employment, community integration, and housing) have the most significant implications for individual quality of life across different subgroups of youth and young adults with ASD. Also important in assessing program efficacy is an understanding of what skills and supports, including the appropriate role of the family, are necessary in order to maintain work positions and social connections once they are obtained. Development of a standardized set of outcome measures that broadly addresses issues related to quality of life, rather than simply employment or independent living status, is critically important. This area of concern is being addressed in part by the National Quality Forum, a public-private partnership to promote and ensure patient protections and healthcare quality through measurement and public reporting. 
Meaningful transition process and outcome measurements are key elements in appropriate program planning. For example, more may be needed than simply tracking whether transition planning occurred on time or not (as current federal tracking requires), or whether or not an individual is able to engage specific resources or life domains (e.g., postsecondary education, health care or rehabilitation services, employment, etc.). Instead, the most important outcomes for stakeholders are:

- Whether or not that individual achieved independence to the extent possible;

- Some individually meaningful measure of social connectedness;

- Life satisfaction and well-being; and

- Overall favorable health status.

In this context, population-based outcome measures of program success are not nearly as important to stakeholders as are individualized, life course outcomes, thus suggesting that mixed methods approaches that employ both quantitative and qualitative data collection tools are particularly needed.

Consideration should be given to whether research on program efficacy or effectiveness should focus not only on the services provided, but also on whether or not these are individualized to support personal development of key life course goals in a heterogeneous population. Concomitantly important are considerations such as how such research could best be conducted, and what and how outcomes would be measured. Population-level measures are important for determining whether the needle is being moved on outcomes for all, but individual-level measures indicate whether goals and services are moving toward outcomes that an individual wishes to achieve.

\section{Research on Access and Barriers to Services}

As described in Part 1 of this report, youth and young adults with ASD lag behind other disability groups in terms of connecting to adult social roles, such as successful employment opportunities, independent living (including independent living with assistance), and engagement with postsecondary education and training. Little is known regarding the barriers to successful achievement of individual life goals among this population. Some potential large-scale barriers include:

- Federal and state eligibility criteria for public services for individuals with disabilities are often tied to having an intellectual disability, thus excluding individuals who need services from receiving them. Intellectual disability co-occurs with ASD only about one-third (31.6 percent) of the time, leaving up to two-thirds of this population potentially without covered services. Greater formal recognition is needed that social interaction challenges and co-occurring mental health conditions may also present significant challenges for accessing community living among youth and young adults with ASD.

- Many publicly funded services end at age 18, with few bridges between high school and adult services.

- It is difficult to find adult providers who are trained and available to care for young adults with ASD.

- Individuals, families, and providers may lack information about the transition process, including the availability of, and eligibility criteria for, existing programs.

- A lack of coordination across services and supports leaves individuals and families to piece together services across different systems on their own. In addition, recent changes in program eligibility for adult services, insurance, and disability assistance add to the information demands involved. 
- Models of coordinated services that include supports for caregivers are needed, especially as caregiver's age.

Research examining access and barriers to services, as well as developing and testing the programs and delivery systems that may help to overcome these barriers, may be important in order to improve life course outcomes among youth and young adults with ASD.

\section{Gaps in Services and Programming}

\section{Individualized Planning}

There is significant heterogeneity with regard to the ASD population. Because ASD can include such a wide range of barriers and challenges across multiple domains of functioning, stakeholders believe a broad array of options and customized solutions is needed to appropriately address the service needs of individuals with ASD who are transitioning from youth to adulthood; one-size solutions across the autism spectrum are not possible and could even be unintentionally harmful. Thus, stakeholders strongly recommend highly individualized transition planning at a young age for those on the autism spectrum.

Under IDEA, Part B, Individualized Education Programs (IEPs) are used to help plan individualized interventions and supports for school-aged children. An Individualized Plan for Employment (IPE) is developed for eligible individuals with a disability receiving services under the Vocational Rehabilitation Services program that is designed to achieve a specific employment outcome that is selected by the individual.
However, in FY 2015, only 10,317 individuals with ASD between ages 16 and 24 received VR services; this is approximately two percent of the estimated 450,000 young people with ASD aged 16 to 24 in the United States. A similar type of individualized planning that includes life goals (including but not limited to employment), as well as bridging between school-based services and employment, is needed to facilitate the transition to adulthood and beyond for young people with ASD who are not eligible or do not apply for VR services, in the view of stakeholders. One approach to help bridge this gap would be to adopt the use of individualized learning plans (ILPs) that help identify individual life goals and needed services and supports, in order to facilitate the creation of continuing objectives for individuals with ASD, including post-secondary education, employment, housing, social network development, and other areas critical to successful life as an adult.

\section{Coordinated, Comprehensive Care Responsive to the Range of Individual Needs}

Coordinated service systems at the individual level are essential to improve access to needed services and supports, including the health care system. As described in Part 1, the heterogeneity of this population combined with a high rate of co-occurring conditions have a major impact on the individual's health, including decreased life span, increased suicidal rates and ideation, and undiagnosed preventable illnesses.

Coordinated, comprehensive services and supports at the individual level may need to be supported by mechanisms for interagency partnership and coordination at the federal level. Stakeholders see a great need for more blended or braided funding streams to successfully meet the complex needs of

The number of youth with ASD meeting eligibility criteria for VR services may increase with the WIOA amendment's emphasis on transition planning, and the new requirement for pre-employment transition services for students with disabilities who are potentially eligible for VR services. 
this population. Particularly vulnerable groups are youth and young adults with ASD who have intensive mental health needs (anxiety, depression, explosive behavior, etc.). Federal and state systems that are siloed-that only provide for educational services, broad disability supports, or mental health servicesare unable to address the complex, multifaceted needs of these individuals.

\section{Transition Planning}

There is currently little research, and no consensus in the scientific community, available on the issue of when transition planning should begin. The IDEA requires that postsecondary goals and the transition services (including courses of study) needed to assist the student in reaching those goals be in place by the student's $16^{\text {th }}$ birthday; IDEA regulations also permit postsecondary goals and transition services to be included in IEPs of younger students if determined appropriate by the IEP Team. Often, however, planning for transition is delayed until the year before schooling is completed. Consistent with the public comments to IACC and the GAO report on transition, stakeholders agreed that transition planning needs to start at a much younger age than 16 , and as early as age 10 or 12 ; accordingly, information about program resources needs to be made available long before transition actually begins. In addition, all those with a key role in the child's development should begin transition planning relative to the child's needs as soon as possible. Some would argue that transition planning for children with special health care and service needs begins at birth and continues across the life span through the development of independence, integration into the community, and increasing specification of tangible plans for adult life.

On a related note, IEP Team meetings under the IDEA are conducted annually but are typically focused on planning only for the following year. There is little to no overarching planning toward preparing a student to achieve life goals and realize individual potential to maximize skills and abilities. Throughout the planning process, stakeholders believe that explicit and continuous attention is necessary to the decision-making supports that youth may need.

Reticence among caregivers about relinquishing care and decision-making responsibilities, and difficulties in letting go of long-standing provider relationships, should be addressed as well.

In addition, clinical resources for transition planning from pediatric to adult health care have been developed through Got Transition. These resources define the basic components of transition support and are applicable across a broad range of health care services.

\section{High-Quality Services and Programming that Challenge All Young People with ASD}

Stakeholders expressed concern regarding inconsistency in the quality of services and programming available; too often, transitioning youth with ASD are prepared by transition programs to cope with the lessening of services and supports in adulthood, rather than being guided through a process of identifying life goals and planning for their achievement. The external stakeholders expressed a critical need for programming that prepares youth for meeting the challenges of adult life, as opposed to focusing on ways to manage the free time that may result from the reduction in services. Setting low expectations may inhibit individuals with disabilities from reaching their full potential as adults. As described above, the use of an ILP to help plan for transition to and continuing growth in adulthood could help address this significant gap. Stakeholders noted several specific service gaps and potential remedies: 
- High-quality effective vocational rehabilitation services are crucial for those in transition in order to prepare youth for attaining competitive integrated employment.

- Adult residential and integrated day or partial-day service resources are critically needed, especially those that provide services that are integrated into community activities rather than in institutions or other isolated settings.

- It is critical for integrated day programs to be available that are specifically tailored to meet the needs of those individuals with very extensive support needs. Federal incentives to scale integrated day programs to meet ASD population needs are needed, as is more consistent quality in state-funded integrated day programs.

- Programs that help prepare individuals with ASD for postsecondary education and training opportunities are needed. This involves community integration through summer programs and additional orientation activities for nonenrolled students. (As an example, Marshall University has one such program for students with ASD attending its university; for additional information, see http://www. marshall.edu/atc/).

- Access to adequate crisis care designed for youth and young adults with ASD is crucial. As more supports and services are moved into communitybased services, families must have access to services that can help maintain physical and mental health as necessary.

- It is critical that health and safety issues be addressed. Some individuals on the ASD spectrum may be inclined to wander and not be able to manage public transportation. They may not be understood by first responders or police during law enforcement activities and interact in atypical ways that lead to unnecessary use of force. They also may be disproportionately subject to abuse, both physical and sexual.

- Also necessary is greater awareness and acceptance by employers, educators, providers, and the general public of both the gifts and talents of, and significant challenges experienced by, those on the autism spectrum. Strategies for reducing stigmatization, as well as supports and services that help to facilitate positive and meaningful social connections, are crucial. Stereotyping (e.g., for STEM skills) may also inhibit integration into the community, and highlights the need for increased understanding.

- Community integration is essential, whether for those with extensive or less extensive needs; all individuals with ASD should have the same opportunities as others to be included in the work and social lives of their communities.

- It is vital that programs and services carefully consider the role of the family during the process of transitioning to adulthood. Understanding how to support and include families, without undermining the autonomy of the individual with ASD, is an important but complicated need.

Finally, the stakeholders stated that it is crucial that programming and services address the existing disparities in receipt of high-quality care across different subpopulations of youth and young adults with ASD, mirroring the health disparities that exist at the national level. Also important to consider is the disparity in receipt of health care transition preparation for youth with ASD as compared to youth with other chronic health conditions.

\section{Public Comments to IACC}

In 2016, the IACC collected information from stakeholders regarding the transition period from youth to adulthood for persons with ASD through a Request for Public Comment. The major issues that emerged from the public comments included the need for:

- Improved transition planning in high school;

- More opportunities to strengthen daily living and social skills in the transition period; 
- Better coordination of transition services;

- Increased access to transition services and reduced waiting times;

- Better preparation for employment, postsecondary education, and community integration;

- Reduction in disparities in access to services for low-resourced and underserved communities;

- Personalized services based on individualized needs; and

- Strengthened workforce of trained providers and other professionals to meet the service and support needs of this transition-age population.

\section{GAO Roundtable Views of Services Needed During the Transition into Adulthood}

As mentioned in Part 1 of this Report, GAO's 2017 Report (Roundtable Views of Services Needed During the Transition into Adulthood) 4 focused specifically on ASD and transition. In particular, GAO conducted a qualitative study involving a panel roundtable with researchers, other professionals, advocacy groups, and caregivers. The panel described services and supports that transitioning youth with ASD aged 14-24 may need in order to address particular challenges they may face. It did this for each of the five life goals identified as critical to transition: postsecondary education, employment, maximizing independent living, health and safety, and maximizing community integration. GAO grouped these services into 14 broad categories (Table 3):

\section{Table 3}

\section{Key Services Identified by GAO Needed} to Support Transitioning Youth with Autism Spectrum Disorder

- Behavioral Interventions

- Mental Health Care

- Case Management/Coordination

- Postsecondary Education Planning and Supports

- Communication Services

- Residential Supports

- Day Programming

- Social Supports

- Family Education and Supports

- Transition Planning Services

- Life Skills Education and Experience

- Transportation Supports

- Medical Care

- Vocational Supports

Based on the panel's input, the GAO report concludes that supporting a successful transition into adulthood requires providing youth with ASD greater access to services that are:

- Individualized to each person's needs;

- Sensitive to the fact that these needs may change over time;

- Available to all youth with ASD regardless of race/ ethnicity, gender, family income, or location;

- Within youths' local communities in order to foster access and community involvement; and

- Evidence-based to the extent possible, with recognition that most existing programs have not been scientifically evaluated, and efficacy testing of new and existing program models is needed. 
In addition, the GAO cites the need for shared responsibility between society and youth with ASD in order to improve community inclusion and integration of this population. As an example, the panel noted that youth with ASD should learn workplace social expectations and strive to meet these norms, but at the same time employers should recognize that some social rules, such as expecting individuals to smile, can be challenging for some individuals with autism. ${ }^{\text {iv }}$ Greater public awareness and knowledge of ASD could lead to better understanding of the gifts and talents of youth with ASD. This will improve the likelihood that they will reach their life goals and contribute in greater ways to society, including through meaningful gainful employment opportunities.

\section{Summary of Input from Stakeholders}

Based on information collected by OASH from stakeholders and from the GAO consultations in preparation of its report, it is clear that youth with ASD and their families and caregivers have complex needs requiring comprehensive approaches that are not necessarily found in programs devoted to addressing singular life aspects (e.g., health care, housing, transportation, social services, or education). Further, they report that agency programs focusing only on children and youth most often have little contact with programs that focus on adults; ${ }^{\text {sss }}$ hence, stakeholders recommend that coordination of services and supports across programs and periods of life is necessary in order to serve the diverse and complex needs of youth with ASD in transition to adulthood.

§§§§ One resource that does bridge this gap are the special education programs under IDEA that coordinate with state VR programs on transition planning and services. 


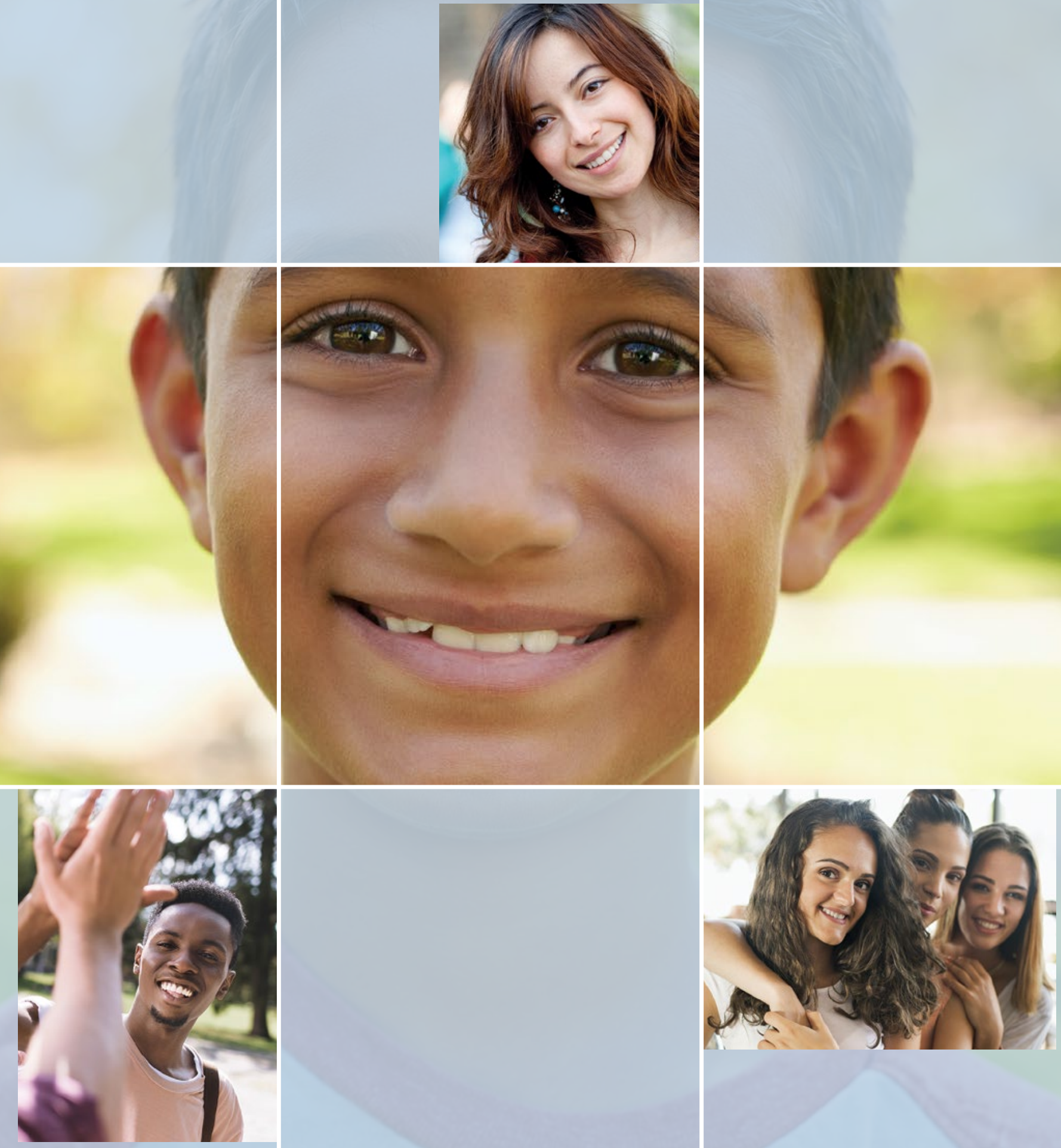


\title{
Part 4:
}

\section{Conclusions and Recommendations}

\author{
In Part 4 of this report, a synthesis of findings is presented; conclusions are offered first and then

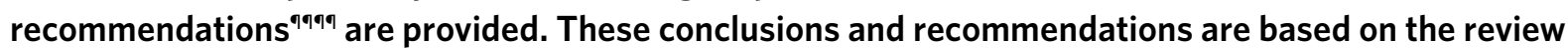 \\ presented in Part 2 of federal programs, policies, services and supports for individuals with ASD who are \\ transitioning to adulthood, as well as on stakeholder input as described in Part 3.
}

\section{Conclusions}

\section{A Coordinated, Comprehensive Approach to Services and Supports}

The terms 'coordinated' and 'comprehensive' have both featured prominently in the healthcare and ASD fields in the past decade and a half. In a 2002 consensus statement regarding health care transitions for young adults with special health care and service needs, 29 the boards of three medical professional societies together described "the critical first steps that the medical profession needs to take to realize the vision of a family-centered, continuous, comprehensive, coordinated...health care system." The terms "coordinated" and "comprehensive" appear again in the Joint Principles of the Patient-Centered Medical Home, first developed and endorsed in 2007 by the major primary care physician associations. The Joint Statement asserts that, "the medical home is best described as a model or philosophy of primary care that is patient-centered, comprehensive, teambased, coordinated, accessible, and focused on quality and safety." It goes on to offer the following definitions of these two terms: ${ }^{30}$
- Comprehensive: A team of care providers is wholly accountable for a patient's physical and mental health care needs, including prevention and wellness, acute care, and chronic care

- Coordinated: Care is organized across all elements of the broader health care system, including specialty care, hospitals, home health care, community services and supports

Many current federal investments incorporate families and/or the targeted individual into their existing program practices. However, only a few federally funded programs coordinate services across agencies at the state and local level. For example, the PROMISE program requires the Social Security Administration and the Departments of Education, Health and Human Services, and Labor to work together to develop and implement demonstration projects that provide coordinated services and postsecondary supports for youth with disabilities receiving Supplemental Security Income (SSI), including services and supports for their families. This innovative program provides a model for other cross-agency partnerships designed to encourage coordination across services. 
The Autism CARES Act specifies that coordinated health and wellness care, services, and community supports for transitioning youth and young adults with ASD must involve "all relevant service providers receiving federal funding," and not only a select few of these providers. The services and supports listed in the 2014 Act mirror the diverse needs of youth and young adults with ASD, cut across the traditional boundaries of multiple federal agencies, and include the following:

- Postsecondary educational and vocational preparation and support;

- Behavioral supports and interventions;

- Community-based, integrated services and supports, including housing and transportation;

- Nutrition, health and wellness;

- Recreational and social activities; and

- Personal safety supports.

According to the 2017 GAO Report and the 2011 Survey of Pathways to Diagnosis and Services, over half of youth with ASD aged 15-17 had also been diagnosed with co-occurring conditions, including attention deficit disorder (53 percent) and anxiety (51 percent). Nearly one-quarter had depression, and 60 percent had at least two concurrent conditions. In addition to mental health needs, other common co-occurrences include sleep disorders, intellectual disability, seizure disorders, and gastrointestinal ailments. These co-occurring conditions indicate a need for a comprehensive, coordinated approach that includes clinical providers as well as communitybased services and supports that a particular individual with ASD may need.
One federal program that meets the criterion of coordination with all relevant providers is SAMHSA's "Now Is The Time" Healthy Transitions program, where sites must provide wraparound coordinated services and supports. Using a wraparound approach, individuals who are relevant to the health and well-being of the child or youth (e.g., family members and other unpaid supportive individuals, clinical and community service providers, agency representatives) work together to develop and implement a plan of individualized supports and services. Given the complexity and heterogeneity of ASD, programs that utilize an individualized, wraparound team approach are especially important and remain a critical need in service provision for this population.

A coordinated, comprehensive approach involves providers from different disciplines and programs from different systems. By finding ways to involve all relevant services and supports, a coordinated approach typically cuts across clinical and community settings to provide supports and services that reflect the varying needs of each individual. However, provision of federally funded supports and services, including health care, that is comprehensive presents challenges for systems that are set up to function separately. Blending or braiding of funds from federal, state, and local sources to support a common project (e.g., as is the case for the PROMISE program $\left.^{* \star * \star}\right)$ is a complicated process. More often than not, it falls upon the individual and his or her caregivers to piece together resources and services across different service systems.

The blending and braiding of funds are done at the state and local level. The federal funds received by the PROMISE projects were awarded as discretionary grants by the Department of Education. SSA is funding the evaluation of PROMISE. 


\section{Support Coordinating Across Systems}

Many families do not have the resources to help them access or consolidate information and resources across systems during the transition process. For youth with ASD who receive special education and related services under IDEA, service providers may be invited to IEP and transition planning meetings. In addition, federal regulations require state $V R$ agencies to coordinate with education officials through a formal interagency agreement to facilitate the transition of students with a disability, including for those students determined to be eligible for VR services, and the development and approval of an individualized plan for employment as early as possible during the transition planning process and not later than the time a student with a disability leaves the school setting.

However, not all youth with ASD receive services under the IDEA, and young adults who received special education and related services while in school are no longer covered once they age out of IDEA services; in all such cases, families are often left to contact each individual agency that provides services and supports (such as SSI, community health services, housing supports, VR or other job and employment or training resources) on their own and then determine which services that agency might be able to provide, how to apply for those services, and how those services might depend on other services they are or are not receiving or may or may not be eligible for.

\section{Family Support}

An underserved area of concern regarding youth with ASD transitioning to adulthood is the issue of family and caregiver health and wellness. As young people age, so do their caregivers; over time, caregivers may become less and less able to provide direct care or to assist their adult child with navigating increasingly complex service delivery requirements. Services for adults living with ASD are quite variable across states and often depend heavily on Medicaid. An adult with ASD can apply for SSI or SSDI since autism is an eligible disability under SSA definitions. However, many young adults with ASD may not meet eligibility criteria for SSI or SSDI; moreover, SSI/SSDI provide monetary benefits, but this may not cover all supports and services needed, or their coordination.

A range of Medicaid home and community based services (HCBS) have been available as an option to states through a variety of statutory authorities, including Medicaid HCBS waivers, other waivers (e.g., authorized as part of demonstration projects under section 1115 of the Social Security Act), and State Plan amendments. These could include many services that help beneficiaries and caregivers (e.g., respite care, chore services, environmental supports, etc.). However, because these services are at the discretion of state programs, they vary considerably across the United States. Some states offer selfdirected service delivery options that include greater choice and control for beneficiaries and families/ caregivers. HCBS could include more extensive caregiver supports, pay caregivers, and provide other benefits that relieve caregiver burdens for those caring for youth and young adults with ASD, but these are at the option of states, not the federal government.

Youth under 21 years of age who are eligible for Medicaid in their state qualify for the Medicaid Early and Periodic Screening, Diagnostic and Treatment (EPSDT) benefit, which allows them to receive any medically necessary service found in section 1905(a) of the Social Security Act including rehabilitation services, dental services, therapy services and personal care. 


\section{Data and Research on Transition-age Youth and Young Adults with ASD}

The 2014 Autism CARES Act calls for the reporting of relevant demographic characteristics for the population of transitioning youth with ASD. In the review of existing federal programs, however, there appears to be no single source for data that describes the transition-age U.S. population with ASD-a significant gap in vital information that deserves attention and needs to be addressed. Most federally funded data sets that include youth focus on children up to the age of 18 and do not continue through young adulthood. One notable exception, the National Longitudinal Transition Study (NLTS2), provides data on transition-age youth and young adults with disabilities, including ASD, who received special education and related services under IDEA in secondary school. However, since not all youth with ASD are eligible for or receive special education and related services, the findings cannot be generalized to all youth and young adults with ASD.i

As described in Part I, there is no survey that covers the full population of transition-age youth and young adults with ASD in the United States. This impedes the identification, development, and implementation of programs that provide comprehensive, coordinated, individualized services and supports across a highly heterogeneous population. This highlights the need for improved ASD surveillance, including youth and young adults, as well as for exploratory/ descriptive studies that focus on youth who may not qualify for school-based services under IDEA, or on young adults who are attempting to navigate adult services and supports on their own.

\section{Improving Outcomes}

The final set of elements specified by the Autism CARES Act focuses on improving outcomes through the transition to adulthood. Although transition issues were included as a topic or potential topic in many existing programs, in no case was a federally funded services program identified that focuses solely on the transition to adulthood among youth with ASD, and only a handful of research studies targeted to this population were funded. Improving outcomes among this population will require increased knowledge of factors associated with improved quality of life in this population, including what works for which persons and under what circumstances, as well as for the development of best practices based on the new knowledge.

In addition, the Act calls for the use of evidencebased practices, and for determining the effectiveness of different practices. The most recent assessments from IACC's portfolio analysis have indicated that 2 percent of research funding on ASD has been dedicated to the needs of adults living with ASD, similar to previous years; when considering just research devoted to transition-related issues, the percentage of the total funding is less than 2 percent (Office of Autism Research Coordination, National Institute of Mental Health). Although there are data from the NLTS 2012 and the NLTS2 on youth and young adults with ASD who received special education and related services in school, there is currently insufficient population-based intervention research focused on the transition of youth with ASD to adulthood to identify best practices. Research designed to build this evidence base is needed. 


\section{Recommendations}

Below, recommendations for further consideration are stratified according to surveillance and monitoring, research, and program services and delivery. These recommendations are based on information gathered by the Transition Steering Committee and IWG.

\section{Epidemiological Data Collection and Monitoring}

a. Service systems within communities must be able to assess and monitor the experiences, needs, and life goals of transitioning youth with ASD in order to identify, develop, plan, and implement vital changes to support this population. Collaborative efforts between public institutions, private organizations, and individuals and families are necessary to better describe the characteristics of youth with ASD, develop standard methods of community needs assessment, and improve the capacity for ongoing surveillance and research.

b. A national survey assessing the full range of service and support needs, barriers, and facilitators for transition-age youth and young adults with ASD is needed, including their access to employment and employment-related supports. Such a survey should include a way to track the use of general and disability-specific services through the transition. c. A more complete surveillance system may be needed in order to provide data on the full spectrum of transition-age youth and young adults with ASD. Such a system should include a way to track the use of mainstream and general disability supports and services, including health care services, through the transition. Current surveillance data are limited to children; adults with ASD are not included in population-based surveys used by the federal government. The current lack of an authoritative national resource for information regarding transition age youth with ASD in the U.S. underscores the need for enhanced investments in ASD surveillance, including youth and young adults.

d. Longitudinal data are vital to follow up on transition outcomes for individuals with ASD. These home and community-based services performance measures should go beyond job placement or post-secondary education to include career development and advancement, life satisfaction and well-being, health status, community integration and social connectedness, personal relationships, access to quality health care including mental health services as needed, and individual financial wellbeing and economic self-sufficiency. 


\section{Research}

a. Although some research has been conducted on the needs of transition-age youth and young adult in general, there is a dearth of research on the needs of transition-age youth and young adults with ASD, with less than 2 percent of combined private and federal autism funding being devoted to this issue (Source: Office of Autism Research Coordination, National Institute of Mental Health). Additional targeted outcomes research is needed to assess the efficacy of transition-oriented programming in achieving positive outcomes in education, daily life and social skills training, vocational training, employment, residential placement, and community integration.

b. In order to improve outcomes among this population, it is necessary to have researchbased information, such as what factors are associated with optimal outcomes in this population, or more specifically, what works for who and in what circumstances? Careful consideration should be given to understanding how outcome goals must vary across the heterogeneous population of young adults and transitioning youth with ASD in order to address their individualized needs.

c. Program model development that includes individualized coordination of supports and services, as well as efficacy or effectiveness testing of those programs by researchers, is critical to establishing a base of evidence regarding what program components are effective for which needs among transitioning youth and young adults with ASD. d. There is a need for a broader array of meaningful outcome measures to facilitate the development and evaluation of effective models for the development of coordinated, comprehensive, and individualized services and supports for transition age youth and young adults with ASD.

e. Research is needed that focuses on implementing promising program models across different settings and populations, as well as better granular information on what services and supports are effective across different ASD phenotypes, genders, race/ethnicity/ cultural groups, and cognitive abilities and other domains of functioning, as well as under what circumstances of social, economic, and institutional support. Models determined to be effective must be evaluated as to how they may be scaled up and adapted to different settings for use with this diverse population.

f. Service delivery research is also necessary to ensure the translation of research into practice, as well as to identify effective strategies for ensuring access to all families, including families that are under-resourced or live in rural areas.

g. Research is needed to better understand how caregivers, and especially parents, can best support youth and young adults with ASD through the transition process. In addition, research examining the extent to which fostering social support systems for individuals with ASD may serve to increase independence and decrease the reliance on families as the single source of support. 


\section{Supports and Services}

a. Better coordination across federal agencies, and across service systems at the state and community levels, is necessary in order to adequately meet the diverse needs of the heterogeneous population of transitioning youth and young adults with ASD. This goal may be facilitated by a specific coordinating office or an expanded role for existing ASD-specific agencies.

b. Programs must be designed for broad access, but with individual flexibility. The heterogeneity of the ASD population demands more than 'one size fits all' approaches. Such program application must be supported by cross-agency coordination at the state level, and informed through research and programming that support the identification of effective programs and program components. Programs and service delivery models that include coordination of a team of professionals across systems is crucial, in order to appropriately individualize services for this heterogeneous population.

c. Trained service coordinators and case managers who understand the potentially multiple needs of individuals with ASD and their families/ caregivers are vital in order to help them navigate multiple, complex service systems early in the process of transition. Specific training, certification, and licensing programs may be needed to assure this type of capacity.

d. Better preparation of all relevant adult service and support providers to receive young adults with ASD is essential in order to provide highquality care that is individualized to meet diverse needs of transitioning youth. This includes primary care providers who provide clinical services but must also understand the developmental and social support system issues faced by youth transitioning to adulthood.

e. Increased coordination between childhoodoriented services, which benefit from Individualized Educational Programs (IEPs), and the adult services and supports provided across different systems, is necessary in order to create transition planning that functions as an effective bridge between child/adolescent and adult services and supports. Some programs of this nature already exist, such as the public-private partnership, Project SEARCH, which provides a combination of classroom instruction, career exploration, and hands-on training through worksite rotations for students in their last year of or recent graduates from high school. Similarly, the vocational rehabilitation (VR) program coordinates with the schools to provide pre-employment transition services to students with disabilities (including students with ASD) who are eligible or potentially eligible for VR services. ${ }^{\dagger i t h}$ Given the wide range of service and support needs among the ASD population, more programs that bridge the gap across child or pediatric and adult systems are needed, as is a way to coordinate systems into flexible, individualized services and supports as needed.

f. Federal policies that encourage blending and braiding of funds for cross-agency funding opportunities are critical in order to design, develop, implement, and evaluate a comprehensive, coordinated approach to services and supports, including health care, that assures broad access but individual flexibility.

g. Concerted communications efforts across federal, state, and community levels, and across different media platforms are crucial to dispel

个it individualized transition services for students and youth with disabilities who apply and are determined eligible for VR services under an approved individualized plan for employment. 
stigma and encourage acceptance of individuals with ASD; such concerted communications efforts are necessary to facilitate full inclusion and community integration for these youth and young adults.

\section{Summary}

This Report is limited to a review of federal programs that may be involved in support for transitioning youth and young adults with ASD. Most of these programs either serve the general population or the broad disability population; only a small set of individual federal grants within programs specifically target youth and young adults with ASD.

The larger disability system plays a critical role in the United States in working to ensure that individuals with disabilities have access to the services and supports that they need to lead independent, self-determining lives and participate fully in the community. Sustained support for the larger disability system and thoughtful consideration of its intersections with ASD initiatives is a vital foundation for efforts going forward to address the needs of individuals with ASD as they enter adulthood. In addition, the federal investments reviewed in this Report suggest that there is a dearth of research and services focused on the needs of individuals with ASD as they enter adulthood and the years beyond. More research and efforts for service and resource expansion should be considered in order to better serve this population. Specifically, there is a need to:

- Design, develop, evaluate, and implement cohesive programs that enable delivery of services in a coordinated, comprehensive, and individualized manner;

- Conduct research to test the efficacy of new and existing service and support models that are designed to improve outcomes for youth and young adults with ASD;
- Increase access to, and the quality of, services and supports;

- Assure the health, well-being, and full integration into community life of youth and young adults with ASD;

- Increase provider training and public acceptance of the neurodevelopmental differences and strengths associated with ASD; and

- Alleviate the growing burden of navigating multiple systems for individuals and their families. Support is needed generally for individuals and their caregivers who too often are required to understand complex program provisions and eligibility without the help of trained professionals or without the proximity or affordability of those programs.

A more integrated and coordinated system of supports, services, and research that accounts for the heterogeneity of the ASD population transitioning to adulthood and their caregivers is needed. Additional work is thus necessary for the federal agencies and external stakeholders with equities in ASD to address the need for integration of funding sources, outcomes research, surveillance, and services among and across those offered to youth in the educational system and those provided to adults in the health care and social services systems. This Report provides the initial assessment of the gaps and a description of existing federal resources. 



\section{References}

1. Wilens TE, Rosenbaum JF. Transitional age youth: A new frontier in child and adolescent psychiatry. J Amer Acad Psych. 2013 Sept;52(9):887-90. DOI: http://dx.doi.org/10.1016/i.jaac.2013.04.020.

2. American Psychiatric Association. (2013). Diagnostic and statistical manual of mental disorders (5th ed.).

3. Christensen DL, Baio J, Braun KV, et al. Prevalence and characteristics of autism spectrum disorder among children aged 8 years - Autism and Developmental Disabilities Monitoring Network, 11 Sites, United States, 2012. MMWR Surveill Summ 2016;65(No. SS-3)(No. SS-3):1-23. DOI: http://dx.doi.org/10.15585/mmwr.ss6503a1.

4. Government Accountability Office. Youth with Autism: Roundtable Views of Services Needed During the Transition into Adulthood. GAO-17-109.

5. Kogan MD, Blumberg SJ, Schieve LA, Boyle CA, Perrin JM, Ghandour RM, Singh GK, Strickland BB, Trevathan E, van Dyck PC. Prevalence of parentreported diagnosis of autism spectrum disorder among children in the US, 2007. Pediatrics. 2009 Nov;124(5):1395-403. doi: 10.1542/peds.2009-1522. Epub 2009 Oct 5.

6. The Child and Adolescent Health Measurement Initiative, Johns Hopkins Bloomberg School of Public Health. (2016.) Experience Matters: A View into the Health and Well-being of US Children and Families with Autism Spectrum Disorder (ASD). Retrieved 11/15/2016 from http://childhealthdata. org/docs/default-source/cahmi/asdchartbookfinal. pdf?sfvrsn=2

7. Zablotsky B, Black LI, Maenner MJ, et al. Estimated prevalence of autism and other developmental disabilities following questionnaire changes in the 2014 National Health Interview Survey. National Health Statistics Reports; no 87. Hyattsville, MD: National Center for Health Statistics. 2015.
8. Lipscomb S, Haimson J, Liu AY, Burghard, J, Johnson DR, \& Thurlow ML. Preparing for life after high school: The characteristics and experiences of youth in special education. Findings from the National Longitudinal Transition Study 2012. Volume 2: Comparisons across disability groups: Executive summary (NCEE 2017-4019). Washington, DC: U.S. Department of Education, 2017. This report is available at https:// ies.ed.gov/ncee/projects/evaluation/disabilities_ nlts2012.asp

9. Van Wijngaarden-Cremers PJ, van Eeten $E$, Groen WB, Van Deurzen PA, Oosterling IJ, \& Van der Gaag RJ. Gender and age differences in the core triad of impairments in autism spectrum disorders: a systematic review and meta-analysis. Journal of Autism and Developmental Disorders. 2014;44(3):627-35.

10. Yurkiewicz, I. (2010). Overlooked and Underdiagnosed: Distinct Expression of Aspergers Syndrome in Females. The Yale Review of Undergraduate Research in Psychology, 80.

11. Personal communication, Nov 8, 2016. Drexel Autism Institute, Drexel University, PA.

12. Parker JG, Rubin KH, Erath SA, Wojslawowicz JC, Buskirk AA. Peer relationships, child development, and adjustment: a developmental psychopathology perspective. In Developmental psychopathology, 2nd ed. (Eds Cicchetti D \& Cohen DJ). 2015. Wiley: Hoboken NJ. doi: 10.1002/9780470939383.ch12

13. Sterzing PR, Shattuck PT, Narendorf SC, Wagner $\mathrm{M}$, Cooper BP. Bullying involvement and Autism Spectrum Disorders: prevalence and correlates of bullying involvement among adolescents with an Autism Spectrum Disorder. Arch Pediatr Adolesc Med. 2012;166(11):1058-1064. doi:10.1001/ archpediatrics.2012.790

14. Roux AM, Rast JE, Anderson KA, and Shattuck PT. 2017 National Autism Indicators Report: Developmental Disability Services and Outcomes in Adulthood. Philadelphia, PA: Life Course Outcomes Program, A.J. Drexel Autism Institute, Drexel University, 2017. 
15. Newman L, Wagner M, Knokey A-M, Marder C, Nagle K, Shaver D, Wei X, with Cameto R, Contreras E, Ferguson K, Greene S, Schwarting M. The PostHigh School Outcomes of Young Adults with Disabilities up to 8 Years After High School. A Report from the National Longitudinal Transition Study-2 (NLTS2) (NCSER 2011-3005). 2011. Menlo Park, CA: SRI International. Available at https://nlts2.sri.com/ reports/2011_09_02/index.html

16. Roux AM, Shattuck PT, Rast JE, Rava JA, Anderson KA. 2015 National Autism Indicators Report: Transition into Young Adulthood. Philadelphia, PA: Life Course Outcomes Research Program, A.J. Drexel Autism Institute, Drexel University, 2015.

17. Schendel DE, Overgaard M, Christensen J. Association of Psychiatric and Neurologic Comorbidity with mortality among persons with autism spectrum disorder in a Danish population. JAMA Pediatr. 2016;170(3):243-250. doi:10.1001/ jamapediatrics.2015.3935.

18. Hirvikoski T, Mittendorfer-Rutz E, Boman M, Larsson $\mathrm{H}$, Lichtenstein P, Bölte S. Premature mortality in autism spectrum disorder. The British Journal of Psychiatry, Nov 2015. DOI: 10.1192/bjp.bp.114.160192

19. Croen LA, Zerbo O, Qian Y, Massolo ML, Rich S, Sidney S, Kripke C. The health status of adults on the autism spectrum. Autism. 2015 Oct;19(7):814-23. doi: 10.1177/1362361315577517. Epub 2015 Apr 24.

20. Cusack J, Shaw S, Spiers J, Sterry R. Personal tragedies, public crisis: The urgent need for a national response to early death in autism. March 2016. Retrieved 11/7/2016 from https://www.sciencemag. org/sites/default/files/documents/AUTISTICA\%20 REPORT\%20-\%20Personal\%20Tragedies,\%20 Public\%20Crisis.pdf.

21. Jacob A, Scott M, Falkmer M, Falkmer T. The costs and benefits of employing an adult with Autism Spectrum Disorder: a systematic review. PLoS ONE. 2015;10(10): e0139896. https://doi.org/10.1371/ journal.pone.0139896

22. Office of Autism Research Coordination, National Institute of Mental Health, on behalf of the Interagency Autism Coordinating Committee (IACC). 2014-2015 IACC Autism Spectrum Disorder
Research Portfolio Analysis Report. October 2017. Retrieved from the U.S. Department of Health and Human Services Interagency Autism Coordinating Committee website: https://iacc.hhs.gov/portfolioanalysis/2015/index.shtml

23. Eseigbe $\mathrm{E}$, Taju N, Lateef $\mathrm{S}$. Challenges in care of the child with special health care needs in a resource limited environment. J Neurosci Rural Pract. 2013 Apr-Jun;4(2):204-206. doi: 10.4103/0976-3147.112770

24. Cappadocia MC, Weiss JA, Pepler DJ. Bullying experiences among children and youth with Autism Spectrum Disorders. Autism Dev Disord. 2012;42:266. doi:10.1007/s10803-011-1241-x

25. Autism CARES Act of 2014. Retrieved 11/10/2016 from https://www.congress.gov/ bill/113th-congress/house-bill/4631/

26. Interagency Autism Coordinating Committee (IACC). 2015 IACC Summary of Advances in Autism Spectrum Disorder Research. April 2016. Retrieved December 30, 2016, from the U.S. Department of Health and Human Services Interagency Autism Coordinating Committee website: https://iacc.hhs. gov/publications/summary-of-advances/2015/.

27. Government Accountability Office. Students with Disabilities: Better Federal Coordination Could Lessen Challenges in the Transition from High School. GAO12-594: Published: Jul 12, 2012. Publicly Released: Aug 7, 2012. Retrieved 2/12/14 from http://www. gao.gov/products/GAO-12-594

28. Federal Partners in Transition Workgroup. The 2020 Federal Youth Transition Plan: A Federal Interagency Strategy. February 2015. Retrieved 2/1/17 from https://www.dol.gov/odep/pdf/20150302-fpt.pdf

29. American Academy of Pediatrics, American Academy of Family Physicians, American College of PhysiciansAmerican Society of Internal Medicine. A Consensus Statement on Health Care Transitions for Young Adults With Special Health Care Needs. Pediatrics. December 2002, VOLUME 110 / ISSUE Supplement 3.

30. Patient Centered Primary Care Collaborative. Retrieved 2/28/17 from https://www.pcpcc.org/ about/medical-home 


\section{Appendix 1}

\section{Autism CARES Act of 2014, amending Sec. 399DD(b) of the Public Health Service Act}

\section{"(b) REPORT ON YOUNG ADULTS AND TRANSITIONING YOUTH.-}

"(1) IN GENERAL. - Not later than 2 years after the date of enactment of the Autism CARES Act of 2014, the Secretary of Health and Human Services, in coordination with the Secretary of Education and in collaboration with the Secretary of Transportation, the Secretary of Labor, the Secretary of Housing and Urban Development, and the Attorney General, shall prepare and submit to the Committee on Health, Education, Labor, and Pensions of the Senate and the Committee on Energy and Commerce of the House of Representatives, a report concerning young adults with autism spectrum disorder and the challenges related to the transition from existing school-based services to those services available during adulthood.

"(2) CONTENTS.-The report submitted under paragraph (1) shall contain-

"(A) demographic characteristics of youth transitioning from school-based to community-based supports;

"(B) an overview of policies and programs relevant to young adults with autism spectrum disorder relating to post-secondary school transitional services, including an identification of existing Federal laws, regulations, policies, research, and programs;

"(C) proposals on establishing best practices guidelines to ensure-

"(i) interdisciplinary coordination between all relevant service providers receiving Federal funding;

"(ii) coordination with transitioning youth and the family of such transitioning youth; and

"(iii) inclusion of the individualized education program for the transitioning youth, as prescribed in section 614 of the Individuals with Disabilities Education Act (20 U.S.C. 1414);

"(D) comprehensive approaches to transitioning from existing school-based services to services available during adulthood, including- 
"(i) services that increase access to, and improve integration and completion of, post-secondary education, peer support, vocational training (as defined in section 103 of the Rehabilitation Act of 1973 (29 U.S.C. 723)), rehabilitation, self-advocacy skills, and competitive, integrated employment;

"(ii) community-based behavioral supports and interventions;

"(iii) community-based integrated residential services, housing, and transportation;

"(iv) nutrition, health and wellness, recreational, and social activities;

"(v) personal safety services for individuals with autism spectrum disorder related to public safety agencies or the criminal justice system; and

"(vi) evidence-based approaches for coordination of resources and services once individuals have aged out of post-secondary education; and

"(E) proposals that seek to improve outcomes for adults with autism spectrum disorder making the transition from a school-based support system to adulthood by-

"(i) increasing the effectiveness of programs that provide transition services;

"(ii) increasing the ability of the relevant service providers described in subparagraph (C) to provide supports and services to underserved populations and regions;

"(iii) increasing the efficiency of service delivery to maximize resources and outcomes, including with respect to the integration of and collaboration among services for transitioning youth;

"(iv) ensuring access to all services necessary to transitioning youth of all capabilities; and

"(v) encouraging transitioning youth to utilize all available transition services to maximize independence, equal opportunity, full participation, and self-sufficiency." 


\section{Appendix 2}

\section{Authorizing Legislation by Agency and Program}

\begin{tabular}{|c|c|c|}
\hline Agency & $\begin{array}{l}\text { Program Name } \\
\text { (FY } 2013 \text { to FY 2016) }\end{array}$ & Legislative Authority \\
\hline $\begin{array}{l}\text { U.S. Department of } \\
\text { Health and Human } \\
\text { Services (HHS) }\end{array}$ & $\begin{array}{l}\text { Interagency Autism } \\
\text { Coordinating Committee } \\
\text { (IACC) }\end{array}$ & $\begin{array}{l}\text { Section } 399 \text { CC of the Public Health Service Act } \\
\text { (42 USC 280i-2), as amended by the Autism CARES Act of } 2014 \\
\text { (P.L.113-157) }\end{array}$ \\
\hline \multirow{6}{*}{$\begin{array}{l}\text { HHS/Administration for } \\
\text { Children and Families } \\
\text { (ACF) }\end{array}$} & $\begin{array}{l}\text { Adoption and Foster Care } \\
\text { Analysis and Reporting } \\
\text { System (AFCARS) }\end{array}$ & $\begin{array}{l}\text { Title IV-E of the Social Security Act (42 USC } \$ 679 \text { ); } \\
45 \text { CFR } 1355.40 \text { et seq. }\end{array}$ \\
\hline & $\begin{array}{l}\text { National Child Abuse } \\
\text { and Neglect Data System } \\
\text { (NCANDS) }\end{array}$ & $\begin{array}{l}\text { The } 1988 \text { Child Abuse Prevention and Treatment Act (CAPTA), } \\
\text { ( } 42 \text { USC } \$ 5104 \text { ) as amended by the CAPTA Reauthorization Act } \\
\text { of } 2010 \text { (P.L. 111-320) }\end{array}$ \\
\hline & $\begin{array}{l}\text { National Youth in Transition } \\
\text { Database (NYTD) }\end{array}$ & $\begin{array}{l}\text { Section } 477 \text { of the Social Security Act ( } 42 \text { USC } \$ 677 \text { ) as } \\
\text { amended by the Foster Care Independence Act of } 1999 \text { (P.L. } \\
\text { 106-169); } 45 \text { CFR } 1356.80 \text { et seq. }\end{array}$ \\
\hline & $\begin{array}{l}\text { Longitudinal Studies of } \\
\text { Child Abuse and Neglect } \\
\text { (LONGSCAN) }\end{array}$ & $\begin{array}{l}\text { The } 1988 \text { Child Abuse Prevention and Treatment Act } \\
\text { (CAPTA), ( } 42 \text { USC } \$ 5101 \text { et seq.) as amended by the CAPTA } \\
\text { Reauthorization Act of } 2010 \text { (P.L. 111-320) }\end{array}$ \\
\hline & $\begin{array}{l}\text { National Incidence Study } \\
\text { of Child Abuse and Neglect } \\
\text { (NIS) }\end{array}$ & $\begin{array}{l}\text { P.L. 93-247; P.L. 98-457 (1984); Child Abuse Prevention, } \\
\text { Adoption, and Family Services Act of } 1988 \text { (P.L. 100-294); The } \\
\text { Child Abuse, Domestic Violence, Adoption and Family Services } \\
\text { Act of } 1992 \text { (P.L. 102-295); The Keeping Children and Families } \\
\text { Safe Act of } 2003 \text { (P.L. 108-36) }\end{array}$ \\
\hline & $\begin{array}{l}\text { National Survey of Child and } \\
\text { Adolescent Wellbeing } \\
\text { (NSCAW) }\end{array}$ & $\begin{array}{l}\text { The Personal Responsibility and Work Opportunity } \\
\text { Reconciliation Act of } 1996 \text { (P.L. 104-193) }\end{array}$ \\
\hline
\end{tabular}




\begin{tabular}{|c|c|c|}
\hline Agency & $\begin{array}{l}\text { Program Name } \\
\text { (FY } 2013 \text { to FY 2016) }\end{array}$ & Legislative Authority \\
\hline \multirow{6}{*}{$\begin{array}{l}\text { HHS/Administration for } \\
\text { Community Living ( } A C L \text { ) }\end{array}$} & $\begin{array}{l}\text { Administration on Intellectual } \\
\text { and Developmental } \\
\text { Disabilities (AIDD) }\end{array}$ & $\begin{array}{l}\text { Developmental Disabilities Assistance and Bill of Rights Act of } \\
2000 \text { (P.L. 106-402) }\end{array}$ \\
\hline & $\begin{array}{l}\text { Independent Living Services } \\
\text { (ILS) Program }\end{array}$ & $\begin{array}{l}\text { Title VII, Chapter I, Part B of the Rehab Act, as amended by the } \\
\text { Workforce Innovation and Opportunity Act of } 2014,29 \text { USC } \\
\S \S 796 \mathrm{e}-796 \mathrm{e}-3\end{array}$ \\
\hline & $\begin{array}{l}\text { Centers for Independent } \\
\text { Living (CILs) Program }\end{array}$ & $\begin{array}{l}\text { Title VII, Chapter I, Part C of the Rehab Act, as amended by the } \\
\text { Workforce Innovation and Opportunity Act of } 2014,29 \text { USC } \S \S \\
796 f-796-f-6\end{array}$ \\
\hline & $\begin{array}{l}\text { National Institute on } \\
\text { Disability, Independent } \\
\text { Living, and Rehabilitation } \\
\text { Research (NIDILRR) }\end{array}$ & 29 USC §§ 760-766 \\
\hline & $\begin{array}{l}\text { State Grants for Assistive } \\
\text { Technology Program }\end{array}$ & $\begin{array}{l}\text { Assistive Technology Act of 1998, as amended by the Assistive } \\
\text { Technology Act of } 2004 \text { (P.L. 108-364). }\end{array}$ \\
\hline & $\begin{array}{l}\text { State Protection and Advocacy } \\
\text { Systems for Assistive } \\
\text { Technology (PAAT) program }\end{array}$ & $\begin{array}{l}\text { Assistive Technology Act of 1998, as amended by the Assistive } \\
\text { Technology Act of } 2004 \text { (P.L. 108-364). }\end{array}$ \\
\hline $\begin{array}{l}\text { HHS/Agency for } \\
\text { Healthcare Research and } \\
\text { Quality (AHRQ) }\end{array}$ & $\begin{array}{l}\text { Project: "A Deliberative } \\
\text { Approach to Develop } \\
\text { Autism Data Collection in } \\
\text { Massachusetts" }\end{array}$ & $\begin{array}{l}\text { Title IX of the Public Health Service Act (42 USC 299-299c-7) } \\
\text { as amended by P.L. 106-129 }\end{array}$ \\
\hline \multirow{3}{*}{$\begin{array}{l}\text { HHS/Centers for Disease } \\
\text { Control and Prevention } \\
\text { (CDC) }\end{array}$} & $\begin{array}{l}\text { Autism and Developmental } \\
\text { Disabilities Monitoring } \\
\text { Network (ADDM) }\end{array}$ & $\begin{array}{l}\text { Section 399AA of the Public Health Service Act ( } 42 \text { USC 280i), } \\
\text { as amended by the Autism CARES Act of } 2014 \text { (P.L. 113-157) }\end{array}$ \\
\hline & $\begin{array}{l}\text { Study to Explore Early } \\
\text { Development (SEED) }\end{array}$ & $\begin{array}{l}\text { Section 399AA of the Public Health Service Act ( } 42 \text { USC 280i), } \\
\text { as amended by the Autism CARES Act of } 2014 \text { (P.L. 113-157) }\end{array}$ \\
\hline & $\begin{array}{l}\text { National Health Interview } \\
\text { Survey (NHIS) }\end{array}$ & $\begin{array}{l}\text { Section 399AA of the Public Health Service Act ( } 42 \text { USC 280i), } \\
\text { as amended by the Autism CARES Act of } 2014 \text { (P.L. 113-157) }\end{array}$ \\
\hline \multirow[b]{2}{*}{$\begin{array}{l}\text { HHS/Centers for } \\
\text { Medicare \& Medicaid } \\
\text { Services (CMS) }\end{array}$} & Federal Medicaid program & Title XIX of the Social Security Act \\
\hline & $\begin{array}{l}\text { Early and Periodic Screening, } \\
\text { Diagnostic and Treatment } \\
\text { (EPSDT) benefit }\end{array}$ & Title XIX of the Social Security Act \\
\hline
\end{tabular}




\begin{tabular}{|c|c|c|}
\hline Agency & $\begin{array}{l}\text { Program Name } \\
\text { (FY } 2013 \text { to FY 2016) }\end{array}$ & Legislative Authority \\
\hline \multirow{10}{*}{$\begin{array}{l}\text { HHS/Health } \\
\text { Resources and Services } \\
\text { Administration (HRSA) }\end{array}$} & $\begin{array}{l}\text { Leadership Education in } \\
\text { Neurodevelopmental and } \\
\text { Other Related Disabilities } \\
\text { (LEND) }\end{array}$ & $\begin{array}{l}\text { Section 399BB of the Public Health Service Act (42 USC 280i-1), } \\
\text { as amended by the Autism CARES Act of } 2014 \text { (P.L. 113-157) }\end{array}$ \\
\hline & $\begin{array}{l}\text { Leadership Education in } \\
\text { Developmental-Behavioral } \\
\text { Pediatrics (DBP) }\end{array}$ & $\begin{array}{l}\text { Section 399BB of the Public Health Service Act (42 USC 280i-1), } \\
\text { as amended by the Autism CARES Act of } 2014 \text { (P.L. 113-157) }\end{array}$ \\
\hline & $\begin{array}{l}\text { Interdisciplinary Technical } \\
\text { Assistance Center (ITAC) }\end{array}$ & $\begin{array}{l}\text { Section 399BB(e)(2) of the Public Health Service Act ( } 42 \text { USC } \\
280 i-1(e)(2) \text { ), as amended by the Autism CARES Act of } 2014 \\
\text { (P.L. 113-157) }\end{array}$ \\
\hline & $\begin{array}{l}\text { Autism Research Networks } \\
\text { Program }\end{array}$ & $\begin{array}{l}\text { Section 399BB(f) of the Public Health Service Act ( } 42 \text { USC } \\
280 i-1(f) \text { ), as amended by the Autism CARES Act of } 2014 \text { (P.L. } \\
113-157)\end{array}$ \\
\hline & $\begin{array}{l}\text { R40 Autism Research } \\
\text { Program }\end{array}$ & $\begin{array}{l}\text { Section 399BB(f) of the Public Health Service Act ( } 42 \text { USC } \\
280 i-1(f) \text { ), as amended by the Autism CARES Act of } 2014 \text { (P.L. } \\
113-157)\end{array}$ \\
\hline & $\begin{array}{l}\text { National Survey of Children's } \\
\text { Health (NSCH)/ National } \\
\text { Survey of Children with } \\
\text { Special Health Care Needs } \\
\text { (NS-CSHCN) }\end{array}$ & Section 501(a) of Title V of the Social Security Act \\
\hline & State Systems Grants & $\begin{array}{l}\text { Section 399BB(b)(6) of the Public Health Service Act ( } 42 \text { USC } \\
280 \text { - } 1(b)(6) \text { ), as amended by the Autism CARES Act of } 2014 \\
\text { (P.L. 113-157) }\end{array}$ \\
\hline & $\begin{array}{l}\text { State Public Health Autism } \\
\text { Resource Center (SPHARC) }\end{array}$ & $\begin{array}{l}\text { Section 399BB of the Public Health Service Act (42 USC } \$ 280 \text { i- } \\
\text { 1), as amended by the Autism CARES Act of } 2014 \text { (P.L. 113-157) }\end{array}$ \\
\hline & $\begin{array}{l}\text { Title V Maternal and Child } \\
\text { Health }(\mathrm{MCH}) \text { Services Block } \\
\text { Grant Program }\end{array}$ & Section 501(a) of Title $V$ of the Social Security Act \\
\hline & $\begin{array}{l}\text { Got Transition/Center for } \\
\text { Health Care Transition }\end{array}$ & Section 502(a)(1) of Title V of the Social Security Act \\
\hline $\begin{array}{l}\text { HHS/Indian Health } \\
\text { Service (IHS) }\end{array}$ & $\begin{array}{l}\text { IHS Telebehavioral Health } \\
\text { Center of Excellence } \\
\text { (TBHCE) }\end{array}$ & Snyder Act, 25 USC $\$ 13$, and 25 USC $\$ 1665 a$ \\
\hline
\end{tabular}




\begin{tabular}{|c|c|c|}
\hline Agency & $\begin{array}{l}\text { Program Name } \\
\text { (FY } 2013 \text { to FY 2016) }\end{array}$ & Legislative Authority \\
\hline \multirow{3}{*}{$\begin{array}{l}\text { HHS/National Institutes } \\
\text { of Health (NIH) }\end{array}$} & $\begin{array}{l}\text { NIMH Services Research } \\
\text { for Autism Spectrum } \\
\text { Disorder across the Lifespan } \\
\text { (ServASD) Initiative }\end{array}$ & $\begin{array}{l}\text { Sections } 301 \text { and } 405 \text { of the Public Health Service Act as } \\
\text { amended ( } 42 \text { USC } 241 \text { and 284) and under Federal Regulations } \\
42 \text { CFR Part } 52 \text { and } 45 \text { CFR Part } 75\end{array}$ \\
\hline & $\begin{array}{l}\text { Grants funded through NIMH } \\
\text { and NICHD extramural } \\
\text { research programs }\end{array}$ & $\begin{array}{l}\text { Sections } 301 \text { and } 405 \text { of the Public Health Service Act as } \\
\text { amended ( } 42 \text { USC } 241 \text { and 284) and under Federal Regulations } \\
42 \text { CFR Part } 52 \text { and } 45 \text { CFR Part } 75\end{array}$ \\
\hline & Project SEARCH & $\begin{array}{l}\text { A public-private partnership program in which NIH participates; } \\
\text { there is no legislative authority for this program, but some of the } \\
\text { partner agencies are authorized to deliver services under various } \\
\text { legislative authorities }\end{array}$ \\
\hline \multirow{3}{*}{$\begin{array}{l}\text { HHS/Substance Abuse } \\
\text { and Mental Health } \\
\text { Services Administration } \\
\text { (SAMHSA) }\end{array}$} & $\begin{array}{l}\text { Child Mental Health Initiative } \\
(\mathrm{CMHI})\end{array}$ & Sections 561- 565 of the Public Health Service Act, as amended \\
\hline & $\begin{array}{l}\text { "Now ls The Time" Healthy } \\
\text { Transitions Program (NITT- } \\
\text { HT) }\end{array}$ & Section 520A of the Public Health Service Act, as amended \\
\hline & $\begin{array}{l}\text { Now Is the Time Technical } \\
\text { Assistance (NITT-TA) Center }\end{array}$ & Section 520A of the Public Health Service Act, as amended \\
\hline $\begin{array}{l}\text { U.S. Department of } \\
\text { Defense (DOD) }\end{array}$ & $\begin{array}{l}\text { Autism Research } \\
\text { Program (ARP) within the } \\
\text { Congressionally Directed } \\
\text { Medical Research Programs } \\
\text { (CDMRP) }\end{array}$ & $\begin{array}{l}\text { Consolidated Appropriations Act of } 2016 \\
\text { (P.L. 114-113) }\end{array}$ \\
\hline $\begin{array}{l}\text { U.S. Department of } \\
\text { Education (ED)/Office } \\
\text { of Special Education and } \\
\text { Rehabilitative Services } \\
\text { (OSERS) }\end{array}$ & IDEA Formula Grant Program & $\begin{array}{l}\text { Part B of the Individuals with Disabilities Education Act (IDEA), } \\
20 \text { USC } \$ \$ 1401,1411-1419\end{array}$ \\
\hline
\end{tabular}




\section{YOUNG ADULTS AND TRANSITIONING YOUTH}

WITH AUTISM SPECTRUM DISORDER

\begin{tabular}{|c|c|c|}
\hline Agency & $\begin{array}{l}\text { Program Name } \\
\text { (FY } 2013 \text { to FY 2016) }\end{array}$ & Legislative Authority \\
\hline \multirow{8}{*}{$\begin{array}{l}\text { ED/Office of Special } \\
\text { Education and } \\
\text { Rehabilitative Services } \\
\text { (OSERS) }\end{array}$} & $\begin{array}{l}\text { IDEA Discretionary Grant } \\
\text { Program }\end{array}$ & $\begin{array}{l}\text { Part D of the Individuals with Disabilities Education Act (IDEA), } \\
20 \text { USC } \S \S 1450-1482\end{array}$ \\
\hline & $\begin{array}{l}\text { Promoting the Readiness } \\
\text { of Minors in Supplemental } \\
\text { Security Income (PROMISE) }\end{array}$ & $\begin{array}{l}\text { Fiscal Year } 2012 \text { Consolidated Appropriations Act (P.L. 112-74); } \\
\text { the Department of Defense Military Construction and Veterans } \\
\text { Affairs and Full-Year Continuing Appropriations Act } 2013 \text { (P.L. } \\
\text { 113-6); and, the Appropriations Act of } 2014 .\end{array}$ \\
\hline & $\begin{array}{l}\text { Vocational Rehabilitation } \\
\text { State Grants }\end{array}$ & $\begin{array}{l}\text { Title I of the Rehabilitation Act of } 1973 \text {, as amended by } \\
\text { Workforce Innovation and Opportunity Act of 2014, } 29 \text { USC } \S \S \\
701-733\end{array}$ \\
\hline & $\begin{array}{l}\text { American Indian Vocational } \\
\text { Rehabilitation Services } \\
\text { Program }\end{array}$ & $\begin{array}{l}\text { Part C of Title I of the Rehabilitation Act of 1973, as amended by } \\
\text { Workforce Innovation and Opportunity Act of } 2014,29 \text { USC } \$ 741\end{array}$ \\
\hline & $\begin{array}{l}\text { State Supported Employment } \\
\text { Services Program }\end{array}$ & $\begin{array}{l}\text { Title VI of the Rehabilitation Act of } 1973 \text {, as amended by Workforce } \\
\text { Innovation and Opportunity Act of } 2014,29 \text { USC } \$ \S 795 g-795 m\end{array}$ \\
\hline & $\begin{array}{l}\text { Rehabilitation Training } \\
\text { Program }\end{array}$ & $\begin{array}{l}\text { Section } 302 \text { of the Rehabilitation Act of 1973, as amended by } \\
\text { Workforce Innovation and Opportunity Act of 2014, } 29 \text { USC } \$ 772\end{array}$ \\
\hline & $\begin{array}{l}\text { Demonstration and Training } \\
\text { Programs }\end{array}$ & $\begin{array}{l}\text { Section } 303 \text { of the Rehabilitation Act of 1973, as amended by } \\
\text { Workforce Innovation and Opportunity Act of 2014, } 29 \text { USC } \$ 773\end{array}$ \\
\hline & $\begin{array}{l}\text { Parent Information and } \\
\text { Training Program }\end{array}$ & $\begin{array}{l}\text { Section } 303 \text { of the Rehabilitation Act of 1973, as amended by } \\
\text { Workforce Innovation and Opportunity Act of 2014, } 29 \text { USC } § 773\end{array}$ \\
\hline \multirow{2}{*}{$\begin{array}{l}\text { ED/Office for Civil Rights } \\
\text { (OCR) }\end{array}$} & $\begin{array}{l}\text { Enforcement of Section } \\
504 \text { which prohibits } \\
\text { discrimination on the basis } \\
\text { of disability in programs or } \\
\text { activities that receive federal } \\
\text { financial assistance from ED }\end{array}$ & Section 504 of the Rehabilitation Act of 1973, 29 USC $\$ 794$ \\
\hline & $\begin{array}{l}\text { Enforcement of Title II of } \\
\text { the ADA non-discrimination } \\
\text { on the basis of disability in } \\
\text { public elementary, secondary } \\
\text { and postsecondary schools }\end{array}$ & $\begin{array}{l}\text { The Americans with Disabilities Act of 1990, as amended, } \\
42 \text { U.S.C. } § \$ 12131-12134\end{array}$ \\
\hline $\begin{array}{l}\text { ED/Institution of } \\
\text { Education Sciences } \\
\text { (IES)/National Center } \\
\text { for Special Education } \\
\text { Research (NCSER) }\end{array}$ & $\begin{array}{l}\text { IES-NCSER Special Education } \\
\text { Research Grants/Transition } \\
\text { Outcomes for Secondary } \\
\text { Students with Disabilities }\end{array}$ & $\begin{array}{l}\text { Part E of the Education Sciences Reform Act of 2002, } 20 \text { U.S.C. } \\
9567-9567 b\end{array}$ \\
\hline
\end{tabular}




\begin{tabular}{|c|c|c|}
\hline Agency & $\begin{array}{l}\text { Program Name } \\
\text { (FY } 2013 \text { to FY 2016) }\end{array}$ & Legislative Authority \\
\hline $\begin{array}{l}\text { ED/IES/National Center } \\
\text { for Education Evaluation } \\
\text { and Regional Assistance } \\
\text { (NCEE) }\end{array}$ & $\begin{array}{l}\text { IES-NCEE Special Education } \\
\text { Studies and Evaluations }\end{array}$ & $\begin{array}{l}\text { Section } 664 \text { of the Individuals with Disabilities Education Act } \\
\text { (IDEA), } 20 \text { U.S.C. } 1464\end{array}$ \\
\hline $\begin{array}{l}\text { ED/IES/National Center } \\
\text { for Education Statistics } \\
\text { (NCES) }\end{array}$ & $\begin{array}{l}\text { IES-NCES Middle Grades } \\
\text { Longitudinal Study }\end{array}$ & $\begin{array}{l}\text { Part C of the Education Sciences Reform Act of 2002, } 20 \text { U.S.C. } \\
9541-9545\end{array}$ \\
\hline $\begin{array}{l}\text { ED/Office of } \\
\text { Postsecondary Education } \\
\text { (OPE) }\end{array}$ & $\begin{array}{l}\text { Model Transition Programs } \\
\text { for Students with Intellectual } \\
\text { Disabilities into Higher } \\
\text { Education (TPSID) }\end{array}$ & $\begin{array}{l}\text { Section } 767 \text { of the Higher Education Act (HEA) of 1965, as } \\
\text { amended, } 20 \text { USC } 1140 \mathrm{~g}\end{array}$ \\
\hline $\begin{array}{l}\text { U.S. Department of } \\
\text { Housing and Urban } \\
\text { Development (HUD) }\end{array}$ & $\begin{array}{l}\text { Accessibility for and rights of } \\
\text { persons with disabilities with } \\
\text { regard to housing }\end{array}$ & $\begin{array}{l}\text { Americans with Disabilities Act } \\
\text { Fair Housing Act } \\
\text { Section } 504 \text { of the Rehabilitation Act of } 1973 \\
\text { Section } 811 \text { Supportive Housing for Persons with Disabilities }\end{array}$ \\
\hline $\begin{array}{l}\text { U.S. Department of } \\
\text { Justice (DOJ), Office of } \\
\text { Justice Programs, Bureau } \\
\text { of Justice Assistance }\end{array}$ & $\begin{array}{l}\text { National Center on Justice } \\
\text { and Disability, "Pathways to } \\
\text { Justice" initiative }\end{array}$ & $\begin{array}{l}\text { Edward Byrne Memorial Justice Assistance Grant Program } \\
\text { (42 USC 3751(a) et seq.) }\end{array}$ \\
\hline \multirow{5}{*}{$\begin{array}{l}\text { U.S. Department of Labor } \\
\text { (DOL) }\end{array}$} & Guideposts for Success & \\
\hline & $\begin{array}{l}\text { Pathways to Careers } \\
\text { Demonstration Grants }\end{array}$ & $\begin{array}{l}\text { Section } 169 \text { (c) of the Workforce Innovation and Opportunity Act } \\
\text { (P.L. 113-128) }\end{array}$ \\
\hline & Employment First & $\begin{array}{l}\text { Section } 609 \text { of the Rehabilitation Act of 1973, as amended by } \\
\text { section } 461 \text { of Workforce Innovation Opportunity Act (WIOA) }\end{array}$ \\
\hline & $\begin{array}{l}\text { Disability Employment } \\
\text { Initiative (DEI) }\end{array}$ & $\begin{array}{l}\text { Section 169, subsection (b), of the Workforce Innovation and } \\
\text { Opportunity Act (P.L. 113-129) }\end{array}$ \\
\hline & $\begin{array}{l}2016 \text { Final Report from } \\
\text { the Advisory Committee } \\
\text { on Increasing Competitive } \\
\text { Integrated Employment for } \\
\text { Individuals with Disabilities }\end{array}$ & $\begin{array}{l}\text { Section } 609 \text { of the Rehabilitation Act of } 1973 \text {, as amended by } \\
\text { Section } 461 \text { of the Workforce Innovation and Opportunity Act } \\
\text { (WIOA) }\end{array}$ \\
\hline $\begin{array}{l}\text { U.S. Department of } \\
\text { Transportation (DOT) }\end{array}$ & $\begin{array}{l}\text { Accessible Transportation } \\
\text { Technologies Research } \\
\text { Initiative (ATTRI) }\end{array}$ & $\begin{array}{l}\text { Section } 6002 \text { (a) of the Fixing America's Surface Transportation } \\
\text { Act of } 2015 \text { (FAST Act), (23 USC } \$ 516(a)) \text {, (P.L. 114-94) }\end{array}$ \\
\hline
\end{tabular}




\begin{tabular}{|c|c|c|}
\hline Agency & $\begin{array}{c}\text { Program Name } \\
\text { (FY } 2013 \text { to FY 2016) }\end{array}$ & Legislative Authority \\
\hline \multirow{2}{*}{$\begin{array}{l}\text { U.S. Social Security } \\
\text { Administration (SSA) }\end{array}$} & $\begin{array}{l}\text { Supplemental Security } \\
\text { Income (SSI) }\end{array}$ & 42 USC $401-434$ and 1381-1383 \\
\hline & $\begin{array}{l}\text { Social Security Disability } \\
\text { Insurance (SSDI) }\end{array}$ & 42 USC $401-434$ and 1381-1383 \\
\hline
\end{tabular}

\section{Other Federal Policies that May Apply To Young Adults with ASD}

The following were also identified by IWG members as federal policies and programs that, as programs targeted to the general population or across disabilities, may also be potentially relevant to youth and young adults with ASD; however, they were not expanded upon in the Report. None of these programs specifically target youth and young adults with ASD but are available to those who meet eligibility criteria.

1. The Higher Education Opportunity Act

2. Section 1915(i) home and community-based services (HCBS) under the Social Security Act, as amended by the Affordable Care Act (ACA)

3. The following parts of the ACA

a. Section 2402(a)

b. Section 4302 of the ACA on population surveys and data collection by federally funded health and health care programs

c. Section 5401 to increase funding to the Centers of Excellence to support health disparities research

d. Medicaid expansion

e. Denying insurance coverage to people who have pre-existing conditions or charging higher premiums to individuals
4. Reauthorization of HHS Office of Minority Health

5. No Wrong Door/ADRC (ACL grant program)

6. CMS SMDL on Habilitation Services in the State Plan
a. Ticket to work
b. Medicaid buy-in

7. Workforce Innovation and Opportunity Act (WIOA)

a. Title I of WIOA authorizes the provision of career planning for eligible individuals. Career planning offers a person-centered approach to coordinate necessary support services before and after job placement.

b. Title VII of WIOA (CILS) includes a new core service for Independent Living for Youth with Disabilities not in school. It facilitates the transition of youth who are individuals with significant disabilities, who were eligible for individualized education programs under section 614 (d) of the Individuals with Disabilities Education Act (20 U.S.C. 1414(d)), and who have completed their secondary education or otherwise left school, to postsecondary life. (Sec. 7(17)(E) of the Act, 29 U.S.C. 705(17)(E)). Some youth transition activities not covered under the new core services (i.e., for those in school/ not eligible for IEPs, etc.) may be included within the other four core services, Sec. 7 (17) (A-D) of the Act, 29 U.S.C. 705(17)(A-D), as well as within the Independent Living Services in Sec. 7(18), 29 U.S.C. 705(18). 



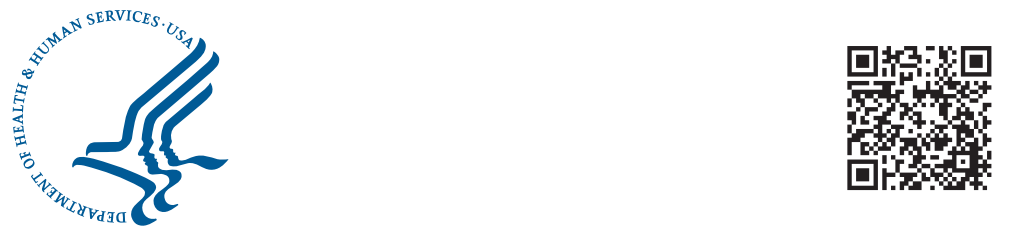

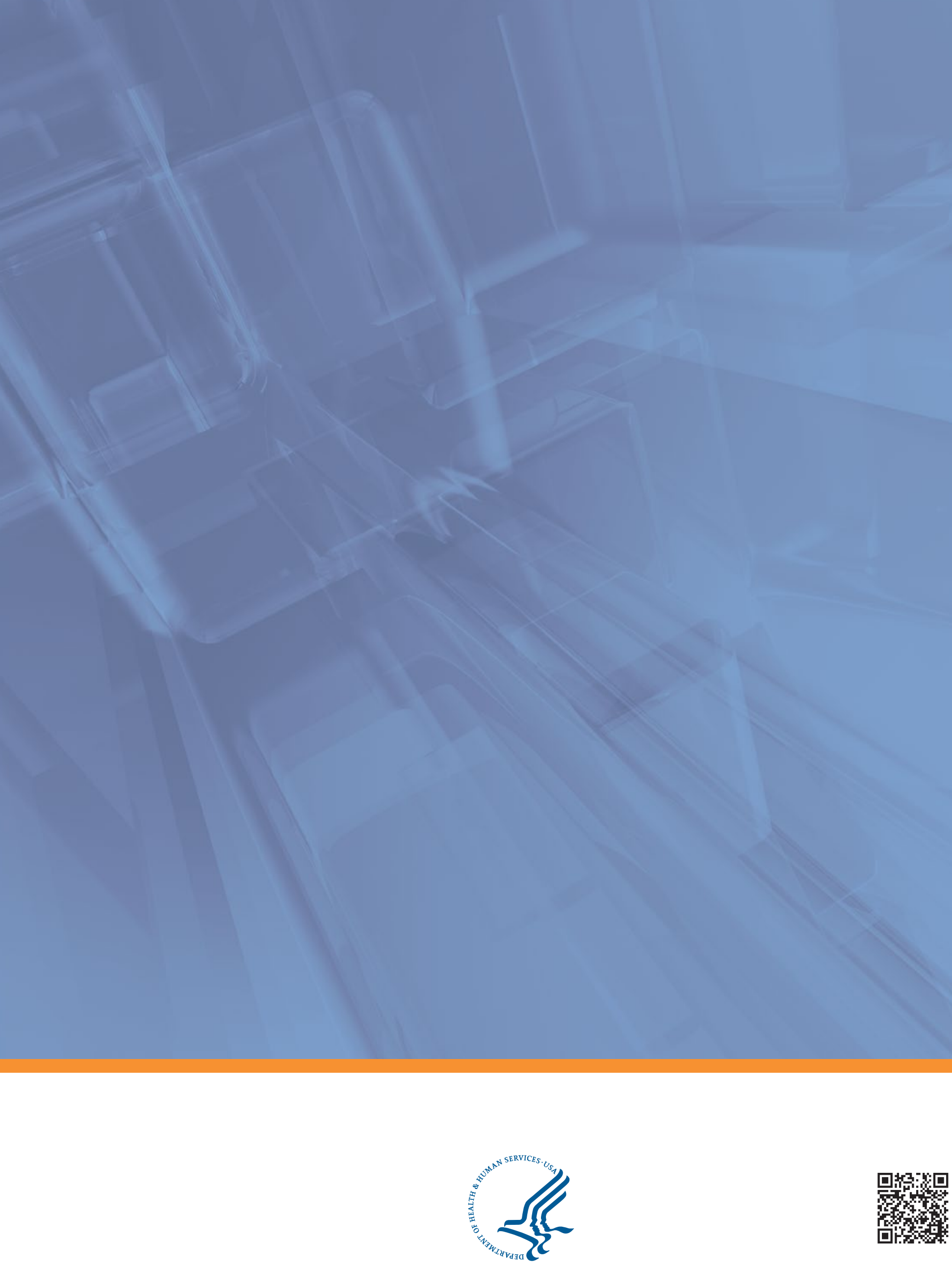

垈

